MEETING THE NEEDS OF MAORI WITH DIABETES:

AN EVALUATION OF A NURSE-LED SERVICE

by

Josephine Mary Elizabeth Janssen

A thesis submitted to the Victoria University of Wellington

in fulfilment of the

requirements for the degree of

Master of Nursing

Victoria University of Wellington

2008 


\section{Abstract}

Designated Maori health service providers and specialised Maori nursing roles using "culturally appropriate" practices have been developed in New Zealand to address health disparities between Maori and non-Maori citizens. This study considers the effectiveness, from several perspectives, of a Maori nurse-led diabetes programme offered by Te Hauora $O$ Ngati Rarua. It also identifies salient features of the experience of having diabetes and being on the programme, which consists of the combination of a six week course of group education sessions with one-to-one case management, involving health care, education and support.

Programme evaluation was conducted using an embedded case study design. Seven programme participants were followed for 9-12 months, during which time multiple sources of data were accessed, including programme documents, clinical notes, laboratory results and stakeholder interviews. Client outcomes were measured in terms of physiological measures, knowledge acquisition, diabetes management and lifestyle behaviour. Some participants demonstrated improved diabetes management and lifestyle behaviour while actively engaged with the programme, but efforts tended to lapse once support was reduced. This highlighted the importance of optimising the level of long-term self-management support for clients with diabetes. High levels of co-morbidity were common and tended to complicate management. The Transtheoretical Model of Change, Chronic Care Model and Systems Theory shaped the evaluation.

The study makes four important contributions to knowledge in this area: 1) it confirms the importance of Maori values and processes in "by Maori for Maori" services as they help to keep clients engaged, 2) it describes how small Maori health providers meet the needs of the local community, and 3) it identifies the value of the Maori Diabetes Nurse Educator (MDNE) role in primary health care. Thus it serves as an affirmation of the importance of the Maori Health Strategy and Maori self-determination in organising and delivering health care for Maori clients. The fourth valuable contribution is the insight gained into the dynamics of Pakeha researchers working in partnership with Maori organisations. 


\section{Keywords}

Maori health

Diabetes

Nurse-led service

Health education 


\section{Acknowledgements}

First and foremost I want to thank the participants, both the clients and service providers involved in the study, for taking me into their lives and their confidence. I hope I have done justice to their stories and honoured their trust in me. It has taken a considerable time to progress from the initial interviews to reporting back to the community, but I trust the conclusions are helpful, constructive and affirming to all concerned

Secondly I must thank my supervisors, Dr Kathy Nelson and Dr Rose Mc Eldowney for their support and guidance. Kathy has been very patient and offered direction and encouragement in just the right measures to keep me engaged and striving towards a thesis I can be proud of. She has been understanding and supportive through some very difficult times for me personally, but also stopped me from straying too far from the track. Rose has been there as a good back up and provided worthwhile insights along the way, including a fresh pair of eyes near completion when perspective is distorted by familiarity with the work.

Third, but certainly not least I thank my wonderful husband, Adrian who has supported and encouraged me, done a lot of housework and childcare and generally refused to let me give up. He has also proof-read and critiqued my work at times and has a constant eye out for articles and news stories that may be beneficial to my studies. No, you can't have him, he's spoken for! Of course my children deserve a mention too for their patience especially through the period of writing up where they have had some inconsistent mothering and put up with me 'hogging' the computer, on the plus side though, they have become very competent cooks.

It is also important to acknowledge the financial assistance I have received with the costs of conducting this research: Wairau Hospital Drug Trial Fund \$1200, Nurses Educational and Research Fund (NERF) \$1000, and Victoria University of Wellington study grant $\$ 1200$. No conditions were attached to this funding. I 
would also like to thank Nelson Marlborough Institute of Technology, Clinical Training Agency and Nelson Marlborough Hospitals' Charitable Trust for their assistance towards my study costs. 


\section{Table of Contents}

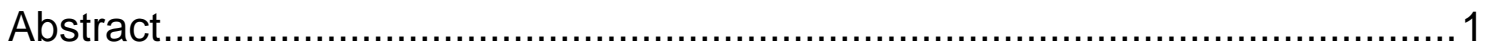

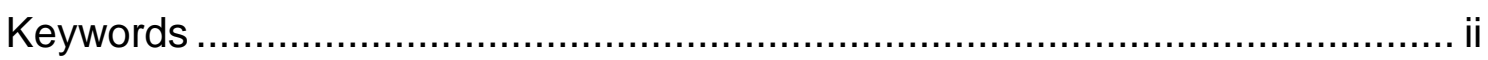

Acknowledgements ..................................................................... iii

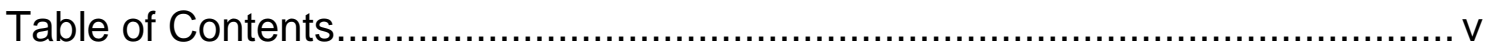

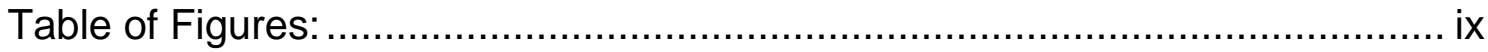

List of Tables:

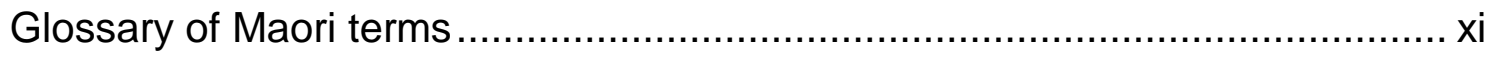

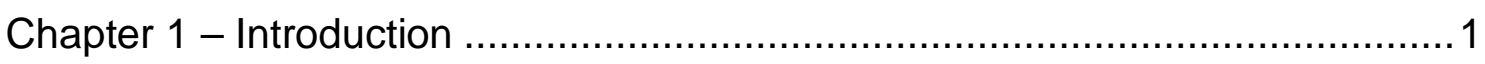

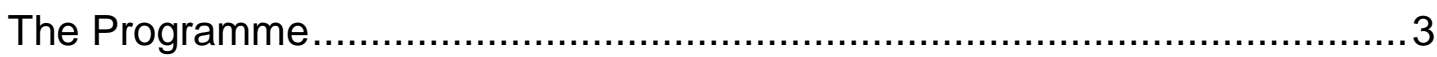

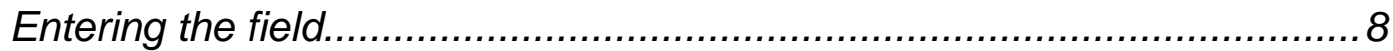

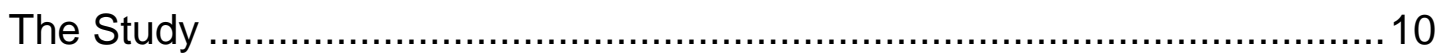

Theoretical approach underpinning the study................................. 11

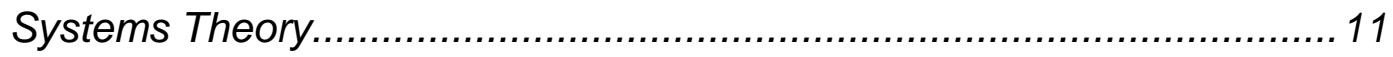

Chronic Care Model:............................................................ 14

Transtheoretical Model of Change...................................................... 16

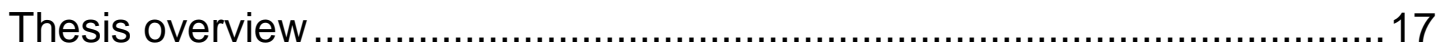

Chapter 2 - Setting the scene: describing the research context ....................19

History of Maori health: Colonisation and structural disadvantage ..............19

The emergence of "by Maori for Maori" services ................................21

Development of Te Hauora O Ngati Rarua.........................................23

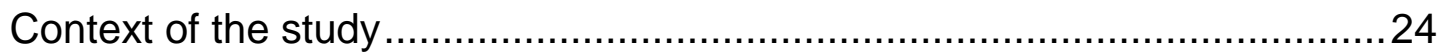

Diabetes as a Maori health issue................................................... 25

Quality of health care to Maori...............................................26 
Positioning this project in relation to existing research and programme development

Summary 33

Chapter 3 - Mixed method case study design 34

Design development 34

Features of case study. 36

Data collection 41

Data analysis 44

Ethical implications 47

Conducting culturally competent research 48

Rigour/validity strategy 52

Internal validity 52

Construct validity 53

Reliability 53

External validity - generalisability. 54

Managing common limitations of case study 55

Chapter 4 - The diabetes programme 58

Inputs. 59

The client's journey through the system 64

Working to provide an integrated service. 69

Chapter 5 - Outcomes 72

Individual measures of effectiveness 72

Physiological outcome measures 76

What impacts on outcomes 77

Organisational measure of effectiveness 82 
Element 1: The community.....

Element 2: Health system.

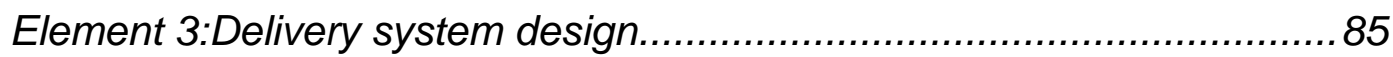

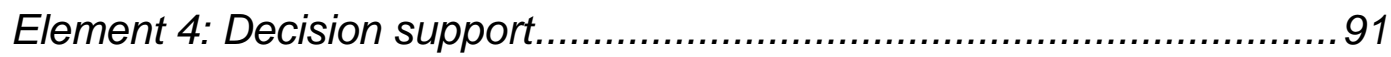

Element 5: Clinical information systems .............................................92

Element 6: Self-management support ..............................................92

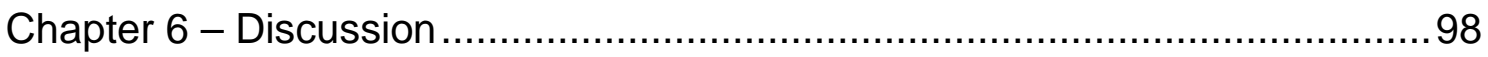

Part 1: Evaluation of the programme .......................................................

Context and organisational influences.............................................. 100

Effectiveness at managing chronic conditions .................................... 103

Providing an integrated service .................................................... 103

Defining features of the programme .................................................. 104

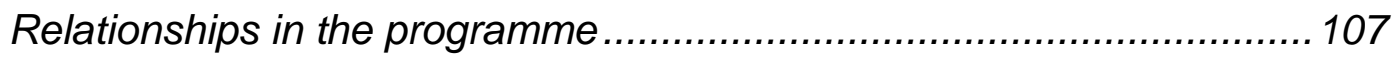

Making change through self-management ........................................ 109

Taking control - making changes ...................................................... 110

Where to from here?

Revisiting initial propositions .........................................................114

Part 2: Perspectives on partnership - insights from the process .................115

Setting the groundwork - the importance of open communication .........116

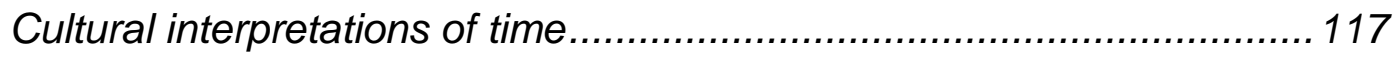

Complexity of cross-cultural communication ......................................117

Attending to that which is pertinent.................................................. 118

Conducting culturally safe research................................................. 119

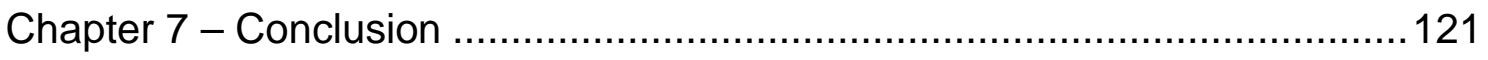

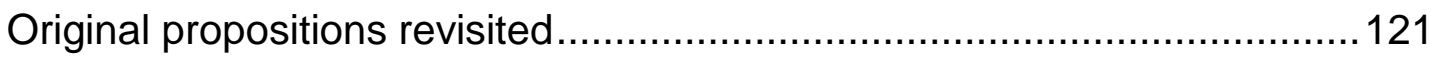


Relevance of Chronic Care Model and Transtheoretical Model................. 123

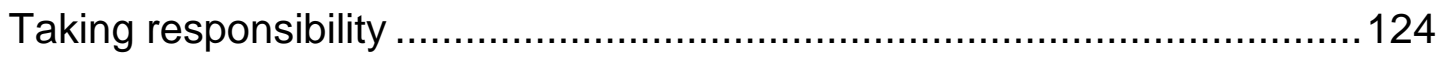

Unique programme contribution............................................... 125

Insights into the partnership process ........................................... 127

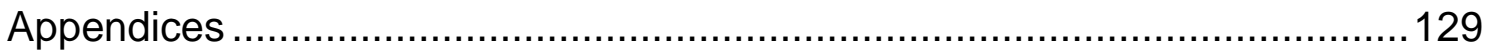

Appendix A - MDNE Service Specifications ....................................... 129

Appendix B - Programme documents ............................................. 140

Appendix C - Director of Maori Health letter of support......................... 157

Appendix D - Contract between THONR and J. Janssen ........................159

Appendix E - Ethics Approval ....................................................... 163

Appendix F - Information Sheets.................................................. 165

Appendix G - Consent Forms.................................................. 175

Appendix H - Interview Guidelines ............................................. 179

Appendix I - Study Enrolment Form ............................................. 193

Appendix J - Transcribers Confidentiality Agreement ............................197

Appendix K - Rigour/Validity Strategy ............................................ 198

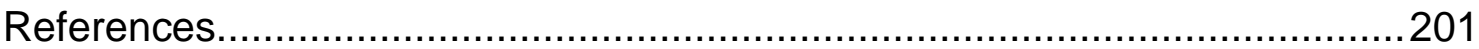




\section{Table of Figures:}

Figure 1: Diagrammatic representation of THONR staff involvement in the programme.

Figure 2: Systems approach to organisational performance analysis and improvement

Figure 3: Basic types of designs for case studies 37

Figure 4: Diagrammatic representation of this case study design 39 


\section{List of Tables:}

Table 1: Criteria for achieving each element of the Chronic Care Model ..........15

Table 2: Characteristics of each stage in the Transtheoretical Model..............16

Table 3: Characteristics and diabetes status of study clients........................61

Table 4: Course outline for group education sessions .............................66

Table 5: Mean physiological indicators and percentage change over time .......76 


\section{Glossary of Maori terms}

hauora - health, health service (Boulton, 2005)

hinengaro - mental wellbeing (Durie, 1998)

hoha - bored, monotonous, humdrum (Ryan, 1997)

hui - meeting, gather (Ryan, 1997)

iwi - tribe (Ryan, 1997)

kai - food (Ryan, 1997)

kaimahi - worker (Ryan, 1997)

kanohi ki te kanohi - face to face (Boulton, 2005)

karakia - prayer (Ryan, 1997)

kaumatua - elders (Boulton, 2005)

kaupapa - philosophy, strategy (Ryan, 1997), eternal principles (Collier, n.d.),

theme (Boulton, 2005)

kawa - protocol, ceremony (Boulton, 2005)

koha - donation, gift (Boulton, 2005)

mana - prestige, integrity (Ryan, 1997)

manaakitanga - caring, respect, hospitality, support (Ryan, 1997)

Maori - native people (Ryan, 1997)

marae - sacred open meeting area (Ryan, 1997)

mihi - greet, greeting (Boulton, 2005)

mirimiri - massage ( $\mathrm{MOH}, 2002 \mathrm{a})$, stroke (Boulton, 2005)

mokopuna - grandchildren, young generation (Boulton, 2005)

poroporoake - farewell, closing ceremony (Ryan, 1997)

Pakeha - non-Maori, Caucasian, European (Ryan, 1997)

rongoa - NZ native herbal remedies $(\mathrm{MOH}, 2002 \mathrm{a})$

tangata whenua - local people, native (Ryan, 1997)

tangihanga (tangi) - mourning, funeral (Ryan, 1997)

taonga - treasures, property (Boulton, 2005)

te ao Maori - the Maori world ( $\mathrm{MOH}, 2002 \mathrm{a})$

te reo - Maori language (Boulton, 2005)

tikanga - customary practices, meaning (Ryan, 1997), 'the right way' (Collier, n.d.)

tinana - physical wellbeing (Durie, 1998) 
tino rangitiratanga/rangatiratanga - Maori control and determination (Durie, 1998), governance and leadership (McNatty, 2001)

waiata - song, chant, psalm (Ryan, 1997)

wairua - spiritual wellbeing (Durie, 1998)

wairuatanga - spirituality (Durie, 1998)

whakama - shy, shameful, embarrassed, loss of mana (Ryan, 1997; Williams et al., 2003)

whanau - extended family (Ryan, 1997) often used in an inclusive sense by THONR staff to refer to clients in general

whanau ora - family health (Boulton, 2005)

whanaungatanga - extended family ties, relationship, kinship, connectedness (Durie, 1998; Ryan, 1997; THONR, 2004) 


\section{Chapter 1 - Introduction}

Nurses are key providers of Maori (indigenous) health services in the current Aotearoa New Zealand (NZ) health service structure (Expert Advisory Group on Primary Health Care Nursing, 2003). This thesis reports the findings of a case study evaluation undertaken by a Pakeha (non-Maori) nurse researcher working in partnership with the Maori staff employed by a Maori health provider. The setting of the research is Te Hauora O Ngati Rarua (THONR), an iwi (tribal) health provider which offers a diabetes and heart disease education and management programme designed for Maori clients. The diabetes and heart disease programme was developed and predominantly delivered by a Maori Diabetes Nurse Educator (MDNE) employed by THONR. The focus of this study is on the diabetes aspects of the service. The MDNE position is a new initiative on the part of the Nelson Marlborough District Health Board (NMDHB), which contracted the position to THONR in 2005.

This case study explored the operation and effectiveness of the programme and adds a human voice to the numerical data that are collected quarterly by the District Health Board (DHB) and Ministry of Health ( $\mathrm{MOH})$. While there have been many other intervention studies focused on primary and secondary prevention of diabetes (Polonsky et al., 2003; Satterfield et al., 2003; Vermeire et al., 2005) and others looking at aspects of service provision among Maori health providers (Abel, Gibson, Ehau, \& Tipene Leach, 2005; Boulton, 2005; Boulton, Simonsen, Walker, Cumming, \& Cunningham, 2004), few intervention studies have focused particularly on the unique contribution that nurses make and on the experiences of clients participating in such a service. This research follows a group of clients through the programme as they learn about diabetes and how to manage it, including the need to make lifestyle changes. The study describes the programme and explores its effectiveness from the perspective of a number of stakeholders.

Care has been taken to present the findings of the case study in a safe way by maintaining the anonymity of most informants. Two key stakeholders, the MDNE and manager are named, in keeping with the partnership agreement 
between THONR and the researcher. Organisational stakeholders have had the opportunity to read and comment on a draft of this thesis.

This introductory chapter provides an overview of the programme, introduces the researcher and the MDNE, outlines the research design and introduces Systems Theory, Chronic Care Model and Transtheoretical Model of Change which were used to inform the evaluation. Finally there is a brief description of the content and purpose of each chapter.

Research has indicated that health services for the general population are not always accessible, acceptable and available to Maori clients (Baxter, 2002; Shea, 2006). Of these three the issue of acceptability has been particularly problematic, with the recognition that such services may not be culturally appropriate to the health needs of the indigenous people of NZ (Durie, 1998; Ramsden, 1990; Willams et al., 2003; Wilson \& Roberts, 2005). The Government's response has been to make Maori health a priority, with strategies that include funding designated Maori health providers such as THONR. Maori clients now have a choice between Maori and mainstream services $^{1}$ for aspects of primary health care $^{2}$ and health education $(\mathrm{MOH}$, 2001b).

Diabetes is much more prevalent among Maori than non-Maori; it affects Maori at a younger age and they develop more severe complications (Robson \& Harris, 2007). Recognition of this situation led the Government to identify diabetes as a health priority area in the NZ Health Strategy $(\mathrm{MOH}, 2000)$ and the NMDHB to contract two MDNE positions, one each in the Nelson and Marlborough provinces. Both of these contracts are held by THONR, but only the programme being offered in the Marlborough region is evaluated in this study.

\footnotetext{
1 "Mainstream services" is used to denote services provided for the general public, most commonly funded/provided by the DHB. This term is used despite the potential to marginalise targeted Maori services by doing so, as the term is widely used and understood.

${ }^{2}$ Primary health care - local, first contact care for people that is accessed by self-referral.
} 


\section{The Programme}

The programme designed by THONR was called "He oranga mo te mate huka", meaning "Wellness with Diabetes". Its aim is to enable participants: "Te hikoi o nga mokopuna - to walk with our grandchildren", thus simultaneously focusing on the objective of staying well and mobile, and highlighting the importance of whanau (extended family) in the Maori value system. This was a small programme, working with a diverse population, who were spread over a large district. Clients resided in three provincial towns and the surrounding hinterland. The following section briefly introduces the programme. A deeper understanding of the functioning of the programme is gained as a result of conducting the research and is presented in chapter four.

At the commencement of the study the programme and the MDNE role had already been established by THONR in Marlborough for approximately one year (see Service Specifications for MDNE role in Appendix A). Clients with type $1^{3}$ and $2^{4}$ diabetes, pre-diabetes ${ }^{5}$ and metabolic syndrome ${ }^{6}$ were referred to the MDNE from a range of sources which included: general practitioners (GPs); other Maori health providers and other services offered by THONR; physicians and health educators based at the local hospital, and by self and whanau referral.

The objectives of the programme were to:

- provide an educational program which promotes wellness and selfmanagement of type 2 diabetes;

\footnotetext{
${ }^{3}$ Type 1 diabetes - a chronic condition characterised by high blood glucose levels caused by a lack of insulin production by the beta cells in the pancreas.

${ }^{4}$ Type 2 diabetes - a condition in which the body becomes resistant to the effects of insulin or the body produces some, but not enough, insulin to maintain a normal blood sugar level. Type 2 is more common than type 1 especially in Maori.

${ }^{5}$ Pre-diabetes - state between normal and diabetic homeostasis. Two distinct states: impaired glucose tolerance and/or impaired fasting glucose.

${ }^{6}$ Metabolic syndrome - a constellation of conditions that predispose one to coronary artery disease and diabetes. These include large waist measurement, high blood pressure, low High Density Lipoprotein, high triglycerides and raised fasting blood glucose.
} 
- use Whanaungatanga as a model to deliver health education, health promotion and diabetes self-management;

- $\quad$ promote regular health checks;

- $\quad$ promote healthy eating and physical activity; and increase awareness and use of diabetes services available.

(Programme documents, Appendix B).

Upon joining the programme the client received an initial assessment and their need for education and support were prioritised. They continued to see the MDNE one-to-one as frequently as was necessary to master monitoring their diabetes, taking medication, and to learn about the importance of making lifestyle changes. Additional services that were offered to clients included smoking cessation, transportation, social services and support when attending appointments. Furthermore, they could join a six week group education course on diabetes.

Maori hui protocols and processes were used throughout these education sessions, including karakia (prayers), waiata (songs/psalms), mihi (greetings and introductions) and poroporoake (farewells). There was a strong focus on goal setting and evaluating progress towards those goals especially in the area of making and maintaining lifestyle change. Another focus was on revision, clarification and reinforcement of the message with review of the previous week's session every week, and the opportunity to cover the material one-toone with the MDNE between sessions and following completion of the course. At the completion of the group sessions, clients could access ongoing education and support from the Diabetes Support Group.

The involvement of THONR staff with the programme is represented diagrammatically in Figure 1. This illustrates that providing the programme to clients with established diabetes, pre-diabetes and metabolic syndrome was a large part of the MDNE's overall workload. Other THONR staff also had some involvement with the programme, mainly the three shown here, the Whanau Ora Nurse, the Whanau Ora Kaimahi and the Smoking Cessation Educator. 


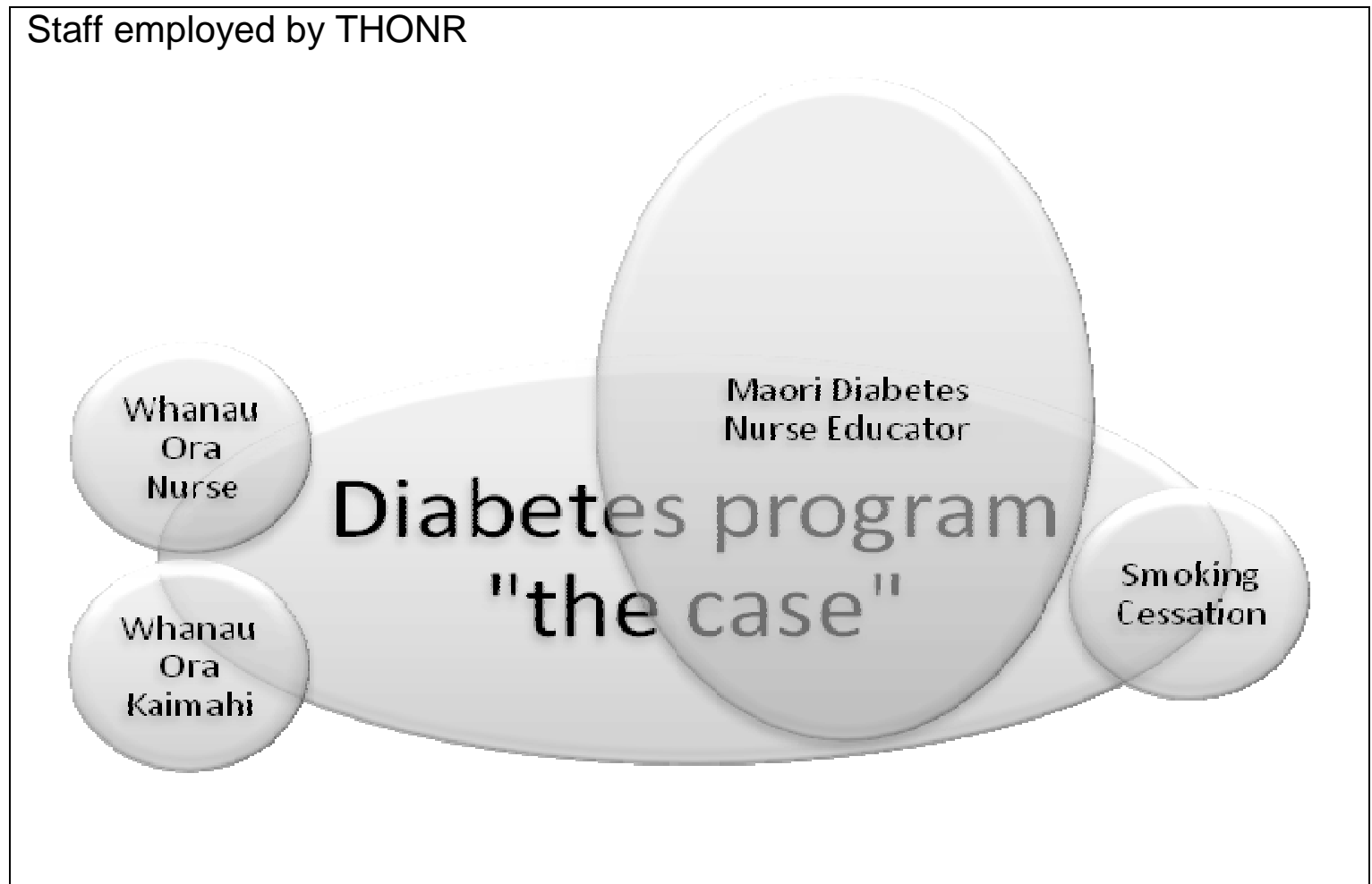

Figure 1. Diagrammatic representation of THONR staff involvement in the programme

Although the service specifications for the MDNE role are referred to at times, this study did not aim to determine whether the requirements of the specifications were being met, that is the function of District Health Board reviews of the service. It was also beyond the scope and purpose of this study to consider the cost effectiveness of the service.

Other aspects of the service that were not evaluated but do form part of the context of the programme or "case" were the MDNE's diabetes screening function, her time as part of the health education team at the local hospital, and her educational role with DHB staff and local practice nurses. These other roles are denoted by the area outside the programme, at the top of the MDNE oval in Figure 1. Other THONR staff were only of interest to the study when they were contributing to the care of people with diabetes on "the programme". Likewise, employees of other agencies contributed to the programme, particularly the education sessions, and some of them were interviewed for the study. However they were only part of "the case" when they were contributing to the programme, otherwise they were part of the context of the case. 
Introducing Jo Janssen the researcher:

I am a Pakeha New Zealander, born in Wellington in 1958, of Dutch immigrant parents. Although outwardly appearing to belong to the dominant Pakeha culture, I didn't always feel like a 'Kiwi' (New Zealander) when I was growing up, due to my parents being 'different'. Hence I identify to some extent with the experience of feeling excluded from "mainstream NZ society". Having spent three decades working in the public health system, I have seen first hand the cultural divide that can exist between the hospital staff and some Maori clients, especially those who are most marginalised due to socioeconomic status and other lifestyle factors.

Throughout the research I recognised my own strengths and inadequacies in engaging with this new and culturally different environment (Mill \& Ogilvie, 2003), and sought support and guidance from participants, especially the MDNE and other Maori friends (although the latter was limited by issues of programme confidentiality). The Director of Maori Health, at the Nelson Marlborough DHB was also helpful, particularly during the study design stage. This assistance included providing a letter of support and identifying important Maori cultural considerations significant in research (Appendix $C$ ). In terms of Pakeha support for myself as a Pakeha researcher, both of my supervisors have researched in partnership with Maori so they were able to guide me in this respect.

I am currently employed in two part-time positions; as a clinical nursing tutor for Nelson Marlborough Institute of Technology and as a staff nurse in the High Dependency Unit at Wairau Hospital in Blenheim. Prior to the current study, my involvement with THONR had consisted of supervising nursing students receiving practical experience with the organisation.

In 2005 Heather Oehlrich, who is introduced in the next section, assumed the newly created MDNE role and started presenting the "Wellness with Diabetes" programme to her clients. At that time I approached her about designing, delivering and evaluating a heart disease programme for Maori clients. She 
suggested her diabetes programme to me as it was already being delivered, seemed to be effective, and included considerable content on preventing/managing heart disease as well as diabetes, so was consistent with my original interest in cardiovascular disease. A literature search indicated that research into Maori health at that stage was mainly descriptive in nature, rather than evaluating intervention programmes, so this was worthwhile research to be undertaking.

Yin (2003) reports that it is preferable to disclose all organisational and individual identities when conducting a case study, but THONR is a small provider in a small community with the identities of most client participants being known to staff of the organisation, so feedback was more likely to be candid if confidentiality was offered to participants. In this report the organisation, the MDNE and the manager are identified, other service providers are numbered and clients are given gender neutral pseudonyms to protect their identity.

The key MDNE position around which this programme and this case study are based was occupied at the time of data gathering by Heather Oehlrich.

Heather introduces herself in the following mihi:

Ko Tongariro te maunga

Ko Taupo te moana

Ko Tuwharetoa te iwi

Ko Ngati Korauia te hapū

Ko Te Arawa te waka

Ko Heather Oehlrich toku ingoa

Tena koutou katoa

I have had the privilege of working for Te Hauora O Ngati Rarua, an iwi health provider for 11 years, first as the Whanau Ora Nurse and since January 2005 as the Maori Diabetes Nurse Educator for Marlborough. I am passionate about the health and wellbeing of our 
whanau and support them through collaborative care on their journey to becoming the expert in self management of their health issues. Our focus is on wellness, individual and group education, screening, prevention, health promotion, advocacy, advice and support to reduce the incidence and impact of diabetes. We use holistic person/whanau-centred models of care, ensuring the person /whanau is linked into all services to support wellbeing. I am working to complete my Master of Nursing and my goal is to be a Nurse Practitioner with Prescribing Rights. I am an Iwi representative on Kimi Hauora Wairau: Marlborough Primary Health Organisation, Member of Marlborough Local Diabetes Team and Marlborough Primary Health Nurse Leadership group. My qualifications are Registered General and Obstetric Nurse, Bachelor of Nursing, Graduate Certificate in Clinical Teaching, Certificate in Health Promotion, Vaccinator, Smear Taker.

The MDNE and the manager of THONR welcomed the opportunity to have the programme evaluated because they believed in the benefit of what they were doing to improve health outcomes for their people and because they wanted constructive feedback so that they could improve the service.

\section{Entering the field}

I approached this research tentatively four years ago, aware of obligations under the Treaty of Waitangi to enable Maori to maintain control (tino rangitiratanga) over Maori resources, including the involvement of their people in research (Health Research Council [HRC], 1998). This meant the wishes of the tangata whenua (local/native people) were paramount and needed to be respected if concerns were raised by stakeholders about aspects of the study (HRC). Consultation throughout the project and beyond was important and allowed us to resolve issues such as access to participants, intellectual property rights, access to data, publication processes, accountability and storage of information (HRC). These were worked through and agreed to in a contract between the organisation and myself (Appendix D). 
I was aware that several authors had raised concerns about non-Maori researchers conducting research in a Maori community (Bishop, 2005; Cunningham, 1998; Smith, 1999). Particularly that such research could leave indigenous people positioned as powerless, when the locus of a research problem was framed as lying with the individual rather than with other social or structural issues (Reid \& Robson, 2006; Smith). But I also noted that the Health Research Council (1998) recognised that research between Maori communities and non-Maori researchers, while not ideal, has an important contribution to make to Maori health knowledge, given the limited number of suitably skilled Maori researchers and the breadth of research to be done. In such a crosscultural setting Bevan-Brown (1998) and Cunningham highlight the importance of maximising Maori involvement and control, which I was committed to doing.

Another consideration was the need to ensure the research was "culturally safe". Kearns and Dyck (2005) state "to be culturally safe in research is to enter a partnership with another person or members of a population group in which they allow you to participate in co-creating a deeper understanding of their world" (p. 86). They claim that culturally safe research involves three key processes: respect for the cultural knowledge, values and practices of others; an awareness of one's own way of seeing and doing; and an analysis of the effect of our actions on the knowledge that is produced.

I suspected that the programme was making an important contribution to the health care of THONR's Maori clients with diabetes, but I had not seen the staff in action with a client and I felt a general uncertainty about what my presence as a Pakeha and a researcher would mean for the 'normal' functioning of the programme. Consequently one of the early considerations for myself and the stakeholders was what my role in the programme should be, whether that be as an insider (one who belongs), an outsider (one who doesn't belong) or someone with multiple roles (Kearns \& Dyck, 2005). Through consultation with the MDNE and manager of THONR we determined that I should be inside the education sessions, developing relationships with potential client participants and gaining a deeper understanding of programme functioning. For indigenous research 
though, the expression 'insider' usually means someone of the same ethnicity, so to that extent I would still be regarded as an 'outsider' to the research setting (Bishop, 2005; Smith, 1999). Another consideration was whether I should have a role in the design and delivery of the education sessions as another health professional; solely observe; or be a participant-observer. The latter was the researcher role we settled on.

\section{The Study}

The aims of the study were to:

- Describe the programme, its various components and their integration;

- Explore the experience of having diabetes and being on this programme, from the perspective of programme participants;

- Determine if the programme was stimulating an improvement in physiological outcomes, knowledge, attitudes and action towards lifestyle changes and blood glucose management; and

- Identify which components of the programme were most useful to participants and to make recommendations for possible improvements to the programme.

Case study methodology was well suited to the objectives of this study because we wanted to know if the programme worked, particularly how and why it worked. As Yin (2003) notes "Case study is suitable if a 'how' or 'why' question is being asked about a contemporary set of events, over which the investigator has little or no control" (p. 9). There are many ways of looking at case study and two main writers in this area; Yin and Stake (1995). This work was based mainly on Yin's approach to case study research design. Having access to a range of evidence such as stakeholder interviews, organisational documents and physiological outcome data also favoured case study methodology because it allowed the capture of the organisation from multiple perspectives.

The study followed seven programme client participants for 9 to 12 months from mid 2006 to mid 2007. Data sources included: notes and reflections from 
participant-observation of the six-week education sessions; and interviews with each client participant and with five service providers, three inside the THONR organisation and two outside. This included a series of meetings and interviews with the MDNE. Physiological data were collected throughout the period including weight, blood pressure, waist circumference, blood glucose and $\mathrm{HbA}_{1} \mathrm{c}^{7}$, and serum lipid profiles. Other data sources included documentation such as clinic notes, service specifications and previous programme participant feedback. The study received approval from the Upper South A Regional Ethics Committee (Appendix E).

\section{Theoretical approach underpinning the study}

The overarching theoretical approach of this study was informed by three general theories. These were Systems Theory (Harris \& Associates, 2002), the Chronic Care Model (Improving Chronic Illness Care, 2008) and the Transtheoretical Model of Change (Highstein, O'Toole, Shetty, Brownson, \& Fisher, 2007). These theories were integrated to create a comprehensive overview of the functioning of the programme as a unit. Each of these is now briefly described and their role in the study explained.

\section{Systems Theory}

The programme was evaluated using a systems approach to organisational performance as cited by Harris et al. (2002). They identify that unlike other businesses that compete for financial survival, health care organisations are founded on humanistic beliefs around social responsibility. However, they are particularly sensitive to the specific political, legal and financial regulatory environments in which they operate. This encapsulates the conflicting pressures on THONR; they were having to reconcile governmental and DHB expectations of achieving improved Maori health outcomes from the funding available, with their own understanding of effective strategies for working with their clients.

\footnotetext{
${ }^{7} \mathrm{HbA} 1 \mathrm{c}-$ glycosylated haemoglobin. A test that measures the amount of hemoglobin bound to glucose. It is a measure of how much glucose has been in the blood during the past two to four months.
} 
Another perspective comes from Anderson and McDaniel (2000) who propose that health care organisations are best viewed as complex adaptive systems;

If we recognise that health care organisations are complex adaptive systems operating in a professional milieu then we focus on different things and arrive at different conclusions than if we believe that they are professional bureaucracies begging to be run more effectively and efficiently according to traditional rules of administrative behaviour. p. 84

These comments also hold true for THONR which values relationships, both with other organisations and clients above traditional business considerations.

Similarly Harris et al. (2002) conclude that services reflecting cost efficiencies may not always meet community expectations of equitable access to services and equitable outcomes for all population groups, whether defined by ethnicity, age, disease, gender or geographic location. This view is consistent with the World Health Organisation's (WHO) World Health Report 2000, which identifies as its prime health objective "good health for all" and defines this as consisting of goodness and fairness. In this instance goodness means a health system responding well to what people expect of it, while fairness means it responds equally well to everyone, without discrimination (WHO, 2000).

Such goals represent the global requirements for health care that individual governments are committed to achieving. Global comparison of population health status between countries shows that New Zealand shares the worldwide trend of significantly poorer health outcomes for indigenous people than the rest of society (WHO, 2008). At the national level the $\mathrm{NZ}$ Government has responded to these inequities by setting 13 health priorities in the national health strategy $(\mathrm{MOH}, 2000)$ and further defining these in He Korowai Oranga the Maori Health Strategy $(\mathrm{MOH}, 2002 \mathrm{a})$. The objectives outlined in these strategy documents have been operationalised by the Nelson Marlborough District Health Board into the MDNE contract (Appendix A). This contract has been further operationalised by the organisation into the programme that is being evaluated for this study. Hence the poorer health outcomes for Maori 
compared to other New Zealanders both in Marlborough and in the rest of the country has been an important driver of this programme.

Figure 2 illustrates the systems approach to organisations used to guide this evaluation. While Systems Theory has largely been written from a quality and performance perspective, in this thesis it is used to capture the content and intricacies of the programme including who is involved and how it works.

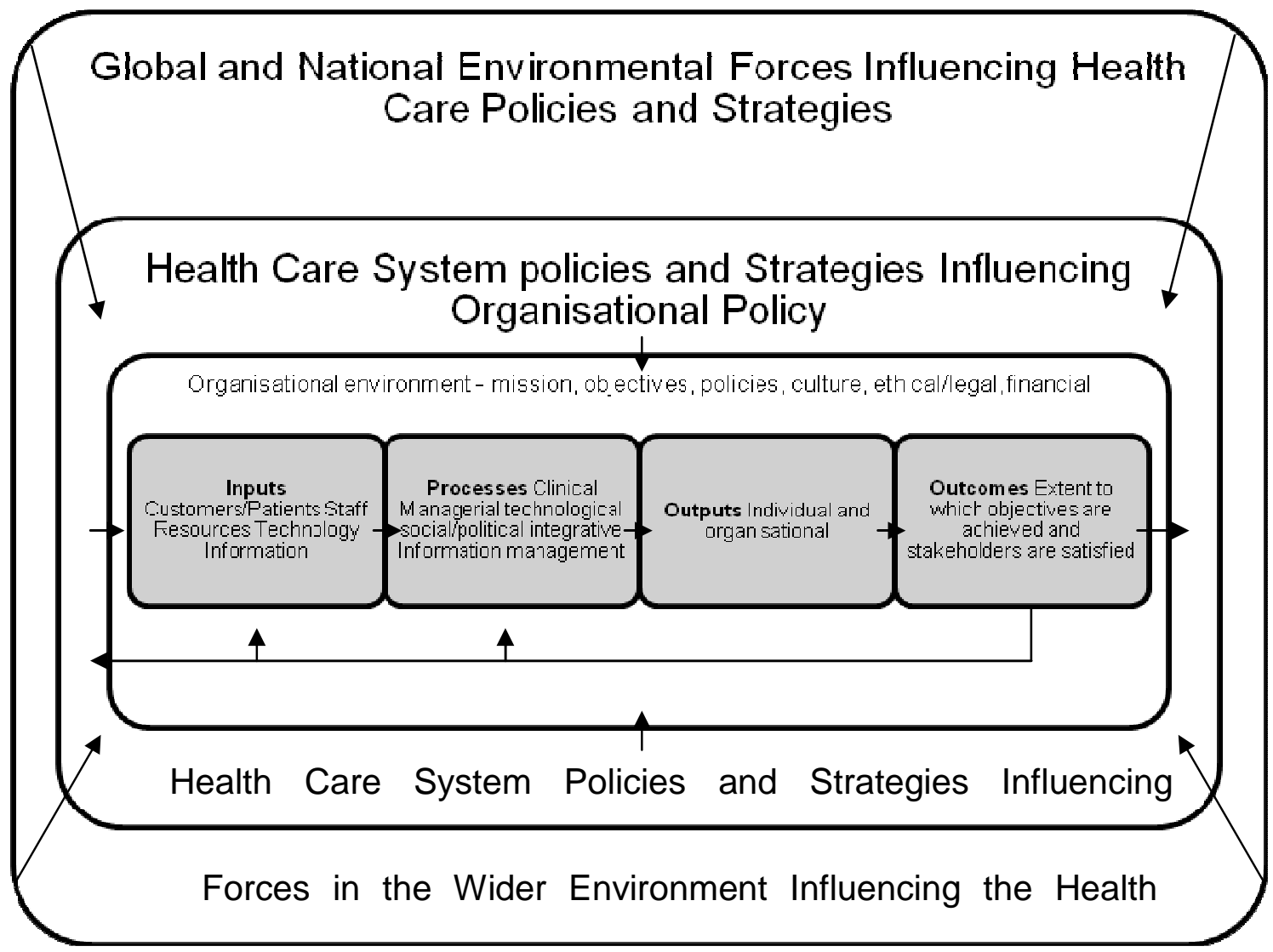

Figure 2. The systems approach to organisational performance analysis and improvement ${ }^{*}$

*Adapted from "Managing health services concepts and practice". By M.G. Harris and Associates. 2002. p. 334. Eastgardens, NSW: MacLennan and Petty Pty Ltd.

The external environment affects health care through a combination of geographical, political, cultural and economic influences, which have an impact on the organisation's performance and how that is interpreted (Harris et al., 2002). Geographical influences include the size of the Marlborough district that THONR covers and the rural isolation experienced by some of their clients with the inherent extra costs in providing services to those people. Cultural 
influences include Maori generally having higher health needs than the rest of the population, and potentially having different health requirements and expectations than the rest of the community. Consequently, all Maori diagnosed with diabetes in the district are expected to be referred to the MDNE who is contracted to provide a culturally appropriate service to them (Appendix A).

This evaluation was shaped by performance in four key areas of Systems Theory as identified in Figure 2, i.e. inputs, processes, outputs and outcomes. These areas align with the four essential characteristics of a Maori service identified by Cunningham and Durie (2005): clinical inputs that are consistent with the best possible outcomes; a cultural context that makes sense to clients and their whanau; outcome measures that are similarly client focused; and the integration of the service with other aspects of positive Maori development. Cunningham and Durie see these characteristics as providing the basis of an appropriate framework for evaluation of the effectiveness of a Maori organisation.

Inputs into the service include staff, clients, resources, technology and information. Outputs are how many people were seen and what they received. Processes involve how people enter the service, what happens to them and how the service functions. Outcomes consist of the extent to which objectives were achieved and stakeholders were satisfied. Performance measures to evaluate these outcomes include the degree to which care was efficacious, appropriate, timely, effective, safe, efficient, caring, respectful and well coordinated (Harris et al., 2002). Performance in these key areas is combined with performance measures from the Chronic Care Model to give an overall view of how well the organisation was meeting the health care needs of clients.

\section{Chronic Care Model:}

As the study progressed it became evident that clients' ability to effect change and improve diabetes management was often complicated by a range of other chronic conditions. This topic is dealt with by Wagner (1998) who proposed the Chronic Care Model (CCM) as a framework for improving the quality of care and 
the outcomes for people with chronic conditions. The model has been further developed, researched and promoted by the Improving Chronic IIIness Care (2008) project team with support from the Robert Wood Johnson Foundation, as a means of reconfiguring health services to address the needs and concerns of chronically ill persons. This model is compatible with Maori values and attitudes to health as identified by Durie (1998) and Jansen and Sorrenson (2002) as it also addresses structural factors and community support, while encouraging clients to develop self-management skills.

The six elements of the chronic care model: the community, health system, clinical information systems, decision support, delivery system design and selfmanagement support are used to evaluate the effectiveness of the programme, by considering whether the criteria outlined in Table 1 were being met.

Table 1. Criteria for achieving each element of the Chronic Care Model ${ }^{\star}$

\begin{tabular}{|l|l|}
\hline Element & Criteria \\
\hline The & $\begin{array}{l}\text { Encourage patient participation in community programmes } \\
\text { Form partnerships and develop interventions with community } \\
\text { organisations } \\
\text { Advocate for policies to improve patient care }\end{array}$ \\
\hline $\begin{array}{l}\text { Health } \\
\text { system }\end{array}$ & $\begin{array}{l}\text { Systematically support quality improvement at all levels of } \\
\text { organisation } \\
\text { Develop agreements to co-ordinate care across organisations }\end{array}$ \\
\hline $\begin{array}{l}\text { Delivery } \\
\text { system } \\
\text { design }\end{array}$ & $\begin{array}{l}\text { Define roles and distribute tasks among team members } \\
\text { Provide clinical case management for complex patients } \\
\text { Ensure regular follow-up }\end{array}$ \\
\hline $\begin{array}{l}\text { Gecision } \\
\text { support } \\
\text { cultural background }\end{array}$ & $\begin{array}{l}\text { Embed evidence-based guidelines into daily clinical practice } \\
\text { Share evidence-based guidelines with patients } \\
\text { Use proven provider education methods } \\
\text { Integrate specialist expertise and primary care }\end{array}$ \\
\hline $\begin{array}{l}\text { Clinical } \\
\text { information } \\
\text { systems }\end{array}$ & $\begin{array}{l}\text { Provide timely reminders for providers and patients } \\
\text { Identify relevant sub-populations for proactive care } \\
\text { Facilitate individual patient planning } \\
\text { Monitor performance of the practice team and care system }\end{array}$ \\
\hline $\begin{array}{l}\text { Self- } \\
\text { management } \\
\text { support }\end{array}$ & $\begin{array}{l}\text { Emphasise the patient's central role in managing their health } \\
\text { Includes assessment, goal-setting, action planning, problem- } \\
\text { solving and follow-up } \\
\text { Organise internal and community resources to provide } \\
\text { self-management support to patients }\end{array}$ \\
\hline
\end{tabular}

${ }^{*}$ Adapted from: Improving Chronic Illness Care. (2008). The Chronic Care Model. Retrieved June 22, 2008, from http://www.improvingchroniccare.org/index.html 
The Systems Theory and Chronic Care Model provided a means of evaluating the functioning of the programme from an organisational perspective. But another focus of the study was identifying salient features of the experience of having diabetes and being on the programme for individual clients. In order to explore these experiences it was desirable to compare them with evidence based findings regarding the process of attempting lifestyle change for other groups. The Transtheoretical Model of Change as described by Highstein et al. (2007) and Lawrence (1999) is well recognised in this respect and was used to determine to what extent the experiences of this group were similar to and different from those of other people attempting to make similar changes.

\section{Transtheoretical Model of Change}

The Transtheoretical Model of Change (TTM) was originally described by Prochaska and DiClemente in 1983. The model defines behaviour change as a dynamic process that develops and evolves through a number of definable stages, drawing on a range of identifiable psychological processes to initiate and support the desired outcome (Lawrence, 1999). The main characteristics of each of the stages of the model are identified in Table 2.

Table 2. Characteristics of each stage in the Transtheoretical Model*

\begin{tabular}{|l|l|}
\hline Stage of change & Characteristics of stage of change \\
\hline Precontemplation & $\begin{array}{l}\text { No intention to change in next } 6 \text { months. May not } \\
\text { recognise/accept diagnosis (I won't), or may not } \\
\text { believe change is possible (I can't) }\end{array}$ \\
\hline Contemplation & $\begin{array}{l}\text { Aware of problem and intending change in next 6 } \\
\text { months (I might). Not motivated to overcome barriers }\end{array}$ \\
\hline Preparation & $\begin{array}{l}\text { Combines intention and behavioural criteria. Plan } \\
\text { to make change in the next month (I will) }\end{array}$ \\
\hline Action & $\begin{array}{l}\text { The new changed behaviour is practised, must be } \\
\text { sustained for 6 months (I am). }\end{array}$ \\
\hline Maintenance & $\begin{array}{l}\text { Change maintained at least 6 months. Work to prevent } \\
\text { relapse and consolidate gains of second stage (I still am). }\end{array}$ \\
\hline Termination & $\begin{array}{l}\text { There is no danger of reverting to problematic behaviour. } \\
\text { Won't be reached for some behaviours }\end{array}$ \\
\hline
\end{tabular}

* Adapted from: Highstein, G., O'Toole, M., Shetty, G., Brownson, C., and Fisher, E. (2007). Use of the Transtheoretical Model to enhance resources and supports for diabetes self management. Lessons from the Robert Wood Johnson Foundation Diabetes Initiative. The Diabetes Educator, 33(Suppl. 6), pp.193S-200S, and Lawrence, T. (1999). A stage-based approach to behaviour change. In E. R. Perkins, I. Simnet and L. Wright (Eds.), Evidence-based Health Promotion (pp. 64-75). Chichester: John Wiley \& Sons Ltd. 
The model has been studied extensively and modified by subsequent authors. When it was used in the current programme the 'termination' stage was replaced by 'relapse' because many areas of lifestyle change require the person to modify their behaviour rather than giving up the undesirable behaviour altogether. This distinction meant that change was likely to be characterised by periods of action and relapse, consequently emphasising that change is an ongoing and dynamic process with a fluctuating level of success (Lawrence, 1999; Zimmerman, Olsen, \& Bosworth, 2000). The discussion chapter (Chapter 6) considers to what extent the TTM model fits with the programme participants' experiences of change processes.

\section{Thesis overview}

This first chapter has introduced the researcher, the MDNE and the reason for conducting the research. It has also briefly described the programme, theory and models that were used to conduct this evaluation; the remaining thesis is organised into six chapters.

Chapter 2 presents the research context. The focus is to provide a background to the global, national and local context in which the programme is situated. This includes the effects of colonisation and government policies on Maori health, and a summary of some of the statistics that demonstrate the disparities between the health of Maori and non-Maori in NZ, especially related to diabetes and heart disease. The political response to this situation in terms of health policies and strategies that drove service provision at the time data was being collected is reviewed. The chapter finishes with an overview of other research in this area and clarifies how this study is positioned in relation to previous and ongoing research.

Chapter 3 gives a fuller description of the research design that was used in this study. As the process developed many ongoing changes to design and tools were made as the potential, and the limitations, of the research became more evident. A large consideration in the development of the design was issues 
related to being a Pakeha researcher working in partnership with Maori stakeholders.

The findings are presented over two chapters. Chapter 4 builds on the brief outline of the programme given in this chapter. It uses Systems Theory to structure a description of the functioning of the programme under the headings inputs, outputs and processes. Inputs in this context include: staff, clients, resources and technology. Outputs and processes are first described by following the clients' journey through the programme and then considered from an organisational perspective including how staff work together within and outside the programme. Chapter 5 presents an analysis of interview and other data to determine the effectiveness of the service, both from individual clients' perspective and from a service perspective.

Chapter 6 discusses what we now know about having diabetes and being on this programme, including the importance placed on various aspects of the programme by the participants. Other findings are related to the experience of attempting lifestyle change while beset by multiple chronic illnesses and the relevance of Systems Theory and the Chronic Care and Transtheoretical models used to inform practice in this setting. These models are also used as a basis from which to make recommendations for further service development. An additional consideration is what this research contributes to our understanding of the functioning of Maori health services and innovative nurse-led primary health care roles in NZ. Finally this chapter provides some insights into the process of being a Pakeha researcher working in partnership with a Maori organisation.

Chapter 7 summarises the main conclusions of the study. It also considers how this study contributes to knowledge in the area of diabetes and chronic illness management, nurse-led services, and the challenges facing small Maori health providers in the current health service environment. 


\section{Chapter 2 - Setting the scene: describing the research context}

A critical aspect of case study is its positioning within context. For the $\mathrm{Te}$ Hauora O Ngati Rarua (THONR) programme this context principally concerns Maori health and Maori service development. THONR, which offers this programme, is one of 240 Maori health providers in New Zealand (Maori Health Directorate, 2008), most of which have become established in the last 15 years (Cunningham \& Durie, 2005). This chapter identifies historically significant events leading to the development of such Maori health services and the current legislation, policy and contractual obligations that drive these programmes. The context of the study in terms of the current state of Maori health, especially diabetes, in New Zealand (NZ), and factors that impact it are also discussed, leading to a consideration of what constitutes a "culturally appropriate" health service.

\section{History of Maori health: Colonisation and structural disadvantage}

Concern for Maori health and wellbeing and the need to provide protection following the harmful effects of colonisation were significant contributing factors to the crafting of the Treaty of Waitangi which was signed in 1840. The Treaty is considered the founding document of the relationship between Maori and the Crown in New Zealand (Durie, 1998). Three of the four articles of the Treaty have health implications for Maori, such as guaranteeing self-determination and control over their resources and taonga (treasures), which includes health (Durie; Health Promotion Forum of New Zealand, 2002). Three main principles have been identified in the Treaty and now underpin the Crown's relationship with iwi: partnership, participation and protection (Royal Commission on Social Policy, 1988). These principles emphasise Maori involvement at all levels of decision-making and delivery of care. This includes appropriate workforce development, working to ensure Maori have at least the same level of health as non-Maori, and safeguarding Maori cultural concepts, values and practices (Durie; Health Promotion Forum of New Zealand; MOH, 2002a). 
The Crown sought to meet its treaty obligations to Maori from 1938 onwards through "universal health care" in the form of free secondary and subsidised primary care. Then from 1993 onwards it sought to further improve access to primary health care for those on low incomes by providing a "High Use Health Card" and means tested assistance such as the "Community Services Card" (Dew \& Kirkman, 2002). These initiatives were expected to benefit Maori and non-Maori equally (Foley, 2008; MacLeod, 1994). However for many years Maori considered that the Crown was not honouring its obligations under the Treaty (Ajwani, Blakely, Robson, Tobias, \& Bonne, 2003; Dew \& Kirkman; Durie, 1998) as the widening disparities, for example in management of cardiovascular disease (Bramley et al., 2004; Tukuitonga \& Bindman 2002) and diabetes (New Zealand Guidelines Group [NZGG], 2003b), provided evidence of inequitable health care and health outcomes for Maori (Reid \& Robson, 2006).

The disparities worsened in the 1980s and 1990s following market driven reforms in the health, housing and education sectors, and deregulation of the labour market (Dew \& Kirkman, 2002). These reforms disproportionately affected Maori through increased unemployment, lower household incomes and increased health costs such as user part-charges (Blakely, Tobias, Atkinson, Yeh, \& Huang, 2007; Cunningham \& Kiro, 2001; Reid, 1999). Since the late 1980s though, evidence has been growing that such socio-economic factors only account for 50 percent of the disparity between Maori and non-Maori health status (MOH \& University of Otago 2006). For example, Maori in the least deprived deciles have a lower life expectancy than non-Maori in the most deprived deciles $(\mathrm{MOH}, 2002 \mathrm{~b}$; New Zealand Guidelines Group [NZGG], 2003a); thus there is an independent ethnicity factor contributing to poorer health outcomes for Maori (Dew \& Kirkman), which will be explored further in the section describing the context of the study.

The next section focuses on the contemporary health service provision environment. This includes the emergence of "by Maori for Maori" services and the development of Te Hauora O Ngati Rarua as an iwi health provider. Prior to 
this exploration, some comparison of the Maori population in the Nelson Marlborough region with that of the rest of the country is provided. The population of Nelson Marlborough is $8 \%$ Maori, compared to an average of $15 \%$ for New Zealand as a whole (Public Health Consultancy, 2001). The entire population of Nelson Marlborough is more "middle class" than the rest of the country, with comparatively fewer people at the extremes of deprivation and affluence (Public Health Consultancy). But Maori are still generally worse off than non-Maori within the region, with the majority of their population being located in deciles 5-9 of the deprivation index (where 1 is least deprived and 10 is most deprived), while most non-Maori are in deciles 4-7 (Public Health Consultancy). Maori in the region have higher rates of diabetes, heart disease and cancer than non-Maori, but generally have lower rates than Maori in NZ as a whole (Public Health Consultancy).

\section{The emergence of "by Maori for Maori" services}

One factor contributing to poorer health outcomes for Maori is under-utilisation of primary health care and over-utilisation of secondary services (Malcolm, 2004). In this respect it has been noted that charging for primary services, while providing free secondary services, produces a perverse incentive for patients. It discourages people from seeking medical treatment when conditions are minor, with the consequence of people presenting directly to hospital when the condition worsens (Dew \& Kirkman, 2002). Utilisation of health care services can also be influenced by a person's comfort with the service provided, including its "cultural appropriateness" (Durie, 1998; Simmons et al., 1998; Willams et al., 2003; Wilson \& Roberts, 2005).

The Government sought to address these reasons for under-utilisation by funding iwi and other non-tribal Maori organisations to provide affordable health services for their own people, particularly from the 1990s onwards (Dew \& Kirkman, 2002). This was viewed by Maori as evidence of the Government's commitment to their rangatiratanga (right to self-determination) (Cunningham \& Kiro, 2001; Durie, 1998). It was also consistent with "a wider government agenda relating to the location of risk within communities of interest" 
(Cunningham \& Kiro, p. 74); hence the government was further removed from responsibility for unfavourable health outcomes. Meanwhile many Maori health providers were under-funded by the state and left to make up the shortfall from their own coffers (Abel et al., 2005; Durie).

Health policy is currently directed by the NZ Public Health \& Disability Act 2000, through two overarching strategies, the $N Z$ Health Strategy $(\mathrm{MOH}, 2000)$ and the NZ Disability Strategy $(\mathrm{MOH}, 2001 \mathrm{a})$. Both strategies focus on the need to improve Maori health outcomes. The NZ Health Strategy identifies 13 population health objectives, six of which are relevant to the THONR programme, namely; reducing the incidence and impact of diabetes, and heart disease, reducing smoking and obesity, increasing physical activity and improving nutrition. The Maori Diabetes Nurse Educator (MDNE) position and this programme are examples of the key role identified for primary health care nurses in addressing some of these health objectives ( $\mathrm{MOH}, 2001 \mathrm{~b})$. Such nurses are identified as working in partnership with people - individuals, whanau, communities and populations - to achieve the shared goal of health for all in their particular areas of professional practice (Expert Advisory Group on Primary Health Care Nursing, 2003; MOH, 2001b).

Cunningham and Kiro (2001) describe the period since the mid 1990s as the kaupapa Maori phase of health policy, with the increase of "by Maori for Maori" policy solutions being promoted within Maori political and operational control. This approach is supported by He Korowai Oranga -The Maori Health Strategy (MOH, 2002a), the first strategic document that attempts to cover all aspects of Maori health (Boulton et al., 2004). It sets Maori health priorities and identifies intervention pathways to achieve these including Objective 2.2 "To increase the capacity and capability of Maori providers to deliver effective health and disability services for Maori" (MOH, 2002a, p.16). DHBs purchase services provided by non-DHB providers including Maori health providers such as THONR and report directly to the MOH. The Government reports on the progress made in each of the health priority areas at a national level in the annual publication entitled Implementing the Strategy (MOH, 2006a). 


\section{Development of Te Hauora O Ngati Rarua}

Te Hauora O Ngati Rarua became established as a Maori health provider under the governance of the Ngati Rarua Iwi Trust in 1996 with a combination of government funding and iwi resources. (Prior to that time the iwi had only been providing social services). In 1997 they were one of three Marlborough health providers to receive a Whanau Ora contract ${ }^{8}$. Since then the service has intentionally grown slowly and focused on contracts related to health education and promotion, such as smoking cessation and cervical screening. THONR gained the status of an Accredited Primary Health Provider with Quality Health $\mathrm{NZ}^{9}$ in 2004, which was renewed in 2007 for a further three years. The Maori Diabetes Nurse Educator contract that shaped the programme the study is based on was commenced in 2005 (Luke \& Oehlrich, personal communication, 21/11/2007).

Three government initiatives in particular were significant to the MDNE role:

1) Screening for diabetes and heart disease based on the NZGG guidelines (NZGG, 2003a \& 2003b);

2) Care Plus which consists of low cost regular access to a nurse and/or doctor for people with significant chronic illnesses such as diabetes or heart disease and the joint development of a Care Plan (MOH, 2008a); and

3) The Get Checked Programme (specifically for diabetes) which consists of annual free GP checks of the person's physical health, lifestyle, and disease management, including referral to appropriate specialist services such as physician, podiatrist, ophthalmologist (NZGG, 2003b).

Enrolment in these programmes by general practitioners (GPs) has been lower for eligible Maori than non-Maori (Robson \& Harris, 2007) so it has become a focus of this service to advocate and ensure that its clients receive the care to which they are entitled.

\footnotetext{
${ }^{8}$ Holding a Whanau Ora contract means staff work with the whole family to support them to achieve the fullness of health and wellbeing.

${ }_{9}^{9}$ Quality Health NZ undertake audits to approved sector standards for $\mathrm{MOH}$ certification
} 
A whanau ora nurse and kaimahi were also involved in teaching on the education sessions and providing care and support to some clients. This role grew out of the Maori Health Strategy and requires health workers to consider individual patients as part of a whanau and to take a multidisciplinary approach to managing their care. Cunningham and Durie (2005) claim such initiatives have moved the health sector closer to the Maori ideal of Maori-centred health service delivery. Another perspective comes from Boulton et al. (2004) who found that broadly, and at DHB level the term is not well defined or understood by many of the people delivering or receiving the service. In the current study the whanau ora roles were only of interest when involved with programme participants and there was no focus on determining the effectiveness of the contract in meeting clients' needs.

\section{Context of the study}

The disparities in health status between Maori and non-Maori are consistent with disparities found worldwide based on factors such as ethnicity, age, gender, socioeconomic position, impairment and geographical region (Reid \& Robson, 2006). But in Aotearoa/New Zealand, ethnic inequalities between Maori and non-Maori are the most consistent and compelling inequities in health (Ajwani et al., 2003; MOH \& University of Otago 2006). For example Maori die on average 8.5 years younger than non-Maori (Statistics NZ, 2008).

Maori also have a very different profile to non-Maori with respect to the determinants of health such as education, employment, occupational class, income, housing, income support, dealings with the criminal justice system, health literacy and deprivation (Ministry of Social Development, 2006). Such conditions impact people's ability to recognise their need for health care and access it appropriately. They also pattern exposures to health risks such as smoking, excessive alcohol consumption, poor nutrition, overcrowded and substandard housing and unsafe workplaces (Howden-Chapman, 2005; $\mathrm{MOH}$, 2002b). 
These health risks undoubtedly increase the chances of ill health, and are often viewed as behavioural and cultural and thus essentially under the control of the individual. However, current models of determinants of health recognise that many complex societal factors contribute to lifestyle behaviour (HowdenChapman, 2005), and that social and environmental factors remain the predominant causes of poor health and premature mortality, whether by influencing these known risk factors or via other pathways (Howden-Chapman). Therefore it is important not to view what may appear to be lifestyle "choices" simply as a matter of personal responsibility, because this view can lead to a victim-blaming approach where the problem of illness is conceptualised in terms of individuals' non-compliance (Germov, 1999). "This is not to suggest that individuals are incapable of improving their health, but that socioeconomic and political structures often inhibit them from doing so" (Germov, p. 61).

Cultural values are also influential in determining clients' ability to make changes. Maori society is based on collective responsibility while Pakeha society tends towards traditional European values of individualism and selfadvocacy (Jansen \& Smith, 2006). The latter values are compatible with the current expectation that people will take responsibility for their own health (Turner, 1999) and with the medical model which believes that compliance will result on the basis of reasoned action. That is people will stop the "unhealthy" behaviour once they know it is not good for them (Lawrence, 1999; Macdonald \& Park, 2005). But this may not be so easy for those with different cultural values as Jansen and Sorrenson (2002) note:

A patient whose culture does not have a model for chronic diseases that fits with the prevailing Western model of illness may perceive little benefit in a programme of lifestyle change and medicines to manage asymptomatic disease today against a potential advantage some time in the future. p. 306

\section{Diabetes as a Maori health issue}

A particular concern nationally is the high Maori mortality from diseases that are amenable to treatment, such as diabetes and cardiovascular disease $(\mathrm{MOH}$, 
2007). Diabetes is almost three times more common in Maori than non-Maori and affects Maori at a younger age. For example, in the age group 45-64 years the death rates due to diabetes are nine times higher than for non-Maori (Robson \& Harris, 2007). Incidence and mortality rates for type 2 diabetes, and the associated conditions of pre-diabetes, insulin resistance, and obesity are expected to significantly increase over the next 20 years. One estimate claims there is one undiagnosed diabetic for every one known, hence the importance of diabetes screening in at risk groups (Robson \& Harris).

Maori develop serious diabetic complications such as eye disease, kidney failure, strokes and heart disease at a younger age; these can inevitably lead to renal dialysis, amputation and blindness $(\mathrm{MOH}, 2008 \mathrm{~b})$. They also have the highest prevalence of any ethnic group of many cardiovascular risk factors such as hypertension, obesity and smoking. For example, in $200650 \%$ of Maori females were smokers compared to $20 \%$ of European females (Robson \& Harris, 2007).

\section{Quality of health care to Maori}

There is evidence that Maori receive a systematically inferior quality of health care compared to non-Maori New Zealanders (Jansen \& Smith, 2006; Reid \& Robson, 2006). Evidence of this includes; departure from clinical guidelines in the screening and management of diabetes $(\mathrm{MOH}, 2005 \mathrm{~b})$ and heart disease (Bramley et al., 2004), the higher incidence of adverse events in hospitals (Davis et al., 2006), and under-utilisation of primary care services (Malcolm, 2004). Also, Maori are referred less often for specialist services, including lower rates of intervention cardiology. Although there have been some recent improvements, rates are still low relative to their higher needs (Penney, McCreanor \& Barnes, 2006; Tukuitonga \& Bindman 2002; Westbrooke, Baxter, \& Hogan, 2001).

The impact of racism on patients' access to and through health services has been described in terms of institutional, personally mediated and internalised racism (Jones, 2000; Reid \& Robson, 2006). Evidence of institutional and 
personally mediated racism is found in many of the examples of inferior care mentioned above. The finding of the New Zealand Health Survey 2002/2003 that Maori were almost 10 times more likely to report experiencing discrimination in three or more settings than were Europeans (Harris et al., 2006) is another example of personally mediated racism. Racism is internalised when negative perceptions are so widely held that the subject comes to believe these perceptions of themselves. The resultant feelings of self-devaluation, resignation and hopelessness contribute to them engaging in risky health practices (Jones), thus perpetuating and exacerbating the health disparities. These are factors that are likely to make Maori health providers a desirable option for Maori clients.

New Zealand researchers such as McCreanor and Nairn (2002) and Penney et al. (2006) have explored the relationship between negative stereotyping of Maori and their unequal treatment and health outcomes. These researchers all found that health practitioners often talked about Maori presenting late with established multiple health problems because they tend to delay seeking help due to ambivalence or stoicism about poor health and fear or reluctance to use health services. Practitioners often cited Maori "non-compliance" with ongoing health care treatment plans and lifestyle changes, and described this as a cultural trait. These non-compliance discourses of health practitioners fit within a general non-compliance literature, that tends towards victim blaming as an explanation for limited success in the management of chronic disease generally (Penney et al.; Reid \& Robson, 2006).

These attitudes of health providers contrast with those of Jansen and Sorrenson (2002) who note that cultural factors impact client relationships with health professionals: "Culture shapes the individual's worldview and influences interaction with others, such as 'help-seeking' behaviours and attitudes toward health care providers" (p. 306). This might be experienced as being whakama (experiencing shame and embarrassment), which is often cited as a barrier to Maori seeking health care when they are continuing an "unhealthy" lifestyle behaviour (Cram, Smith, \& Johnstone, 2003). This avoidance might be 
interpreted as non-compliance or lack of motivation by some health professionals if the clients did not maintain a prescribed regime (Cram et al.; Zimmerman et al., 2000).

It has long been recognised that even though health services are provided, people may not be able to access them due to primary, secondary and tertiary barriers. Primary barriers are most readily recognised and concern the availability of the service and patient uptake of those services. Factors include: cost, transportation and socio-organisational factors such as being child friendly and culturally comfortable. Secondary barriers are structural and system factors such as difficulty getting an appointment, advice after hours or referral to a specialist. Tertiary barriers are practitioner factors such as holding requisite knowledge and skill, and having the ability to understand and meet the patient's needs (Penney et al., 2006; Simmons et al., 1998).

The importance of tertiary barriers is being recognised with research exploring the impact of the patient/physician relationship on Maori access to quality, effective health care (Baxter, 2002; Cram et al., 2003; Penney et al., 2006; Willams et al., 2003). Maori clients identified that poor communication and lack of rapport with practitioners could leave them feeling misunderstood, ill informed and dissatisfied with the quality and effectiveness of care, while it could leave practitioners impeded in their ability to achieve effective assessment, diagnosis, and treatment (Baxter; Cram et al.). Conversely practitioner/patient concordance or understanding and agreement, had been associated with improved health outcomes, patient satisfaction and adherence to treatment (Ferguson \& Candib, 2002; Jansen \& Smith, 2006; Kearse et al., 2004). As will be shown in the thesis, THONR sought to improve communication and facilitate this concordance by providing support people, including the MDNE, to ensure that clients understood the information they received from the doctor and felt able to ask questions.

Maori health providers are also charged with overcoming some of the other barriers that Maori experience in seeking timely health care. This may be a 
matter of developing distinctly Maori strategies, or making sure that client access to health services is unimpeded in cultural, financial, or social terms (Durie, 1998; Simmons et al., 1998). For example, providers may provide transport, mobile services and outreach clinics, free or low-cost health care, flexible appointment systems and proactive follow-up and assistance in accessing social services, they may also provide information in ways that are easily understood and appreciated by Maori (Crengle, 2000; Ellison-Loschman \& Pearce, 2006). THONR was offering all of these services.

Ellison-Loschman and Pearce (2006) identify the importance of Maori control and the use of Maori cultural processes in the delivery of care as key features of Maori health providers. Another requirement of a Maori health provider is that they employ Maori staff if possible (Ellison-Loschman \& Pearce). Although as Cunningham and Durie (2005) note, it depends very much on the Maori staff concerned, as some hold few cultural skills, or their cultural skills are not shared by the majority of the service's Maori clients. Hence Maori providers must also be cognisant of, and sensitive to, the diversity of their clients - "diversity of cultural experience, diversity of health status, and diversity of expectation" (Cunningham \& Kiro, 2001, p. 68). As Durie (1998) notes only about one third of Maori have a secure Maori identity, but more than three-quarters have high aspirations of greater involvement in te ao Maori (the Maori world) (Durie). Secure Maori identity is associated with better self-perceived general health (Waldon, 2003) and protects against poor health, even in the presence of adverse socio-economic conditions (Howden-Chapman, 2005).

Fundamental to providing a culturally appropriate health service to Maori is the incorporation of Maori values and concepts. The programme offered by THONR is based on the Whare Tapa Wha model in which health is seen as a four sided house with the sides representing four aspects of a person's wellbeing: wairua (spiritual), hinengaro (mental), whanau (family) and tinana (physical). If each side of the house works in harmony, there will be positive benefits to whanau ora (Durie, 1998). THONR also values the Te Pae Mahutonga model of health promotion, which emphasises the importance of a secure cultural identity, 
environmental protection, healthy lifestyles, participation in society, leadership and autonomy (Durie, 1999). Use of such models is strongly supported by $\mathrm{He}$ Korowai Oranga: Maori Health Strategy $(\mathrm{MOH}, 2002 \mathrm{a})$.

Two other features that are identified by Crengle (2000) as being important for a Maori organisation are positive Maori development and kaupapa/tikanga Maori. These were consistent with the values demonstrated as being important to the organisation in the Strategic Plan 2005-2010, including whanaungatanga (kinship, connectedness) tikanga (customary practices, 'the right way'), rangitiratanga (Maori control or self-determination), manaakitanga (caring) and wairuatanga (spirituality) (Durie, 1998; Collier, n.d.; McNatty, 2001; THONR, 2004).

\section{Positioning this project in relation to existing research and programme development}

The disparities in health outcomes between Maori and non-Maori have driven research interest in the area for the last two decades. A literature search prior to study commencement identified that most contemporary research relating to diabetes and heart disease for Maori was descriptive in nature. Although an intervention study measuring the effectiveness of targeted services was identified as being a worthwhile research undertaking, it was also established that there was limited knowledge available concerning Maori nurse-led primary health care services. It was therefore decided that this research would concern the functioning and effectiveness of a small nurse-led diabetes service based at a Maori health provider.

The aforementioned descriptive research identifies the nature and severity of diabetes and heart disease for Maori (Kerr, Gamble, Doughty, Simmons, \& Baker, 2006; Simmons, Schaumkelt, Cecilt, Scott, \& Kenealy, 1999; TipeneLeach et al., 2004). More recently research has sought to determine the effectiveness of risk screening and risk management by ethnicity, for diabetes and heart disease (Riddell, Jackson, Wells, Broad, \& Bannink, 2007; Whittaker et al., 2006). Others have looked at the experiences of clients with diabetes and heart disease, and barriers to accessing health care for diabetes (Baxter, 2002; 
Penney et al., 2006; Simmons et al., 1998). Another perspective is provided by McCreanor and Nairn (2002) and Penney et al. (2006) who canvassed the perceptions of health professionals caring for Maori.

There are a number of large diabetes intervention studies underway; one is working with an iwi health provider/Primary Health Organisation (Otago University, 2008), another is marae-based (Simmons \& Voyle, 2003), a third involves a DHB with a large Maori population (Waikato DHB, 2005) and a fourth is promoting physical exercise and nutrition in a kaupapa Maori framework and involves the researcher working with a number of local Maori health providers (Whariki, 2005). Projects of this size were not feasible in this setting, instead this study journeys with clients to develop a deeper understanding of their experiences and the functioning of this much smaller programme.

A number of studies have also looked at aspects of client satisfaction and service provision for Maori health providers. Client utilisation of and satisfaction with Maori providers on a national basis has been monitored (MOH, 2006b), with the conclusion that Maori providers appear to be increasing access to health care for Maori. Furthermore a higher percentage of Maori staff employed by Maori providers suggests Maori workforce development initiatives are also proving successful (Robson \& Harris, 2007). Hansen, Carryer and Budge (2007) canvassed the perceptions primary health care nurses' had of the advantages and disadvantages of working for a Maori provider. Yet others have considered contractual and organisational issues for Maori providers. In the case of Abel et al. (2005) this was for a single large provider that is also a PHO, while Boulton (2005) considered what these issues are for smaller Maori providers working in the mental health area.

An aim of the current study is to describe the way the MDNE contract, as an example of a Maori primary health care nurse role, has been operationalised in this setting. Maori nurse-led services have been described before. Manchester (2006) profiles a diabetes nurse clinician and Moloney-Moni and North (2003) describe aspects of a Maori Mobile Disease State Management service, which 
includes diabetes among the conditions being managed. Others have described "mainstream" primary health roles and nurse-led services (Manchester, 2008, $\mathrm{MOH}, 2005 \mathrm{a}$ ), and Cassie (2004) describes a diabetes service managed by a nurse practitioner. None of these look into a nurse-led service or Maori primary health nurse role in the depth of the current study, simultaneously considering client experience and satisfaction, and programme functioning and effectiveness.

Numerous studies have explored the effectiveness of diabetes management interventions and education programmes (Deakin, McShane, Cade, \& Williams, 2007; Polonsky et al., 2003; Satterfield et al., 2003), including programmes with other indigenous populations and ethnic minorities (Rowley et al., 2000; Wong, Wong, Makrides, \& Weerasinghe, 2002). Nurse-led diabetes services have been researched internationally and have been found to improve physiological outcome measures for clients (Barr Taylor et al., 2003).

Another consideration in the positioning of this current study is the Pakeha/Maori research context. Cunningham (1998) identifies a continuum of research based on the degree of Maori involvement and control over the research project. This study displays elements of the two types of research at the centre of this continuum, namely "research involving Maori" and "Maoricentred research". Cunningham defines research involving Maori as likely to use mainstream analysis and produce mainstream knowledge of Maori. While Maori are more likely to be involved at all levels with Maori-centred research, this would include Maori analysis and would generate Maori knowledge. Likewise Bevan-Brown (1998) talks about the importance of control of the research remaining in Maori hands, while Boulton (2005) identifies another goal for Maori research as being concerned with encouraging change and that it should be transformative and grounded in the needs and aspirations of Maori communities. 


\section{Summary}

This chapter established the significance of inequities in health between Maori and non-Maori New Zealanders, which contravene the obligations under the Treaty of Waitangi. Some of the reasons for Maori under-utilising primary health services were identified, including such services being felt to be not culturally appropriate. Thus the historical and contemporary context that led to the establishment of designated Maori health providers has been outlined. Within the primary health care research environment of many large intervention studies, this smaller study was designed to make a contribution to knowledge regarding the operation of Maori health providers and nurse-led services. Many factors in the context and operation of the programme suggested that mixed method case study was a suitable methodology to use to conduct culturally safe research in this situation as outlined in the next chapter. 


\section{Chapter 3 - Mixed method case study design}

This programme evaluation research is based on case study methodology as outlined by Yin (2003). Yin defines a case study as "an empirical inquiry that investigates a contemporary phenomenon within its real-life context, especially when the boundaries between phenomenon and context are not clearly evident" (p. 13). Case study provides the opportunity to deal with rich contextual data and it comprises an all-encompassing method - covering the logic of design, data collection techniques, and specific approaches to data analysis, thus providing a comprehensive research strategy.

This chapter outlines why case study was selected as the most appropriate methodology and follows the process of design development, tool development, data collection and analysis. Methodological limitations of this design and how they were addressed, including the cultural and ethical requirements of the study are presented next. Finally, conclusions on the merits or otherwise of the study design are identified.

\section{Design development}

The original objective of the study was to establish if this programme was improving outcomes for the Te Hauora O Ngati Rarua (THONR) clients with diabetes. The optimum method of demonstrating this within a positivist paradigm was an intervention study comparing this programme with "usual care", but the number of clients attending were too small to yield meaningful results in such a design (Greenhalgh, 2001; Hutchinson, 1999). In addition, some clients were also attending other service providers so crosscontamination from many sources would have been difficult to control (Israel et al., 1995). Other considerations were that THONR staff prefer to work collaboratively rather than appearing to compete with other services, and a significant part of the Maori Diabetes Nurse Educator (MDNE) role involved her working as part of the mainstream service provider at the local hospital. Therefore, ideas of a comparison study were soon rejected. 
The following study questions were identified:

- What are the salient features of the experience of having diabetes and attending this programme for Maori clients?

- How and why is this programme contributing to an improvement in knowledge, monitoring and lifestyle behaviours related to diabetes and heart disease management?

- Is this diabetes and heart disease education programme effective at producing identifiable improvements in clients' physiological outcome measures?

The primary purpose of the study was programme evaluation, which as Robson (2006) observes is not restricted in terms of the type or style of research that can be used. Design choice is determined by the purpose and the questions asked of the evaluation (Patton, 1997). Robson identifies four general models of evaluation; namely needs-based, outcome-based, process and cost-benefit evaluations. Of these, an outcome-based evaluation, especially using quantitative data would address whether the programme was making a difference to participants' knowledge, lifestyle behaviour and physiological indicators. Process evaluation, utilising qualitative methods such as interviews and observation, would explore how and why the programme worked in practice and the experience of those involved (Patton). Thus a design that favoured the use of mixed methods, such as a case study with quantitative and qualitative aspects, became desirable.

These conclusions are supported by Yin (2003) who states that case studies have a distinctive place in evaluation research and cites a number of reasons why case studies might be chosen as an appropriate research design. These are to: explain causal links; describe an intervention; illustrate certain topics; explore situations where the intervention has no clear outcome; and finally as a meta-evaluation. Of these, the first two purposes are particularly relevant to the current study: "to explain the presumed causal links in real-life interventions that are too complex for the survey or experimental strategies" and "to describe an intervention and the real-life context in which it occurred" (Yin, p. 15). 
This study is asking both exploratory ("what") and explanatory ("how" and "why") questions, but according to Yin (2003) it is the explanatory questions that particularly favour the use of case study methodology. The aim in this study was to understand if and how this contemporary intervention worked in a situation where multiple aspects of the context were likely to contribute to the effectiveness of the intervention. Given that the study had some explanatory elements, it was appropriate to identify a series of propositions around expected findings (Yin):

- Some participants will demonstrate improved physiological outcome measures: blood glucose, $\mathrm{HbA} 1 \mathrm{c}$, blood pressure (BP), cholesterol profile and weight;

- Most participants will demonstrate better knowledge related to diabetes, ischaemic heart disease and risk factor management;

- Most participants will demonstrate better awareness of behavioural change processes and have moved in that process towards successful change in one or more aspects of their diabetes management and lifestyle behaviours; and

- Participants will report that they found the programme culturally appropriate, supportive and beneficial to their health objectives.

\section{Features of case study}

Yin identifies four basic case study designs in a $2 \times 2$ matrix (see Figure 3). There are two types of single case study and two types of multiple case study formats. Single case studies can be: type 1) holistic (single unit of analysis), and type 2) single case with one or more embedded units (multiple units of analysis). Multiple case studies are also of two types, type 3) holistic and type 4) with embedded units. Three of these four constructs were considered for this study.

First there was the possibility of doing a type 4) multiple case design by also evaluating the 'sister' service being offered by THONR under the MDNE contract in the neighbouring district of Nelson. This would have constituted an interesting comparison as the nurse in that role was working in isolation without 
much of the supportive infrastructure enjoyed by the MDNE in Marlborough. Ideas of extending the study into such a multi-case design were soon rejected due to lack of time and resources on the part of the researcher.

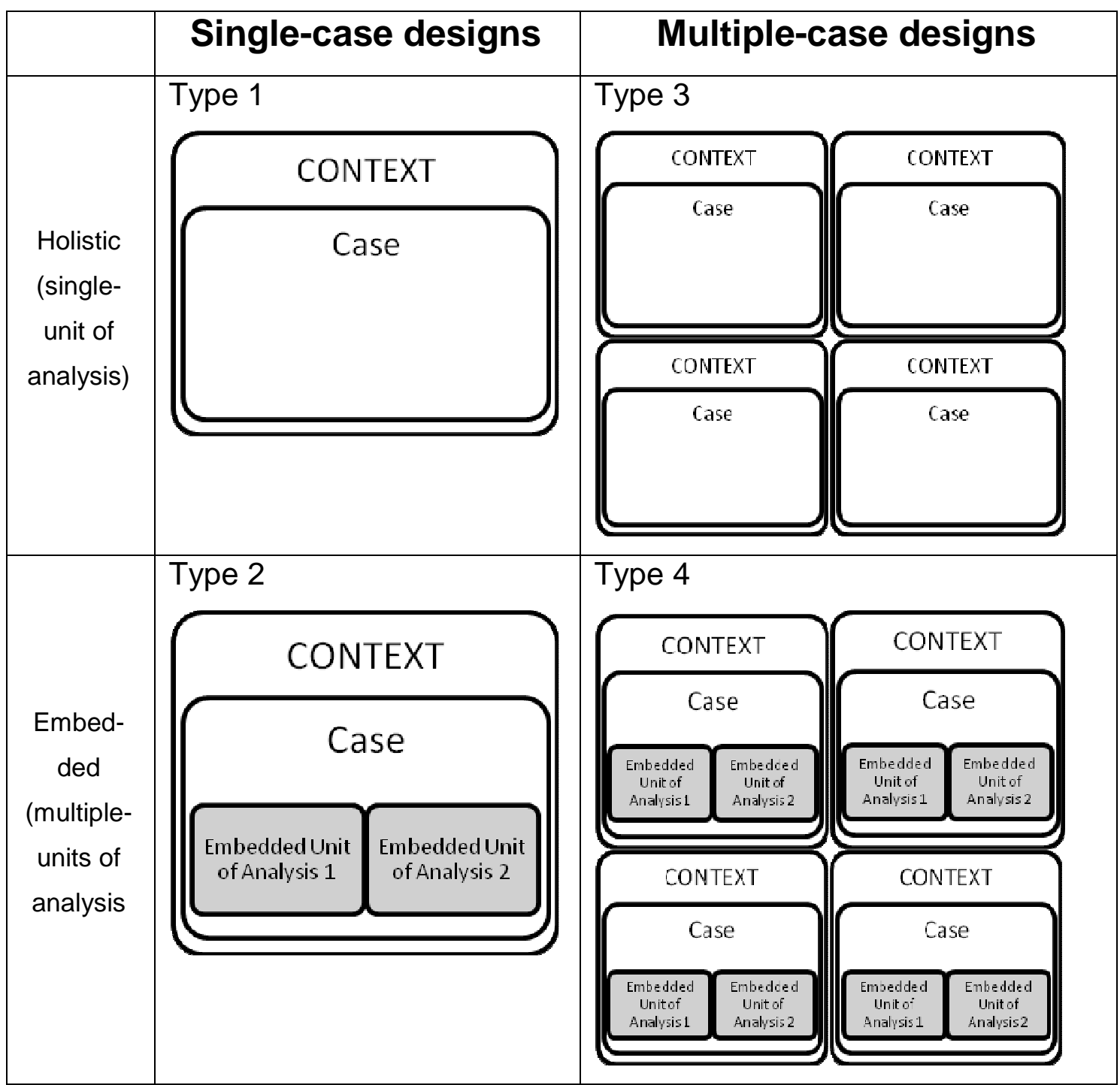

Figure 3. Basic types of designs for case studies*

*Adapted from "Case study research design and method". By R. Yin, 2003, 3rd ed., p. 40. Thousand Oaks: Sage Publications.

The two single case study constructs defined by different foci of analysis, were also considered for this research. The first option was type 1 , to treat the programme as a single holistic case, with the course of education sessions being simply one facet of the programme. The second option, and the one that was ultimately used, was type 2 . This had a single main case - the programme, with the course of education sessions being treated as an embedded unit within 
that larger case. Yin (2003) advocates the use of such subunits because they can "add significant opportunities for extensive analysis, enhancing the insights into the single case" (p. 46) and they can protect against the slippage that can happen in a single case study when the nature of the research changes without the realisation of the researcher. In this study there was some change in focus as the study progressed, due to wanting to work in a culturally appropriate manner, but attention to research design processes as set out by Yin ensured that a rigorous piece of research has been produced.

Yin warns that the embedded case study design also has pitfalls, particularly when it focuses only on subunit level and fails to return to the larger unit of analysis. In this instance, the original phenomenon of interest has become the context and not the target of study. Care was taken in analysing and presenting the results of this case study to maintain the focus on the overall programme rather than focusing excessively on the group education sessions. However when findings or conclusions are specific to the education sessions, this is stated.

One of the most challenging steps for this case study has been delineating the "unit of analysis". Yin (2003) warns that programmes cannot be easily defined in terms of beginning and end points of the "case", attempts to do so may reveal variations in programme definition, depending on the perspective of different actors, and programme components that pre-dated the formal designation of the programme. In this study participants did sometimes refer to educational hui that preceded the current education sessions. Consequently I made a point of defining just what was meant by "the programme" when conducting interviews because this was clearly a point of potential confusion. The case, or primary unit of analysis, is the diabetes and heart disease intervention offered by the MDNE and the other staff at THONR. This includes the one-to-one case management offered to clients at the clinic and in their own homes, the six week course of group education sessions (the embedded unit) and the support service offered by other THONR staff at the time the study was conducted. The time period of interest in studying this programme was May 2006 to May 2007. 
CONTEXT - Health care environment and community in which programme is located

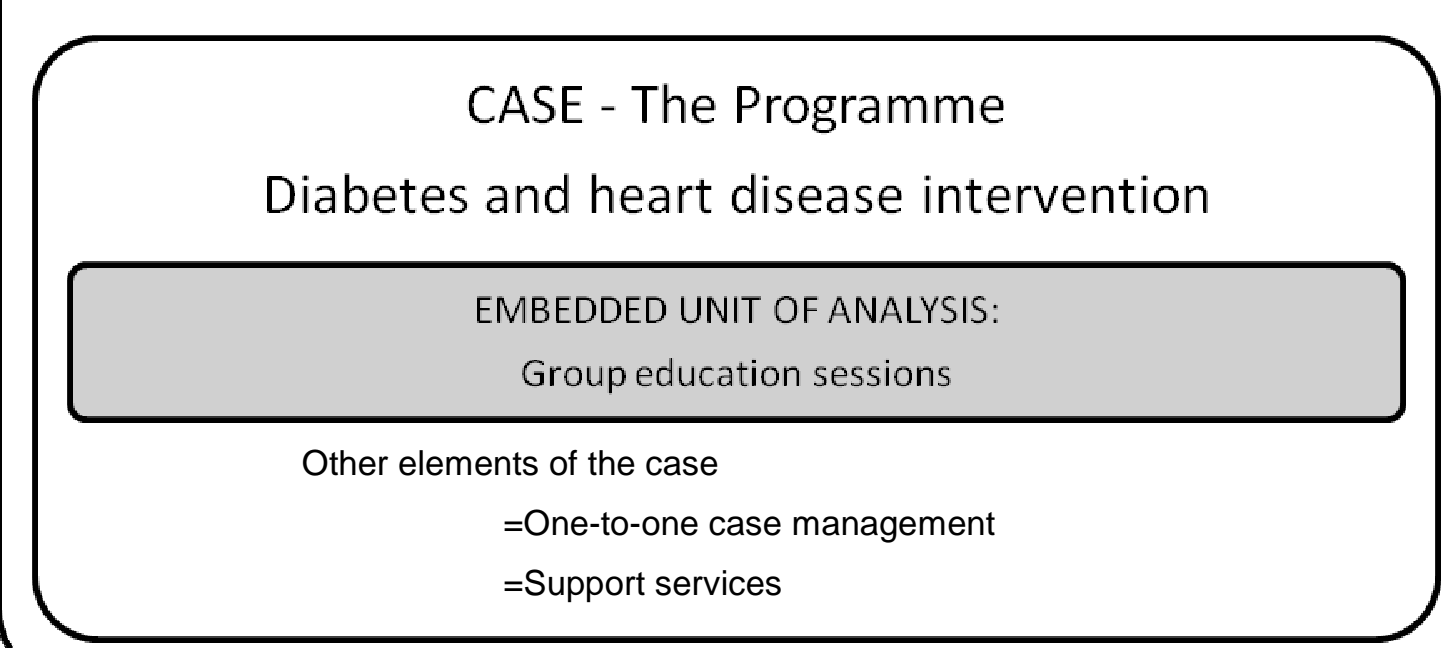

Figure 4. Diagrammatic representation of this case study design

*Adapted from "Case study research design and method". By R. Yin, 2003, 3rd ed., p. 40. Thousand Oaks: Sage Publications.

Case management provided an opportunity to clearly target the information to the specific educational needs of the individual client. Nonetheless, the education sessions were a distinct and clearly defined part of the study in terms of venue, timing, format, objectives, content and evaluation feedback, so they were dealt with as an embedded unit within the overall case of the service offered by THONR to people with diabetes. The level of involvement of key THONR staff with the "programme" or "case" were represented diagrammatically in Figure 1 on page 5 in Chapter 1. A diagrammatic representation of the case study design is presented in Figure 4.

Yin (2003) identifies that case study can be based on any mix of quantitative and qualitative evidence and that its unique strength is its ability to deal with a full variety of evidence - documents, artefacts, interviews and observations. This case study uses data from client notes, documents, previous client evaluation feedback to the agency, laboratory results and other physiological data, participant observation and stakeholder interviews. This fits clearly with Yin's approach to case study inquiry and: 
copes with the technically distinctive situation in which there will be many more variables of interest than data points, and as one result relies on multiple sources of evidence, with data needing to converge in a triangulating fashion, and as another result, benefits from the prior development of theoretical propositions to guide data collection and analysis. p. 13-14

Which data to collect is a contentious issue in lifestyle behaviour education (Israel et al., 1995; Nutbeam, 1998), as impact on patient outcomes is the most difficult link to establish (Hutchinson, 1999). Mortality and morbidity data is the most conclusive, but impractical due to the time and resources required. Reduction in $\mathrm{HbA} 1 \mathrm{c}$, fasting glucose and serum cholesterol, weight and blood pressure and smoking cessation are generally accepted as outcome measures in their own right (Rosenson, 2004; Van Horn, 2001). Israel et al. argue in favour of using impact evaluation (looking at changes in intermediate impacts such as changes in knowledge, attitude, beliefs and behaviour of the target group). This research will evaluate a combination of impact and outcome indicators.

The intervention is complex, addressing multiple aspects of diabetes management and lifestyle behaviour and it is recognised that outcome responses to the intervention may be equally complex, e.g., weight may actually go up in response to regular use of insulin, improvements in lipid profile may be due to weight loss, exercise and/or regular statin use (Best \& O'Neal, 2000; Robbins et al., 2001; Willett \& Stampfer, 2003). Therefore the study does not attempt to separate out aspects of the intervention. The intervention aims to provide best practice guided by the New Zealand Guidelines Group (NZGG) guidelines for management of diabetes and heart disease (NZGG, 2003a \& 2003b). The approach of this study was to adopt what Perkins, Simnet and Wright (1999) call the 'black box' approach - "we know what goes in (the intervention), we know that something comes out, but we're not sure what happens in the middle" (p. 38). 


\section{Data collection}

Four sets of data were collected: 1) Physiological outcome measures of client participants 2) Participant observation, 3) Stakeholder interviews and 4) Programme documents. The opportunity to participate in the study was offered to all 14 clients attending one of the two courses of the group educational sessions that were followed. An introductory 'whanaungatanga' week was added to the six week programme to facilitate development of relationships between group members and give the researcher an opportunity to explain the study and the consenting process to potential study participants. Programme clients were then sent away for a week with the Information Sheet (Appendix F) and Consent Form (Appendix $G$ ) and advised to discuss it with whanau and sign in the following week if they were prepared to participate. One participant insisted on signing on the spot, some took several weeks, and others didn't confirm until after the education sessions were completed, in which case they signed consents prior to their first interview. Seven service providers were approached individually and given a minimum of a week to read and consider the information and consent forms prior to signing at the time of their interviews.

\section{1) Clients' physiological outcome measures}

Baseline readings of blood pressure, heart and respiratory rate, weight, height, waist circumference and random finger-prick blood glucose were taken at the first, and most subsequent, sessions, usually by the MDNE, but the researcher also assisted with this occasionally. Weight and height were used to calculate body mass index (BMI) (weight in kilograms/squared height in metres) (Castelli et al., 1986). This data was routinely recorded on the client's own progress record and the MDNE's clinic notes. Once the client had consented, it was stored as study data against the participant's study number. Weight, blood pressure and blood glucose were assessed again at six months after the education sessions. Laboratory fasting glucose, $\mathrm{HbA} 1 \mathrm{c}$ and fasting lipids were assessed for all participants at the start of the education sessions and repeated six to nine months after completion of the sessions. Blood tests were the only physiological data not being collected routinely and there were some problems ensuring that six month follow up tests were completed. Urinary albumin 
concentration and albumin/creatinine ratio were only collected once for most participants as part of their annual diabetes review.

Lifestyle behaviour was assessed informally throughout the education sessions in a variety of ways: by self-report during "group check-in rounds"; in the second week of the sessions as part of a preparedness to change activity; in more detail at the interviews at the end of the sessions and at six months post completion of the course. Participants were followed for six to nine months and the study ran for one year. The physiological measures at six to nine months were considered the definitive endpoint, although previous success that had regressed by six months was also of interest.

\section{2) Participant observation}

This happened in two ways, during education sessions and at other times when I was involved with the organisation. During the education sessions I was the participant observer which is a way to "perceive reality" from the viewpoint of someone "inside" the case study rather than external to the study (Yin, 2003). My role could be further defined as observer-as-participant which means the participants approve of the researcher's presence and the researcher can ask group members to explain activities or events that have been observed (Watson \& Whyte, 2006).

Field notes were taken during the education sessions to give an outline of setting, those attending, material covered and participants' responses that were thought to be significant. These were followed with documented reflections and thoughts and combined with other observations, impressions and field data. As themes emerged, follow up questions for the next session or one-to-one conversation with the MDNE were identified.

\section{3) Stakeholder interviews}

The main source of participant data was from interviews with the seven clients and five service providers. Clients had their first interview within eight weeks of course completion and their second interview approximately four months later. 
Four of the client interviews involved two study participants being present as they belonged to the same household and were supporting each other. One client was not able to meet for a second interview due to personal commitments. So there were a total of nine interviews (five first and four second interviews), with all but one client participant being seen twice. Most service providers had a single interview, which was conducted within 12 weeks of completion of the second course of education sessions. The exceptions to this were the key service provider informant, the MDNE, with whom I had regular meetings throughout the study; plus two taped interviews at nine and 16 months into the study. The Manager was interviewed 18 months into the study. Thus there were six service provider interviews in total. All participants chose the venue for interviews; most clients were interviewed in their homes, while most service providers chose to be interviewed at work.

The Client Interview Guideline (Appendix H) used open-ended questions and prompts to explore client learning from the education sessions, including their comments on aspects of the programme they found helpful, and suggestions for improvement. Other questions assessed what, if any, lifestyle change they had made. The final section sought to compare their experiences on this programme to previous health education, and determine the significance of it being a by Maori for Maori programme. The semi-structured question format enabled a balance to be achieved between direction and flexibility (Tod, 2006). The service provider interview guidelines (Appendix $\mathrm{H}$ ) required more flexibility due to the varying circumstances of the people being interviewed. The questions explored the interviewee's preparation for their role in the programme, comments and suggestions, feedback on the teaching, and their thoughts on the cultural aspects of the programme.

Semi-structured interviews are challenging to undertake because as Yin (2003) and Tod (2006) identify, they require you to operate on two levels at the same time - satisfying the needs of your line of inquiry while simultaneously putting forth "friendly" and "non-threatening" questions and being responsive to the interviewee's agenda and views. All interviews started with informal greetings, 
clarification of the information and reiteration of the right to withdraw. For most interviews the schedule was only loosely followed, as aspects of the questions would often be covered in general conversation. Client interviews took between $1 \frac{1}{2}$ and 2 hours, while most service provider interviews lasted approximately one hour, except for interviews with the MDNE, which averaged 2 hours each. Every interview closed with thanks to the participant and explanations of the next steps. They were advised that the transcript would come back to them for approval; that they had the right to remove any material they were uncomfortable with, or to add more information; that there would be a follow-up interview in 3-4 months and a general report back to all of those involved in the study in approximately one year.

\section{4) Programme documents}

Various documents were accessed to corroborate and elaborate on the interview and observational data. They included participant feedback on the previous education sessions, the course outline and handouts, organisational documents such as the MDNE service specifications, the service's quarterly reports to the District Health Board (DHB), the strategic plan for THONR, and the clinic notes of client participants. Some of these documents were used to complete aspects of the Study Enrolment Form (Appendix I). Yin (2003) identifies that if such documents contradict rather than corroborate other sources of information, it highlights the need to pursue further. In this study some small points required further explanation usually by following up with the MDNE, but no serious contradictions were identified. The service specifications and strategic plan deepened my understanding of the objectives of the MDNE role and the organisation and provided structure while writing up the case study, but this case study does not aim to determine whether the objectives in those documents are being met.

\section{Data analysis}

Much of the physiological outcome data consisted of continuous (interval) data such as weight, serum cholesterol and blood pressure. Demographic 
information included a mixture of binary and categorical (nominal) measures such as gender, and a series of related illnesses that might be relevant. There was also an open section for 'other' not specifically identified information such as co-morbidities ${ }^{10}$. All physiological outcome data available for each participant was entered onto individual spreadsheets. Data for study commencement, end of group education course and end of study, for all participants was then aggregated and the percentage changes for those time periods were calculated. But restricting analysis of some physiological indicators to three time points meant the full fluctuations in these measures might not be captured. To address this concern (which was particularly relevant to weight), a separate analysis was conducted on all weight data collected to identify the maximum percentage of weight lost by each participant over the duration of the study.

Analysis of the interview data and other qualitative aspects of the study were ongoing and iterative throughout the research process, so they were able to inform the research design while also providing findings (Lathlean, 2006). For example, the final drafts of the interview schedules were not completed until data from the educational sessions had been analysed. The content of the second client interviews was governed by an analysis of the transcript of the first interview. The interview with the manager was intentionally left until most of the data analysis was complete to enable questions that were raised by the analysis to be addressed at that time.

The first client interviews were transcribed by the researcher, who benefited from total immersion in the data, but this was ultimately not an efficient use of researcher time. The client's second interviews and the service providers' interviews were transcribed by contracted transcribers, who were required to sign a confidentiality agreement (Appendix J).

The first stage of analysing the interview data involved repeatedly listening to the tapes and reading the transcripts. First level analysis for each interview

10 co-morbidity - the simultaneous presence of multiple health conditions, when there is one index condition and other unrelated conditions 
came next, with the grouping of relevant data under headings such as "introduction to the service", "lifestyle change", "resources", "Maori programme". This process also raised a number of action points to follow up on, often in the second interview. Second interviews were analysed in the same way and the findings from first and second interview were aggregated for each individual client. The data analysis for service providers followed the subjects of their interview schedules, for example "preparation", "venues", "timing", "resources", "teaching methods" and "Maori programme aspects".

The data from clients' and service providers' interviews was then combined under shared headings with the sources of each piece of data remaining identified. At this stage relevant information from other documents such as the MDNE's written feedback from previous educational sessions, the analysis of the observational data and field notes and the physiological data were added under the established headings. This was the stage where triangulation occurred. In some cases this triangulation highlighted differences in perspective between different clients, or between clients and service providers, which provided points for contemplation and discussion. For example at this stage in data analysis it was noted that staff felt they spent sufficient time with clients and that this was a strength of the service, while some client interviews and previous feedback revealed that staff often seemed to be rushing.

One step in the triangulation process involved identifying emergent themes under suitable headings. Such themes, significant quotes from interviews and other observations were written on individual cards and arranged in related clusters. Some quotes or comments were written on a number of cards if they seemed relevant to more than one subject area and the best "fit" was not initially obvious. Further analysis of the data occurred during writing up of the thesis as the emergent themes were explored new connections with other sections of the data became evident.

This data analysis process equates with that suggested by Miles and Huberman (1994) of having three concurrent flows of activity: data reduction; data display; 
and conclusion drawing/verification. Data reduction consists of: selecting, focusing, simplifying, abstracting and transforming the data found in field notes and transcriptions and occurs throughout the project. Data display consists of presentation of an extended quantity of text or verbatim snippets such as charts, graphs, matrices and networks, which begin to show relationships and connections. While conclusion drawing and verification starts at data collection and consists of noticing patterns, explanations and propositions and equates with Yin's (2003) pattern matching stage. In this study the patterns consisted of the propositions identified at the start of the research - if the outcomes coincided with the predicted propositions then pattern matching was considered to have occurred.

\section{Ethical implications}

"Inherent in the ethical principle of respect for persons are the concepts of autonomy, dignity, uniqueness, freedom, and choice. This principle forms the foundation of the participant's rights to informed consent, privacy, and confidentiality" (Gillis \& Jackson, 2002, p.330). How the study sought to maintain these rights was set out in the study's ethics application. Ethics approval was granted by Upper South A Regional Ethics Committee in December 2005 (Appendix E). Requirements included obtaining a locality agreement from the manager of THONR and a letter of support from the Director of Maori Health for the Nelson Marlborough District Health Board (Appendix C). Subsequent modifications have consisted of simplifying and updating study documents and prolonging the duration of the study due to personal circumstances. The main processes concerned with maintaining consent, confidentiality and safety of participants will be outlined below.

Informed, signed consent was sought from all participants. The education sessions and case management were available to all clients irrespective of research participation, and clients were viewed as a potentially vulnerable group. No pressure or coercion, either explicit or implicit was applied to participate in this study (Oberle \& Storch, 2004). A "process consent" with 
ongoing permission-seeking helped to ensure that participants felt free to withdraw consent at any time as they developed a fuller understanding of what they had consented to (Oberle \& Storch). I explained the study in the group setting but was aware of the potential for coercion in that setting, so I left it to the MDNE to liaise with clients individually on whether they would enrol. She alerted me if participation was not desirable for someone, as she did with the client who withdrew due to ill health. It was possible that the MDNE's "dual role" was another source of coercion (Oberle \& Storch), but this seemed preferable given my sensitivity to being a Pakeha researcher working with Maori participants.

Maintaining the client's confidentiality was also an important principle. Study records were stored under their study number; there was one master list, held by the researcher, which combined the clients' and service providers' names, and study numbers. Interview transcripts used numbers for the client and codes for other participants and health professionals. Clients' clinic notes and laboratory forms were destroyed once data had been entered under their study number. All remaining documentation, including the researcher's journal, field notes and analysis documentation were stored in a locked cupboard at the researcher's home and will be kept for ten years.

Having weight, blood pressure and blood glucose monitored publicly as part of the education sessions was a potential issue for some, but this was more of a programme issue than a study issue as it was the normal practice. One participant in particular didn't seem comfortable with being allocated a study number, but appeared much happier once she had selected her own pseudonym, which as Tod (2006) reports can help participants to understand the confidentiality implications of participation.

\section{Conducting culturally competent research}

Attention throughout the research process was given to ensuring the research was culturally responsive. I was informed by the writings of several authors 
(Bevan-Brown, 1998; Bishop, 2005; Meleis, 1996; Smith, 2005; Walsh-Tapiata, 2003) regarding what constitutes culturally competent research, especially when involving Maori participants. The above authors identified the need for utu or reciprocity, which means "sharing, hosting and being generous" (Smith, p.98). This can relate to the researcher's responsibility to self-disclose (Mill \& Ogilvie, 2003), to taking and sharing food or to the ongoing obligation of the researcher to those being studied (Bevan-Brown p.232). This was consistent with whanaungatanga or connectedness, so it was important to establish a connection with people before expecting them to share personal information. To this end I ensured all participants were comfortable with me before the first interview, which in one case meant a preliminary untaped meeting at their home. I often took koha (a gift), such as cherries and Weight Watchers biscuits to share at interviews. My ongoing obligation to participants has meant maintaining the relationships, even though the study is completed.

Reciprocity also refers to the need to ensure that all parties meet their own goals from the research process and through research findings (Meleis, 1996, p.12). An additional meaning relates to ensuring no one is left worse off than when you entered their home and that recommendations are made for positive changes (Bevan-Brown, 1998; Walsh-Tapiata, 2003). Kearns and Dyck (2005) note that researchers have a propensity for not honouring their promises to report back to the community. They state that "Culturally safe research requires a radical commitment to reciprocity such that interpretation and ownership of results is shared and local communities are involved in ways of capitalising on the findings for their own development" (p. 87). The need to do this was noted and acted upon throughout.

Authors such as Meleis (1996) refer to the need to take a flexible view on time as this construct is open to cultural interpretation and the time taken to develop trust and enhance disclosure differs between cultures. Care was taken to allow an adequate amount of time for interviews, but some unexpectedly went over two hours which meant that time constraints did have an impact on a few interviews. It was also important to explain the study "kanohi ki te kanohi" (face- 
to-face) (Smith, 2005), rather than expecting prospective participants to read about it from an information sheet, this was done by explaining the objectives and methodology of the study to the whole group at the education sessions and one-to-one by the researcher or MDNE to clarify any further uncertainty on the part of prospective participants.

According to Stake (1995) a considerable proportion of case study data is impressionistic and researchers have a great privilege and obligation: "the privilege to pay attention to what they consider worthy of attention and the obligation to make conclusions drawn from those choices meaningful to colleagues and clients" (p. 49). In this respect Smith (1999) states: "they [researchers] have the power to distort, to make invisible, to overlook, to exaggerate and to draw conclusions, based not on factual data, but on assumptions, hidden value judgements, and often downright misunderstandings. They have the potential to extend knowledge or to perpetuate ignorance" (p.176). This was a great responsibility that required careful management and reflection, followed by discussion with my supervisor, particularly throughout data gathering and interpretation stages.

It was important to consider the power differential between myself as the researcher and the participants. Meleis (1996) highlights that a researcher and participant can never have equal power, "they are differentiated by knowledge, boundaries, power and the purpose of the encounter" (p.11). This point is also made by Bishop (2005) who identifies that the locus of power over issues of initiation, benefits, representation, legitimacy and accountability lying with the researcher, is the focus of Maori people's concerns about research. I did not have experience of the programme as a client or as a staff member; in this regard the power balance was with the participants. But I was aware of power issues in my role as observer. I addressed these to the best of my ability by participating in group activities, asking questions so that others could see that I did not hold all the knowledge myself, and by being willing to take the time to reveal myself, and to explain what I wanted to know and why, to them (Smith, 2005). 
Kearns and Dyck (2005) identify one of the barriers to culturally safe practice being the 'detachment' of positivist social science which leaves little room to consider subtleties of culture, because the propensity to enumerate can easily reduce the nuanced meanings of another ethnic group to a mere statistic. To address this barrier, as the study progressed tools were modified in line with the research shifting from a more quantitative to qualitative focus. This process was partly driven by a realisation that the numbers generated would not capture the subtlety of the experience of being on the programme and that was, in fact, the most important contribution the study had to make to knowledge in the area.

Given the comfortable nature of the relationships between myself and client participants, which had usually developed over the course of the group education sessions, there was often a temptation to inform and potentially influence their lifestyle behaviour during their interviews. Tod (2006) identifies that it is difficult to avoid such role conflict especially for nurses and others with clinical training and cites the importance of the interviewer not putting his or her own view and perspective forward during an interview. But this was difficult to achieve because clients knew I was a nurse and were naturally inclined to ask questions during the loosely structured interviews. Also, to not engage in a conversational way during the interviews could have impacted on the clients' comfort and level of honesty in the responses. I reflected carefully following interviews and discussed my conclusions with my supervisor to identify ways my objectivity might have been compromised.

Being both a nurse and a researcher also created conflict for me; there was a tension between my nursing role and my researcher role regarding participants' management. As a nurse it was acceptable for me to pass information on to the MDNE regarding some clients' eligibility to receive statins. I also advocated for a client who was leaving the area, with their GP, regarding eligibility for statins. These activities were not part of my brief as a researcher, but in this research as part of partnership it seemed right and was done with full support of the participants and the MDNE. Such difficulties are also identified by Borbasi, 
Jackson, and Wilkes (2005) who report that an increasing number of nurses undertaking field research report pragmatic, ethical and epistemological difficulties surrounding the multifaceted nature of the role.

\section{Rigour/validity strategy}

The case study methodology has been retained throughout the planning and conduct of the study, but as the study progressed, the emphasis subtly shifted from a more quantitative approach to a more qualitative focus. For this reason the full consideration of the rigour and validity strategy for the quantitative aspects of the study are presented separately in Appendix K. Four tests, internal, external and construct validity and reliability have commonly been used to establish the quality of any empirical social research including case studies (Yin, 2003). Yin identifies several tactics for dealing with these four tests when doing case studies.

\section{Internal validity}

Internal validity refers to the extent to which what is observed truly represents the variable under investigation (Topping, 2006), that is the effects of the programme intervention in this case. There were multiple threats to the internal validity of the explanatory aspects of this case study, but establishing causal relationships was not feasible due to the small sample size so these are presented separately in Appendix K. More importantly, Yin states that the concern over internal validity for case study research can be extended to a broader problem of making inferences related to unobserved events based on interview or documentary evidence collected as part of a case study. "Is the inference correct? Have all the rival explanations and possibilities been considered? Is the evidence convergent? Does it appear to be airtight?" (p. 36). But Merriam (1998) claims that internal validity is a strength of case study methodology because it enables us to understand the perspectives of those involved in the phenomenon of interest, by uncovering the complexity of human behaviour in a contextual framework. Both authors identify strategies to improve 
internal validity including pattern matching and addressing rival explanations, both of which were done in this research.

\section{Construct validity}

Construct validity concerns establishing the correct operational measures for the concepts being studied. Yin (2003) reports that case studies have been criticised in the past because the investigator failed to develop a sufficiently operational set of measures and that "subjective" judgements were used to collect data. He highlights two important steps to overcome these problems of construct validity: 1) select specific types of changes to be studied (and relate them to the original objectives of the study) and 2) demonstrate that the measures do reflect the changes selected (p. 35).

In terms of 1) and 2) above, the physiological outcome measures assessed throughout the study have established standards of construct validity which are considered in more detail in Appendix K. The initial design sought to quantify knowledge, lifestyle behaviour and preparedness to change. These constructs were eventually assessed more informally throughout the study, with the analysis describing rather than attempting to quantify the amount of change made. This approach was appropriate given the qualitative focus of the study and the small sample size. Although change in knowledge may give an indication of the effectiveness of the education, it does not correlate well with a change in lifestyle behaviour (Twinn, 2000). According to Yin, construct validity is improved by using multiple sources of evidence and having the draft case study report reviewed by key stakeholders, both of which were done in this study. Corroborating the essential facts and evidence presented in the draft case report was also part of meeting partnership obligations under the Treaty of Waitangi (HRC, 1998).

\section{Reliability}

Demonstrating reliability consists of ensuring that the operations of a study, such as the data collection procedures can be repeated, with the same results, with the goal of minimising the errors and biases in a study. Case study researchers have been accused of only presenting the evidence that supports 
their interpretations because they use mainly narrative presentation that does not distinguish between evidence and interpretation (Yin, 1999). Another problem is the potential bias produced by using participant observation such as the researcher advocating for or supporting members of the group or being distracted from observation due to group participation (Yin, 2003). On some occasions I did step out of my 'impartial' researcher role to support clients or to ask questions, but on reflection the impact on final conclusions was found to be minimal.

To address these concerns and manage reliability Yin (2003) recommends careful documentation of procedures such as developing a case study protocol and maintaining a case study database. Gillis and Jackson (2002) recommend maintaining an audit trail, with decisions and rationales being documented. All such decisions were documented chronologically in the researcher's journal. Decisions related to findings were also captured in data analysis and pattern matching documentation. These process documents, combined with all the raw study data such as interview transcripts, spreadsheets of physiological outcome figures, field notes and study documents constituted the case study database. Sequential versions of writing up particularly the findings and discussion chapters further capture the progressive development of the analysis and the pattern matching process.

\section{External validity - generalisability}

Establishing external validity or the ability to generalise a case study's findings to another setting has been considered a major shortcoming of the case study method (Clarke \& Reed, 2006; Yin, 1999). It may occur with this programme, as the quality of a health educational intervention can depend on the individual characteristics of the person providing it (Hutchinson, 1999). Perhaps there is too much focus on being able to generalise findings as Stake says "the case study method has been too little honored as the intrinsic study of a valued particular" (Stake, 2005, p. 448). However Yin (2003) claims that generalisation of the case study results can happen, but that it should occur at the theory level rather than the statistical level. He refers to the former as "analytic 
generalisation" in which a previously developed theory is used as a template with which to compare the empirical results of the case study (pp. 32-33). He describes this as distinct from the more common "statistical generalisation" in which an inference is made about a population based on a sample of that population. In analytic generalisation the researcher is striving to generalise a particular set of results to some broader theory. There is then a need for replication to confirm the theory (Yin).

Consequently, Yin (2003) sees theory development as an essential part of the design phase, "whether the ensuing case study's purpose is to develop or test a theory" (p. 28). Three theories positioned and informed this study and analysis: Systems Theory, the Chronic Care Model (CCM) and the Transtheorerical Model of Change (TTM). Systems Theory was used in the initial analysis to guide the description and evaluation of the programme. The CCM added a chronic care lens to the Systems Theory and also provided a framework to guide the evaluation and make recommendations. The transtheoretical model provided a way to explore the change process of individuals in the programme, which was also important given the focus on self-management in the CCM. Thus these three theoretical perspectives were complementary to each other in providing a well-rounded approach to analysis and evaluation of the programme.

\section{Managing common limitations of case study}

Due to the low participant numbers, the informal assessment of lifestyle behaviour and diabetes monitoring variables and the multiple threats to internal validity cited in Appendix $\mathrm{K}$, it is not possible to draw causal inferences from the results (Gillis \& Jackson, 2002). However the interview data does indicate that the programme stimulated some albeit unquantifiable lifestyle change in most participants.

Yin (2003) states that case studies have been criticised in the past for lack of rigour and for their limited basis for generalisation. But he argues that both of 
these concerns can be adequately managed within the study design with the procedures he suggests, many of which are used in this study. Although Yin also concedes that, in his view, the current single case study with an embedded unit, does present the least potential to maintain rigour.

Although many authors see triangulation and the use of multiple sources of evidence as a strength of case study (Bergen \& While, 2000; Merriam, 1998; Stake, 2005; Yin, 2003), others claim that it can merely compound sources of error inherent in the methods employed (Armitage \& Hodgson, 2004) and lead to inconsistent results (Mathison, 1988). It certainly helps to identify different realities (Stake, 2005). Lastly there is the issue of how the reader should judge quality, particularly if competing research traditions are used in the same study (Topping, 2006).

Evaluations can engender a climate of fear and suspicion, even in situations where the evaluation is being carried out in good faith (Robson, 2006). I am very aware of the risks all participants were taking in opening up to me as a researcher and trusting me to accurately represent their views in this evaluation. I am also aware that evaluations occur in a political context. The fact that an evaluation is taking place increases the sensitivity of all involved, and those affected may seek to influence the evaluation to best serve their interests (Robson). Other authors highlight the problems of researchers becoming too dependent on key informants and losing objectivity, which can bias the findings (Holloway \& Todres, 2006; Merriam, 1998; Yin, 2003). Throughout this study my focus was on preserving and presenting "the multiple realities such as the different and even contradictory views of what was happening" (Stake, 1995, p. 12). Thus a range of stakeholders were interviewed to provide a rounded and comprehensive view of the effectiveness of the programme, so the interpretations of events came from within and between stakeholder groups, with the aim being to provide a balanced perspective taking all participants' views into account (Stake). 
As the next chapter reveals, despite these multiple limitations to the validity of the quantitative and qualitative data gathered, the study was able to provide many valuable insights into the experience of the clients and the functioning of this nurse-led programme designed by Maori for Maori. 


\section{Chapter 4 - The diabetes programme}

This programme evaluation draws on information from a range of sources: the service specifications for the Maori Diabetes Nurse Educator (MDNE) role, Te Hauora O Ngati Rarua's (THONR) strategic plan, course notes for the group education sessions, interview data from clients and service providers, clinical notes, physiological data from physical assessments and laboratory results, evaluation feedback and the researcher's observation of the education sessions. No one-to-one education or consultation was observed. The seven clients who were interviewed had all attended the group education sessions and had also been seeing the MDNE on a one-to-one basis. An eighth client originally consented to being interviewed, but withdrew due to ill health before any interviews were conducted. The study was explained to an additional six clients who didn't participate. They did not clearly decline; rather they stopped attending the education sessions for various, sometimes unknown reasons. Seven service providers were approached, of whom five participated, three from within the organisation including the Manager and the MDNE and two outside THONR, who both taught on the group education sessions. Two other service providers, one inside and one outside the organisation considered participating, but eventually declined due to workload issues.

This first chapter of the study findings uses this study data to describe the programme in three sections. The first section describes inputs, namely staffing, clients, resources and technology. The second presents the process and outputs as the client's journey through the programme; what clients receive, and how staff work with them. The third section considers the process and outputs from an organisational perspective including how staff work together within and outside the organisation. In each section the focus starts broadly, for example with the client base in general and then narrows down to the individual clients. Interview excerpts (in italics) are used to illustrate the experiences and perceptions of clients and service providers. 


\section{Inputs}

\section{Staffing}

Heather Oehlrich, the Maori Diabetes Nurse Educator (MDNE) for Marlborough is the key staff member on the programme. She has been in this role for two years and has developed it and the programme as both were new to THONR and the district prior to this. She also maintains links and memberships with a number of professional groups including the NZ Society for the Study of Diabetes. Heather is introduced fully on pages 7 and 8 of the thesis.

In addition to the MDNE there were two other THONR staff members regularly involved in the programme, the Whanau Ora Nurse (who was an enrolled nurse) and the Whanau Ora Kaimahi. Both of them contributed to diet and lifestyle aspects of the teaching during group sessions and both worked one-toone with clients offering assessments, education, transport and support as required. In the later months of the study the enrolled nurse left the organisation, leaving only the kaimahi offering the Whanau Ora service. She did not have formal nursing qualifications but had been on a number of shorter courses over the years and worked closely with qualified nursing staff at THONR and practice nurses.

Staff reported that one benefit of the organisation as an employer was its support for continuing education. All staff received cultural education and support on a regular basis both within the organisation and from an external consultant. Cultural supervision meant being able to discuss situations with the resident cultural advisor and other colleagues to keep people safe, as they often worked in isolation. This was seen as an important part of their ongoing inservice education with THONR. Staff varied in their mastery of te reo, with some only knowing greetings and other words in common usage, but there were others who were more fluent when required.

Three staff from other organisations helped with the teaching on the "Wellness with Diabetes" educational sessions at the MDNE's request. Two of them, both 
Pakeha, were interviewed for this study. They reported being well set up to teach on a Maori programme;

They (THONR staff) are always really good to say, 'yes, you need to learn this' or 'no, just come and you need to be quiet at these points'.

Provider \# 3

\section{Clients}

In October 2007 there were 182 clients registered with the diabetes service, of whom 92 (51\%) were on the screening register and 90 (49\%) were on the diabetes register. The MDNE's annual report for 2006 showed that she had 709 client contacts in total, 377 of whom were seen in their own homes. By 2007 the total seen had risen to 924 with 385 seen in their own homes (Oehlrich, 2007). This was an average of 18 client contacts a week. She usually saw 5-6 clients on a Monday at her clinics in GP practices. Apart from this she visited clients in their own homes and saw them at her THONR clinic rooms either by appointment or on a drop-in basis.

Clients with diabetes or pre-diabetes were referred from a range of sources, mainly general practice, health educators and physicians at the hospital and other Maori health providers. Approximately 30 were internal THONR referrals at the commencement of the MDNE contract. Diabetes screening clients tended to come from community contacts such as marae-based hui and iwi annual general meetings, self and whanau referral, and through other community activities such as smoking cessation programmes. Three of the client interviewees reported self-referring in response to the organisation's advertisements in newspapers and the Communities Services Building. The remaining four came via other services offered by the organisation such as cervical screening, social services and whanau ora.

The service was open to clients of any ethnicity, but their client base indicated that the public predominantly perceived them to be for Maori. Of the 182 clients, 164 (90\%) identified as Maori, 9 (5\%) Pacific Islander and 11 (6\%) of other ethnicities. In the MDNE's experience their Pakeha clients tended to have Maori 
whanau or identify strongly with Maori values or perspectives on health, such as the wellness focus and holistic approach.

The seven client participants were diverse in terms of their expectations and understanding related to diabetes; also their socio-economic position, age and progression of diabetes. One was a secondary student, two were working parttime, and the remaining four were beneficiaries, so although there was variation in socio-economic status, they had a lower household income than the population in general. They all self-identified as Maori, however information on iwi affiliation was not routinely collected as study data, following consultation with the Director of Maori Health. None were fluent te reo speakers, but four had attended courses in te reo.

Table 3 identifies some relevant features of the client participants. Six were female, one was male; ages ranged from 17 to 69 years but the average was 52 years.

Table 3. Characteristics and diabetes status of study clients

\begin{tabular}{|l|l|l|l|l|l|l|l|l|}
\hline Client & Gender & Age & $\begin{array}{l}\text { Metabolic } \\
\text { Syndrome }\end{array}$ & Diabetes & Metformin & Insulin & Smoker & BMI \\
\hline 1 & Female & 38 & Yes & type 2 & Yes & $\begin{array}{l}\text { During } \\
\text { study }\end{array}$ & Ex & 51 \\
\hline $3^{*}$ & Female & 62 & Yes & type 2 & Yes & $\begin{array}{l}\text { During } \\
\text { study }\end{array}$ & No & 33 \\
\hline 4 & Female & 69 & Yes & type 2 & No & Yes & Ex & 40 \\
\hline 5 & Female & 58 & Yes & type 2 & No & Yes & Yes & 35 \\
\hline 6 & Male & 55 & Yes & type 2 & Yes & No & Yes & 43 \\
\hline 7 & Female & 62 & No & No & No & No & No & 33 \\
\hline 8 & Female & 17 & No & $\begin{array}{l}\text { Pre- } \\
\text { diabetes }\end{array}$ & Yes & No & No & 44 \\
\hline
\end{tabular}

* Client \#2 withdrew from the study

Five participants had type 2 diabetes; a sixth one had pre-diabetes and was on metformin and the seventh didn't have diabetes but was there to help whanau who did. Of the five with type 2 diabetes, two were already on insulin, two were on metformin and glipizide at the start and went onto insulin during the study, 
and one was just on metformin. They were similar to the programme's client base in all respects except gender, as the client base was 50/50 male/female. Of the seven, two were ex-smokers, three had never smoked and two were current smokers. The body mass indexes (BMI) of the entire seven ranged between 33 and 51, (Maori are classified as overweight from 26-32 and obese greater than 32 [Maori Health, 2008]), so all client participants were classified as obese.

The presence of co-morbidities in individual clients was to be expected, but the severity of the conditions was not anticipated and the consequent effects on their health status were profound. Three client participants were receiving treatment for coronary artery disease and five met the criteria for metabolic syndrome, which is associated with an increased risk of heart disease and diabetes. Two clients had chronic obstructive airways disease (both ex or current smokers) and one had asthma. Two had received cataract operations and three had osteoarthritis and other knee, hip and spinal problems. Other conditions included; breast cancer/mastectomy, hysterectomy, coronary artery bypass grafts, pacemaker insertion, obstructive sleep apnoea, hepatitis B with liver enlargement, fatty liver, hypothyroidism and dyspraxia. A common finding was depression, which five out of seven had experienced recently, although only three participants were being medicated for this. Two clients exhibited complications of diabetes. Of these, the one with the most advanced complications had chronic renal failure, retinopathy and peripheral neuropathy. A strong family history of diabetes and to a lesser extent heart disease was another common finding among the seven client participants. According to the MDNE this high level of co-morbidity is typical of many of the THONR clientele on the diabetes register.

\section{Educational resources}

At the commencement of the series of educational sessions the MDNE gave each participant the course notes, a diary to track changes in physiological data and a folder of pamphlets. The notes contained the words to karakia (prayers) and waiata (songs) and provided further explanation of the information covered 
in the sessions. These were popular and meant that clients could do some prereading to prepare for the coming week's session.

They were also given a folder that contained a range of pamphlets related to diabetes education and encouraging lifestyle change, especially in the area of diet and exercise. Further pamphlets were given out week by week when particularly appropriate to the topic of the day. Heather reported assessing the wishes of the client in terms of whether they wanted more "wordy" resources or preferred the picture variety. Meanwhile one service provider thought that pamphlets were not well utilised by participants and that their use should be minimised. They also commented that staff should give out just one or two a week, give participants a week to look at them and then go over them as a group the following week.

All participants reported finding the pamphlets worthwhile and that they were something they would look at when they got home, or they would refer to when they became concerned about their condition for some reason. The most popular pamphlets were the ones that gave sample recipes and had appealing pictures. "Oranga Kai Healthy eating for adult Maori" was liked by some clients, but another laughed at it being designed for "adult Maori" as they saw themselves as eating quite a basic kiwi diet ("meat and three veg"). Healthy methods of preparing boil ups ${ }^{11}$ were often mentioned by staff and clients, hence "Nga miti - He kai reka" was mentioned by some clients because it had recipes for healthy boil ups and other low cost recipes. One pamphlet from the Diabetes Society called "Physical Activity" that might not have been given out on the programme was complemented by one participant because it had good information on how to manage blood glucose around exercise.

\footnotetext{
11 Boil up - involves boiling different foodstuffs in a large pot together to create a crossover between a soup and a stew. Traditionally ingredients used are pork bones, puha, potato, pumpkin, watercress, and dumplings.
} 
Another resource that was used in one-to-one teaching with two participants rather than the group sessions was the "Effect of food and exercise on cholesterol" table designed by the researcher (Janssen, 2006). This resource gives detailed information on the effect of various dietary patterns on aspects of the cholesterol profile. Clients need a basic understanding of their lipid profile for it to be suitable. Clients had responded positively when the MDNE used this resource in her case management and screening work.

\section{Technology}

The MDNE used a range of equipment in her assessment and education role, which included portable scales, blood glucose meter, sphygmomanometer, tape measure for height and girth, 10 gauge microfilament to test feet for peripheral neuropathy, and a laptop to enter consultation and intervention data and to calculate BMI. She had a "cholescheck" meter to check serum lipids but at \$17 per test the cost of this was prohibitive so she tended to send people to the laboratory or request that the client's general practitioner (GP) do this. She ensured that eligible clients received a blood glucose monitor and that they knew how to use it.

During the group educational sessions The MDNE used PowerPoint slideshows to emphasise the main points. For these she had drawn together a range of information and images and created a resource that was appropriate to her Maori clients. Feedback from the clients indicated that they found the sessions very informative. The resources she had developed were also popular especially the graph demonstrating the process of micro and macrovascular damage and the simple diagrams demonstrating how insulin works (Appendix B).

\section{The client's journey through the system}

The objective of preventing the development of diabetes was advanced through THONR's screening programme. If clients gave two or more positive answers to 
a series of assessment questions, they would be offered a fuller lifestyle and physiological assessment by the MDNE. If the client only required the screening component, they would receive lifestyle education and the MDNE would send their data to their GP, but they would stay on the screening register for annual recall.

When clients had diabetes, pre-diabetes or metabolic syndrome, the MDNE's focus shifted to management, with the intensity of the intervention being determined by a process of assessment and prioritising. If she felt they were a person who required some intense input and support, she'd see them on a more regular basis, maybe weekly or even more frequently initially. For example, a client with a new diagnosis of diabetes who was learning to monitor blood glucose and make dietary changes, or someone who had newly started injecting insulin would be seen more regularly. Others would be seen once a month, three monthly, six monthly, annually or only on request, but she might maintain phone contact with some in the latter group. According to the MDNE the goal was always to foster client independence so visit frequency was reduced once the client had the knowledge and skills to manage their own condition.

Our emphasis has always been on whanau knowing what their condition is, knowing and taking their medication as prescribed, healthy food, because healthy food for the diabetic or person with cardiovascular disease is healthy for the whole family, so it's getting those concepts through. Regular physical activity and regular health checks. So it focuses on wellbeing rather than illness. Yes, we've got diabetes, heart disease, whatever, but how can we be well with that and how can we reduce our risk. Heather Oehlrich, first interview

In addition to this one-to-one teaching, the MDNE had been running group diabetes and heart disease educational sessions. Self management of type 2 diabetes was promoted through regular health checks, healthy eating and physical activity, and increased awareness and use of available diabetes 
services. The course used whanaungatanga and family togetherness as a model, as the group became the client's diabetes whanau.

The course consisted of six, weekly education sessions of $2 \frac{1}{2}$ hours duration, see Table 4 on page 61 and Appendix B. At the end of the six week programme people could continue to meet six weekly through the Diabetes Support Group. The educational sessions were based around hui protocol and cultural processes such as karakia, mihi and poroporoake, which were well integrated with the more typical diabetes and heart disease programme content and processes.

Table 4. Course outline for group education sessions

\begin{tabular}{|l|l|}
\hline Session number & Topic \\
\hline Week 1 & What is diabetes? \\
\hline Week 2 & Lifestyle changes \\
\hline Week 3 & Preventing and managing complications \\
\hline Week 4 & Healthy kai choices \\
\hline Week 5 & Supermarket tour \\
\hline Week 6 & Your partners in diabetes care \\
\hline
\end{tabular}

Given the diversity in comfort with Maori identity amongst the clients who participated and because the programme was not solely for Maori, it was important for the MDNE to ensure that the use of te reo and other Maori aspects of the programme were comfortable for all participants. The MDNE did this by role modelling what was expected at group rounds, providing the words to karakia and waiata on PowerPoint and keeping conversational Maori to words in common usage. Apart from this, education and discussion, including introductory mihi, tended to be conducted in English. This approach seemed to work well based on participant feedback and my own perceptions as a Pakeha participant-observer. I felt welcome and included, despite my limited knowledge of te reo and tikanga. 
Another important cultural aspect of the programme was the value placed on the sharing of kai (food) after the group education sessions. It was also an excellent opportunity for the staff to role model healthy eating choices and make suggestions regarding lifestyle change. The "social" chat at these times could often yield valuable additional information and had an important function in terms of building trust and comfortable relationships. Most clients made positive comments about the food that was provided, but also appreciated the times they had been involved in preparing the kai together and one client expressed a willingness to contribute towards the cost.

The sessions included exercises when the physical activity educator was available to attend. These sessions consisted of some theoretical discussion on the benefits of the activities planned for that day. For example, stretching, followed by an active stage where he demonstrated exercises and they copied them while he observed and gave feedback. This involved a range of low impact exercises, usually supported by a chair. Involvement in group activities was voluntary, so if people were reluctant to participate there would be a brief period of encouragement, but if they were still resistant their wishes would be respected.

In response to feedback from previous courses, the session before the supermarket tour in week five, was devoted to learning how to read food labels and ensuring that impediments were catered for during the tour. This included having a supply of glasses and magnifying glasses for the short-sighted and a seated walking frame for those that could not stand for long. The educator commented that reading food labels is difficult for those that generally learn by observation, so the MDNE's preparatory work resonated when they actually saw the food products. As the clients moved down the aisle they were able to compare the fat, sugar and calorie content of various foods. The focus during the tour was on what their choices were and why, rather than what they shouldn't have. The educator hoped that every person in the group might influence 20 others, and then this would be a good way to stimulate change over a larger area. Although the tour was long at $1-1 \frac{1}{2}$ hours, the participants 
were happy with the duration and enjoyed going back to the clinic rooms afterwards for further discussion and to share kai.

Between meetings and at the end of the group programme the MDNE would follow up with people one-to-one, reinforcing the message, clarifying anything they hadn't understood, or catching them up if they had missed the group session. This enabled her to target information to the individual and was particularly important in instances where participants' level of comprehension varied widely. She also needed to incorporate an appreciation of cultural aspects of lifestyle change in her education. For example, one client had reported difficulty controlling his eating at tangi (funerals) and she advised that it was important to celebrate life events in a way that he saw as appropriate, but that he could go without something else, or modify portion size.

I acknowledge education's important, but it's about making that connection with each individual client, because how they might address it might be quite different, and their needs and their financial circumstances might be quite different to the next person, so it requires a lot of tailor-made. Heather Oehlrich, second interview

Another service provider talked about the way they worked with people and the importance of not putting pressure on people with talk about their condition and prognosis, but rather to create a friendly atmosphere with music and kai.

So the less pressure you put on clients of their own sicknesses, and you just have to bring it in gently and say "well, you know, your glucose is high, it would be really nice if you get it down. Maybe you could be doing this, change this - one thing at a time". Yes, so slip in a message, and say "well, what did you have for tea last night, oh, we had such and such, oh, have you tried it this way", and it's just like every day conversation that you could slip in and do these little messages if you wanted, and that's the way I work. Provider \#1

In addition to the assessment and education described above, the MDNE offered a range of other services. These services included ensuring that clients 
had adequate medical supplies and information to monitor and manage their diabetes, monitoring blood results and other physiological indicators, and assessing clients for the presence of pulmonary and peripheral oedema. She provided appropriate management including mirimiri (therapeutic massage) in the case of peripheral oedema and skin conditions. She also ensured that clients were receiving the health services they were entitled to, such as home visits from the laboratory if appropriate and supported them to specialist appointments, explaining any points they had not understood themselves.

Additional management, education and support were offered by the organisation's Whanau Ora service. All people with diabetes in the THONR service were referred to the MDNE automatically, but they still remained with the Whanau Ora service for ongoing management, including transport and support to appointments such as podiatry and GPs. The whanau ora nurse also liaised with Work and Income New Zealand (WINZ) to ensure clients accessed the social services and benefits that they were entitled to. This might include negotiating for a part of their benefit to go to the chemist or the doctor so that they could access the medications that they need, or helping with budgeting and other assistance; for example organising a phone that only receives incoming calls. Housing and food were examples of conditions that would have a considerable impact on a client's health and once they were addressed the person's health might improve quite dramatically.

\section{Working to provide an integrated service}

To ensure her clients received a "continuum of care", the MDNE had to work intersectorially by maintaining constructive interpersonal relationships with a number of organisations. These included; other Maori health providers and rongoa (herbal remedies) practitioners, GPs and practice nurses, diabetes specialist doctors, nurses, dieticians, podiatrists and ophthalmologists (Appendix A). These relationships were distinguished by a strong focus on collaboration and coordination of care for her clients, although the manager and the MDNE noted there was a measure of fragmentation and competition due to 
three local Maori providers all holding Whanau Ora contracts. They suggested that more specialisation within services might be desirable.

Relationships with GPs and practice nurses were vital to the MDNE role. The MDNE worked to maintain these by receiving referrals from practices and doing monthly clinics in GP practices in Havelock and Picton, which are the other towns in the area. There was no charge to the clients and she provided the practice with the client information, with the client's consent. For some practices she entered data directly onto their system, while for others she completed a client form and they processed it, indicating a difference in the nature of the relationship she held with these different practices. Likewise when she was doing community screening she would send the information to the client's practice; if they met the criteria for a blood test she would give them a laboratory form or ask the practice to arrange for it to be done.

Interviews with the MDNE indicated that there were differences in the level of care clients on the programme were receiving from their GP, particularly with respect to being signed up for Care Plus and receiving their annual diabetes reviews (Get Checked). The MDNE had a variety of ways of dealing with that situation. These methods included advocating with the practice staff for the clients to receive the service and doing some of the assessments and health diaries herself and feeding back information to the practice. She felt in doing this she was treading a delicate line between maintaining helpful relationships with others and ensuring that the clients received the services that they were entitled to. In completing this service herself she was in fact offering cares that GPs were funded to provide.

In the first participant interviews four clients identified a wish to keep meeting after the course of group education sessions, unfortunately however, the Diabetes Support Group had lapsed due to staffing issues. For a time the MDNE tried to establish a consumer driven group, but this was hampered by the organising consumer's intermittent illnesses. More recently THONR had moved to regular monthly meetings, the "Whanau Hui". All staff contributed to 
these and the emphasis had shifted from strictly diabetes and heart disease education to more broadly topical issues such as chronic conditions, a holistic perspective on health, abuse of the elderly and stress management. All the old "Wellness with Diabetes" content would be covered over the year and they could discuss client issues at open forum times. It appeared to be a successful shift in format because attendance, which had started at 10, had risen to 22 at the last meeting.

This chapter has described the functioning of the service based on Systems Theory. The clients who were participants and the client base in general were described, as were aspects of the functioning of the programme and the integration of that with other services. This gave an indication of the context in which the programme was operating, the following chapter presents, integrates and analyses the data from the various sources to develop a picture of the experience of being on the programme for the clients and to assess the impact and effectiveness of the programme, both on an individual and organisational level. 


\section{Chapter 5 - Outcomes}

This chapter reports on the findings related to the effectiveness of the programme in terms of the outcomes achieved. The findings are drawn from a range of sources: the service specifications for the Maori Diabetes Nurse Educator (MDNE) role, interview data from the seven clients and five service providers, clinic notes, physiological data from physical assessments and laboratory results, evaluation feedback from previous programme participants, and the researcher's observation of the education sessions in action.

This chapter is in two parts; the first part considers programme effectiveness from the clients' perspective, and the second provides an organisational perspective. The client section starts with general findings about the experience of having diabetes and being on the programme. Then the impact and effectiveness of the programme for the seven client participants in terms of changes in knowledge, lifestyle behaviour and finally the more tangible changes in physiological outcome measures and factors that impact on the outcomes are presented. This section provides some understanding of the issues in making and sustaining change. Gender neutral pseudonyms (Toni, Casey, Ali, Lee and Sam) are used to give voice to clients' perspectives. The organisational outcomes section uses the six elements and criteria of the Chronic Care Model as a framework (see Table 1, p. 15) to evaluate the effectiveness of the programme. This includes: contractual obligations and funding; service integration and systems; and consideration of what this programme is offering that is different, particularly staff and programme attributes.

\section{Individual measures of effectiveness}

One of the principal objectives of the programme was to use whanaungatanga as a model to deliver health education, health promotion and diabetes selfmanagement. Whanaungatanga, getting together with, learning from, and being motivated by, others with diabetes and sharing jokes and fun times, were cited as being important in previous feedback to the MDNE and by five participants of the current study. Clients appreciated that on the programme there were other 
people who knew what they were going through and who took a genuine interest in them, even when they just "bumped into them uptown". These were things they could not get from seeing the health educator at the hospital.

They also appreciated the opportunity to share some healthy kai and talk to people at different stages of diabetes to themselves. This often stimulated comparisons, such as which foods others found raised blood glucose quickly (although this was noted to be quite an individual thing). For those on tablets it was a chance to hear about a possible future on insulin, while for those on insulin it was the opportunity to forewarn others. Toni, who had advanced diabetes, said "It's too late for me now" and "if only I had listened" which had a very powerful effect on other members of the group. This was just what Toni had hoped for, to dissuade younger people from ignoring the advice and continuing to eat "Iollies and cakes" as they had done.

The previous paragraphs gave an indication of the impact of the programme as a whole, but it was also important to determine which aspects of the programme clients had found most helpful. Most participants had developed a better understanding of the pathophysiology and complications of diabetes in recent years. Regarding attribution of this increased knowledge, opinions ranged from the programme 'teaching them all they knew', to 'having heard it all before elsewhere'. It was difficult to achieve more accurate information around this as healthy lifestyle education is so heavily promoted in today's society that it is not possible to identify exactly at what point knowledge was gained and a decision was made to change. For example two of the participants already knew about healthy oils and reported cooking with olive oil before commencing the programme.

Some of the most worthwhile education sessions from the participants' point of view were weight management, the effects of foods on the body, especially fats, and the disease process of diabetes and its complications. The micro and macro vascular damage caused by raised blood glucose and the range of organs that could be silently affected made quite an impression on some 
participants. For example, Casey cited a breakthrough in understanding the disease process after 30 years with diabetes and Lee gained a better understanding of the difference between metformin and glipizide and how they actually work. They also discovered that insomnia could be caused by overnight lows in blood glucose. Lee was also interested to hear that Maori carry a sodium sparing or 'thrifty' gene that predisposes them to heart failure. There was also practical learning, such as how to check the underside of their feet for injury with a mirror.

Evaluation feedback from a previous course indicated that five of the eight had continued to read food labels - this was a much better outcome than for study participants, only the two who read labels before the course were still doing so two months later. Poor eyesight was often given as the reason for this. Yet those who attended often cited the supermarket tour as the most beneficial part of the education sessions. They could find out whether some favourite foods were a healthy choice for them and make notes for future reference. Also, they had choices and didn't have to shop separately from the rest of the family. For example Toni discovered that people with diabetes could use any jam, not just diabetic jam, as long as it was possible to see the "bread through the spread". Although Toni didn't remember the expression exactly, the message of spreading jam thinly was understood.

The activity coordinator was only available for the first two sessions of the first series of the six week course, so only four of the seven study participants experienced this aspect of the group education. For the first session five out of the nine people present participated in the group activity. For the second session all three people attending the session were involved in the activity. The aim was to give them some activity they could use at home, but even though they reported enjoying the activities on the programme, no one had done them at home. This raises questions regarding the viability of the activity sessions for future courses, or whether more could be done to motivate participants to continue activities away from the programme. 
The majority of participants in the study reported an increase in activity though, often as a result of their involvement with Green Prescription and Te Hauora $O$ Ngati Rarua (THONR). For Lee this was joining the gym;

I've got to pay for it regardless... The gym at \$13 per week is only the same money as McDonald's twice and you can always find money for that.

Two participants found going to the gym much more motivating than trying to do some exercises on their own at home, although the importance of variety was also identified, as was the benefit of diarying activities, exercising with a friend, and having a goal such as wanting to cycle with children or do a triathlon.

The Transtheoretical Model of Change (TTM) group activity was well remembered (Appendix B, p. 140). This activity involved each participant standing at the appropriate point on the cycle of change marked on the floor, for their stage of diabetes management and lifestyle behaviour. For example, Lee self-identified as being in "relapse" on diet and "maintenance" on taking medications at the time. Participants found the TTM activity to be a worthwhile and affirming exercise, which illustrated to them that others also struggle to maintain stability. Apart from this specific session, change was assessed on a regular basis throughout the education sessions, with most participants identifying changes they had made and planned to make.

Dietary changes that people identified at the interviews included avoiding boil ups and cutting the fat off beforehand if they did make one. Three clients identified changing from blue to green or yellow top milk ${ }^{12}$ and white to brown bread and all participants identified making an effort to increase their intake of vegetables. Fried food had new meaning for Casey, who no longer made fried bread.

\footnotetext{
${ }^{12}$ Milk bottle top colours denote fat content of the milk. Blue top is standard milk, green top is low fat and yellow top is low fat, calcium fortified.
} 


\section{Physiological outcome measures}

Table 5 demonstrates the average outcome figures for five of the seven participants for three time points: the start of the study, end of the education sessions, and end of the study. The other two participants didn't have figures for both the start and end of the study so their percentage of change could not be calculated. The last two columns show the percentage change in physiological outcome measures from the start to the end of the group education course and the start to end of the study. These results demonstrate that weight, body mass index (BMI), blood pressure (BP) and glycosylated haemoglobin ( $\mathrm{HbA1c}$ ) all improved over the short-term (2-4 months) while attending the education sessions, but that all of those improvements were reversed when taken over the 9 to 12 month period covered by the study.

Table 5. Mean physiological indicators and percentage change over time

\begin{tabular}{|l|l|l|l|l|l|}
\hline Indicator & Start & $\begin{array}{l}\text { End of } \\
\text { course }\end{array}$ & $\begin{array}{l}\text { End of } \\
\text { study }\end{array}$ & $\begin{array}{l}\% \text { change } \\
\text { over course }\end{array}$ & $\begin{array}{l}\text { \% change } \\
\text { over study }\end{array}$ \\
\hline Weight $(\mathrm{Kg})$ & 107.60 & 105.40 & 108.00 & $-2.0 \%$ & $+0.37 \%$ \\
\hline $\mathrm{BMI}^{\star}$ & 40.32 & 39.44 & 40.50 & $-2.2 \%$ & $+0.45 \%$ \\
\hline $\mathrm{BP}(\mathrm{mmHg})$ & $134 / 92$ & $129 / 84$ & $132 / 81$ & & $-9.0 \%$ \\
\hline $\mathrm{HbA1c}{ }^{\#}(\%)$ & 9.54 & 8.63 & 10.40 & $-9.5 \%$ & $+2.3 \%$ \\
\hline $\begin{array}{l}\text { LDL Cholesterol } \\
(\mathrm{mmol} / \mathrm{L})^{€}\end{array}$ & 2.58 & & 2.64 & & $-17.0 \%$ \\
\hline $\begin{array}{l}\mathrm{HDL} \mathrm{Cholesterol} \\
(\mathrm{mmol} / \mathrm{L})^{€}\end{array}$ & 1.30 & & 1.08 & & $+18.0 \%$ \\
\hline $\begin{array}{l}\text { Chol/HDL Ratio } \\
(\mathrm{mmol} / \mathrm{L})^{€}\end{array}$ & 3.86 & & 4.56 & & $+17.6 \%$ \\
\hline $\begin{array}{l}\text { Triglycerides } \\
(\mathrm{mmol} / \mathrm{L})^{€}\end{array}$ & 2.16 & & 2.54 & & $-0.4 \%$ \\
\hline $\begin{array}{l}\text { Total Cholesterol } \\
(\mathrm{mmol} / \mathrm{L})^{€}\end{array}$ & 4.86 & & 4.84 & & \\
\hline
\end{tabular}

${ }^{*}$ For Maori a BMI of 26-32 is classified as overweight and greater than 32 is obese

\# Normal range of HbA1c $4.0-5.9 \%$

${ }^{€}$ Lipid target levels: $\mathrm{LDL}<2.5 \mathrm{mmol} / \mathrm{L}, \mathrm{HDL}>1.0 \mathrm{mmol} / \mathrm{L}$, total cholesterol/HDL ratio $<4.5 \mathrm{mmol} / \mathrm{L}$, triglycerides $<1.7 \mathrm{mmol} / \mathrm{L}$, total cholesterol $<4.0 \mathrm{mmol} / \mathrm{L}$

The only measure that was slightly better at the end of the study was blood pressure. All components of the lipid profile were worse from start to finish of the study (HDL is the 'good' cholesterol so a decrease signifies worsening), no lipid figures were available for the end of group education course. Particularly 
significant are the $17 \%$ decrease in $\mathrm{HDL}$ and the $17.6 \%$ increase in triglycerides which are two of the five criteria for metabolic syndrome, which predisposes to diabetes and coronary artery disease. Also an 18\% increase in the total cholesterol/HDL cholesterol ratio indicates an increased risk of cardiovascular disease. Three of the participants were on a statin, and two others were eligible. This information was passed on to the MDNE who followed up with the participants' GPs. The $9 \%$ reduction in $\mathrm{HbA} 1 \mathrm{c}$ from the start to the end of the education course indicates the efforts of some clients at lifestyle change at that time. However, by the end of the study those clients had regained the weight they had lost and $\mathrm{HbA} 1 \mathrm{c}$ results had generally regressed or worsened, hence the overall worsening by $9 \%$ over the duration of the study.

Weight data was collected more frequently than the three occasions shown above. Consequently the figures above don't reflect the true maximum weight loss that some participants achieved. Analysis of all the figures gathered indicated that maximum weight loss around the education sessions for four of the seven participants was as follows: Lee had lost $5 \%$ of body weight, Casey $5 \%$, Sam $9 \%$ and Ali $6 \%$. For Lee and Sam this was related to a period of concerted lifestyle change, while for Casey it was probably in response to commencing insulin and Ali had an exacerbation of congestive heart failure treated with diuretics.

\section{What impacts on outcomes}

There were various ways that clients indicated they hadn't accepted the diagnosis of diabetes, didn't believe that lifestyle change was important, or didn't believe that they were able to make changes and commit to maintaining them. Several talked of the difficulty of accepting the diagnosis of diabetes as they felt well for many years, for example Lee commented "I felt o.k., looked o.k., not like having cancer, a cold, or a broken arm". Lee and Toni reported that their diabetes was originally brought on by a stressful event in their lives, following which it seemed they "got better" or they "felt better" so they ceased monitoring and managing their lifestyle. Ali was diagnosed with diabetes and put on metformin; but blood glucose levels were consistently within the normal 
range so they didn't believe the diagnosis and commit to lifestyle change. In terms of believing lifestyle change was important; several participants questioned the accuracy of some common health advice such as the dangers of smoking, and avoidance of unhealthy fats and carbohydrates. Three participants commented that they knew what they had to do to manage their diabetes, they just had to do it and that wasn't so easy.

The findings also suggested that the motivation to change could come from a variety of sources. Sam talked about making changes for "the girls" (THONR staff) because;

A lot of it was because they tried to help me, they went out of their way to help me. They didn't push the issue down my throat.

For Lee motivation was more complex, their grandparents had lived into their nineties, so that would be possible, but Lee was also well aware that poor diabetes control could significantly foreshorten that potential life span. On the other hand, living into their nineties would be a long time to endure having an amputation, should that prove necessary.

Client participant's whanau were also an important influence on their motivation. This influence could take a variety of forms, it could be positive as in someone to exercise for or with, or it could be a caution or negative role model to warn of potential consequences, such as Casey's son who had required an amputation following poor blood glucose control. Whanau could have a positive or negative influence on smoking and food intake though. For example, Lee highlighted the importance of making healthy changes for the whole family, "when you don't have unhealthy foods in the pantry they stop looking for them after awhile" and talked about whanau not buying them a pie because it contained a golf ball of fat. However Casey, who sometimes couldn't be bothered cooking a balanced meal while living alone, also found it hard to stick with lifestyle change when whanau came, as they might say "we want a decent feed" shortly after they had eaten a healthy meal. It was also noted that expectations from, staff that whanau would ensure the client maintained diet and exercise change could put stress on whanau relationships. Other factors that influenced diet were having 
someone else shop and prepare the meals and being restricted by the need to feed two people on $\$ 100$ per week.

A common feature of trying to improve self-management of diabetes for these clients was that it often required action in a number of conflicting areas simultaneously. For example, in addition to giving up cigarettes, Sam had started trying to maintain better diabetes control through regular blood glucose monitoring, insulin use and taking snacks between meals. Success in these objectives could undermine Sam's additional objective of losing weight, as all of the former can predispose to weight gain. Sam talked of having gone through a period of high motivation and intense lifestyle change including establishing good routines, only to have "lost confidence" and regressed to the previous lifestyle pattern when no weight had been lost. Sam talked of being "hoha", a feeling between boredom and indifference, and said s/he couldn't care less about it now, "It's not interesting anymore. It seems to be dead, you know it now".

The relationship between making lifestyle change and managing diabetes came through in other interviews as well. Lee was concerned about how to lose weight while also having to eat before and during exercising to avoid hypoglycaemia. The possibility of putting on weight on insulin was also a concern, but the two clients who started insulin during the programme both lost weight (possibly because they stayed on metformin as well). While for Toni it was an achievement to be able to maintain a steady weight that was always within a kilo up or down.

Change can affect many areas of a person's life - for example some participants had given up a previously high alcohol intake and completed a number of adult education courses, drawing confidence from these achievements to set new goals for themselves. On the other hand, failure to achieve or maintain change could be very demoralising and undermine confidence, often it was a matter of two steps forward one step back or even one step forward, two steps back as people ended up worse off than when they had started. This served to deepen 
the sense that they were not controlling their own diabetes, the diabetes was controlling them, or that the locus of control was elsewhere rather than with them.

The interplay between this disappointment and the inability to go on to make lifestyle change illustrates an aspect of living with chronic illness. The comorbidities that were typical of chronic illness could impact clients' ability to participate in healthy activities and also had a debilitating and depressing impact on their outlook. For example, Sam in the second interview talked of having been hoha for several months and how they (Sam and partner Ali) struggled with their other conditions (chronic obstructive respiratory disease and congestive heart failure). Ali had been sleeping on the floor with legs raised, resulting in sleep deprivation and was also unable to walk to the shops. Their lifestyle was further impeded by a lack of transport. It became evident during this interview that such difficulties in their everyday existence had led them to largely give up on health promoting practices such as smoking cessation, monitoring blood glucose, taking insulin and maintaining a healthy diet and exercising. Rather they were "living for the day" and were "living here watching ourselves die away".

With an attitude that the damage had been done, was it worth denying themselves simple pleasures; they asked if that one bottle of cream they identified having would really make so much difference? But the deterioration in Sam's albumin concentration from 392 to 1140 (normal value <30) and albumin/creatinine ratio from 31.1 to 106.5 (normal value <3.5) over the nine months of being hoha, clearly indicate renal damage was occurring due to continued raised blood glucose. A notable feature of this interview was that they both presented as very low in mood. In a subsequent discussion the MDNE indicated to me that she suspected that Sam in particular should be treated for depression, but their GP was reluctant to prescribe anti-depressants.

Two of the three younger clients that attended the first course seemed to be there to appease whanau, rather than because they acknowledged their 
diabetes and wished to make changes. They were reluctant to participate in group activities or have their blood pressure measured in public and only attended the first session. It may be that they didn't relate to the group, for example one provider talked about the need to be able to relate to the educator;

Young kids relate to young kids, they don't care if a 45 year old guy

has beaten drugs and comes to their school, they don't relate...so if

you can relate then you can get something out of it. That's generally

how I see it. Provider \#3

This point was also recognised by the MDNE, who identified the importance of involving the male staff member in their proposed male group sessions, because the issues and perceptions of men with diabetes might be different to her own. Also, Lee had commented that both this service and the hospital service were too clinical. They (the clinicians) knew all the theories but they had never experienced a sugar high or a hypo, they hadn't needed to use diet to control their blood glucose, so they didn't know what their clients were going through.

Clients identified a number of ways that health professionals told them both implicitly and explicitly that they were responsible for their own conditions and that change was in their own hands. For example Lee talked about health professionals viewing obesity as the client's lack of self-control, and that it was easy to 'just shut your mouth' and not eat as much. Practitioners could readily and unintentionally cause clients to take offence as conversations regarding lifestyle behaviours might involve a delicate interplay between spoken and unspoken judgements. For example, during a study interview, when the participant mentioned that working at a sawmill had damaged their lungs; my unthinking response was to ask if they were wearing a mask. This innocent question carried an unintended implicit message regarding the participant's personal responsibility. I sensed a conspicuous embarrassment and withdrawal in the participant's body language as they admitted they hadn't worn a mask.

There was evidence in the interviews of such misunderstandings and the resultant embarrassment (whakama) leading to reluctance to see a health 
professional, especially while continuing what they knew to be unhealthy lifestyle practices. There were also more blatant examples of impaired communication with health professionals, such as Sam describing "getting a growling" from their GP if they had put on weight or had not controlled their blood glucose. Not understanding or wanting to hear what they were being told could also have had an impact on clients' seeking timely health care. These were areas where the relationship the THONR staff built with clients sought to overcome the barriers that were being created between their clients and staff from other agencies.

\section{Organisational measure of effectiveness}

The Chronic Care Model (CCM) (see Table 1, p. 15) is used as a framework to organise and present the findings related to the organisation's effectiveness, base on information from all data sources. Findings related to the context of the programme, the programme's interaction with the wider community, other organisations and the THONR organisation as a whole is presented under the sections the community and health system. Other findings related to programme effectiveness are covered under the remaining sections of: clinical information systems, decision support, delivery system design and selfmanagement support.

\section{Element 1: The community}

\begin{tabular}{|l|l|}
\hline Criteria & Encourage patient participation in community programmes \\
& Form partnerships and develop interventions with community \\
& organisations \\
& Advocate for policies to improve patient care
\end{tabular}

The programme had mobilised community resources by developing relationships and interventions with local organisations to fill gaps in needed services, because they realised they could not do everything themselves. Such organisations included the Diabetes Society, stroke groups, Presbyterian Social Services, the food bank, local activity programmes, especially for the elderly and fall prevention, and social service agencies such as Work and Income NZ (WINZ) and Housing NZ. They saw encouraging clients' involvement with such 
community organisations as an important part of their wellness and selfmanagement objective.

\section{Element 2: Health system}

\begin{tabular}{|l|l|}
\hline Criteria & $\begin{array}{l}\text { Systematically support quality improvement at all levels of the } \\
\text { organisation } \\
\text { Develop agreements to co-ordinate care across organisations }\end{array}$ \\
\hline THONR achieved the important characteristics of an effective health care
\end{tabular}
organisation such as commitment to quality improvement, by maintaining their ongoing accreditation, which required them to regularly update policies, (including risk management) and to conduct peer and case reviews. In terms of developing agreements that facilitate care coordination within and across organisations, they shared information and referred clients across a range of services including physicians, health educators, general practitioners (GP), podiatrists, mental health services and renal physicians. Only retinal screening services required a GP referral.

The MDNE's role as the chairperson of the Local Diabetes Team demonstrated her ability to work in an integrated way with other professionals, who had a specific interest in diabetes. This confirmed that she was maintaining the linkages that were required for her to offer a "continuum of care" to her clients (Appendix A). District Health Board (DHB) input on whether the programme was meeting their expectations was sought at the time of data gathering but this was not forthcoming.

THONR was very open to review, the MDNE had sought feedback from every group of participants that had attended the education sessions and had made changes to the course accordingly. Such feedback contributed to innovative changes, such as the change from the education sessions followed for the study to the recent Whanau Hui. This change was supported by the study findings that the majority of clients were dealing with much more than diabetes alone. Client feedback and the growing attendance from month to month 
provided evidence that these hui were meeting the needs of the population being served.

Data on the outputs of the MDNE role were collected and evaluated quarterly by the DHB and Ministry of Health (MOH). The MDNE also had to report annually to the Local Diabetes Team (LDT) on her progress and caseload (MDNE Service Specifications, Appendix A). As client feedback and requests from the current study were gathered through the stakeholder interviews, they were fed back to her for actioning. More general findings and observations had to wait until all data had been analysed to maintain the integrity and balance of the process.

From an organisational point of view several issues came to light in the study. The MDNE contract was considered by the manager and the MDNE to be under-funded for the service provided. There seemed to be some overlap between that and the Whanau Ora contract, which was not surprising given that many of the clients were covered by both services. The feeling was that the proposed chronic conditions contract would be an improvement and might address some of the inequities in this diabetes contract. The MDNE seemed to be doing a number of things that PHOs and GPs were funded for.

Another issue identified by the manager and MDNE was that the contract did not specify the number of clients to be treated. Rather it was the commitment to do an initial follow up visit on all Maori people in the district diagnosed with diabetes. The service would then be prioritised based on her clinical and cultural assessment (MDNE Service Specifications, Appendix A). The number of clients on the diabetes register had risen from 85 in 2005 to 108 in 2006. By Dec 2007 the numbers had dropped slightly to 94 as 15 clients had recently deceased or relocated out of the district (Oehlrich, 2007). The overall trend in the diabetes register was a slow but steady increase in numbers. The screening register showed a more rapid rise from 9 in 2005 to 34 in 2006 and 71 in 2007. Concern was expressed about this rise in the screening register, which committed the MDNE to targeted screening and annual recalls for those clients. 
It was noted that the only ways clients left the service was either through death or leaving the area, which raised concerns about the service continuing to grow at the current rate, without discharging clients or taking on a second staff member. The Local Diabetes Team had raised the need for THONR to either prioritise the service or discharge clients back to their GP. However the MDNE was concerned that such discharged clients might get "lost in the system". The service specifications (Appendix A) also indicated there were concerns about mainstream services being able to meet the holistic health needs of Maori clients on discharge. Simultaneously referring them to the Whanau Ora service was an option that might reduce this risk.

The findings raised questions regarding the value of group physical activity sessions in the format used in the education sessions, due to apparent discomfort of some participants and low rate of uptake outside sessions, despite participants speaking highly of the educator. There may have been barriers to participation such as self-consciousness, embarrassment and fear of failure. It may be that incorporating a walk or active "games" into support group gatherings in future may be more successful.

\section{Element 3: Delivery system design}

\begin{tabular}{|l|l}
\hline Criteria & $\begin{array}{l}\text { Define roles and distribute tasks among team members } \\
\text { Provide clinical case management for complex patients }\end{array}$ \\
& Ensure regular follow-up \\
& Give care that patients understand and that fits with their cultural \\
background
\end{tabular}

The design of the delivery system was an important aspect of the programme's focus on providing planned care, self-management support and prevention rather than having to react to acute episodes/exacerbations in the clients' health. Their approach was resource efficient due to the emphasis on building independence, because the least intensive intervention possible tended to be used. Other aspects of the system design that indicated a proactive focus, were the system flagging when follow up was due and the tendency to remind certain clients of their appointment. The use of computerised staff appointment diaries 
enabled team members to streamline the service and avoid doubling up on visits.

\section{Staff attributes}

The MDNE and other THONR staff coordinated the care of vulnerable clients with complex health needs; this included negotiating the space between clients and mainstream services. They were aware of what services were available and how to access them. Toni talked of falling "through the cracks" until THONR staff became involved in their care and ensured that initial and follow up appointments were made appropriately. Lee appreciated THONR being a free service, so they could be referred to Green Prescription and the dietician without incurring a doctor's fee. Also Lee could discuss health issues with THONR staff to decide if a GP visit was necessary. This suggested that programme staff were seen as approachable and knowledgeable enough to provide this service.

The findings indicate that staff were the programme's most valuable resource; they were very skilled on multiple levels in what amounted to a very diverse role. Staff were also familiar with Maori ways of doing and knowing and were able to bridge to the non-Maori way and help others to do likewise. They had a role in teaching, advising and supporting mainstream service provider staff in delivering a culturally appropriate service, while also ensuring that clients' needs were met. Their support of clients might involve translating medical terms into language they could understand. The MDNE in particular received positive feedback regarding her ability to make medical terms meaningful for clients. In addition she needed to communicate the significance of her assessment findings to other health professionals in a way they would appreciate, when she wanted her clients to be seen.

Hung et al. (2007) identify the employment of allied health professionals and a multidisciplinary team approach in design of primary care practices as supporting the use of CCM as a framework for prevention. THONR employed staff with qualifications in a number of disciplines, who were generally able to 
work together. The MDNE had a role in orientating, informing and supporting her colleagues, who were then able to assist her in aspects of her role. Having this assistance generally worked well, but it was also noted that the MDNE, with her higher level of knowledge and understanding related to diabetes, was more confident and flexible regarding adapting recommendations to a client's individual context and at assessing clients and problem solving issues. It was therefore desirable to have more than one qualified nurse on staff, as had happened for several months at the end of the study following the resignation of the enrolled nurse.

Staff showed a great deal of commitment to the programme and to the clients; their involvement didn't stop when the appointment was over or when the client left the district. They would stay late, work in the evenings or on the weekend, or come in on their own time. There were opportunities for flexible working conditions such as taking time in lieu, to compensate for this, but it was significant because it was viewed as a cultural commitment rather than an employment obligation.

\section{Programme attributes}

Providing care that clients understood and that fitted with their cultural background and health literacy were very important aspects of the delivery system design. Evidence from previous and current participants and service providers outside the organisation indicated that the group education sessions were viewed as a safe environment for participants. Service provider \#2 noted that there was a good level of questioning from participants, which they had come to associate with a successful session and the development of a good level of trust among the participants. Several sources reported that the MDNE had skills in developing a rapport with participants and in putting information across so as not to cause offence. There was a suggestion though that some participants might not be comfortable with the expectation to participate in group exercise activities or having weight, blood glucose levels and blood pressure monitored in public. 
A focus in the interviews was trying to establish whether this programme was offering something special to clients that they hadn't been able to receive elsewhere in their diabetes education and management. This naturally seemed to lead to the distinctly Maori aspects of the service and programme, these included use of Maori greetings and hui protocols. Four participants reported a real comfort with the atmosphere in the programme, and the use of protocols, having been brought up with karakia, which were described as a good way to settle down an upsetting situation, although two participants were quick to add that they would also readily have gone to a mainstream provider.

I think maybe because they're Maori, you're more at home with them, I'm not saying... I get on with anybody, but when I'm with them, we do enjoy it and I think everybody else does too. They have got your things at heart you know, they know what you're like. Toni

However one participant found aspects of the course unnecessarily repetitive and wasn't so comfortable with the use of protocols and te reo and another talked about a situation of being asked for details of iwi and birthplace and was embarrassed at not knowing. Yet others recognised the importance of Maori protocols for people who were brought up that way even though they themselves didn't require it. This illustrates the diversity of the group regarding comfort with their Maori identity.

A service provider outside the organisation thought the Maori aspects of the course were its defining features (rather than any educational content differences between it and mainstream services). They thought these were important even to Maori clients who were not as strongly in touch with their cultural heritage.

It helps them appreciate the information they're getting a little bit more, they actually buy into it a little bit more. Provider \#3

The MDNE identified a strength of the service as being the holistic perspective and use of the Whare Tapa Wha model, which meant giving people the opportunity to discuss their spiritual, mental, family and physical wellbeing. This was confirmed by feedback from clients that the programme's wellness 
approach was evident and different to what the clients had encountered with other health care providers.

THONR staff members felt that one of the strengths of the programme was the ability to empathise and spend more time with clients; this was borne out by feedback from providers outside the organisation and participants in relation to the education sessions. Regarding case management though, three of the clients commented that staff always seemed to be rushing and that they wished staff had more time to spend, sharing information about themselves, having a cup of tea or lunch, because they would get more out of clients then and ultimately provide a better service. Feedback from previous education sessions revealed that the MDNE had identified lack of time as an issue for her as well. It may be that due to the familiarity in the relationships and the service being provided by Maori for Maori that the clients had expectations in excess of what they would expect from mainstream services in this regard. An additional consideration was whether this was adequately allowed for in the MDNE contract. Although THONR is an iwi based health provider and the participants were generally from different iwi this did not constitute a problem for any, but they were aware of the difference.

\section{Balancing relationships}

A distinguishing feature of the education programme was the use of humour, which seemed to be an essential ingredient to getting a message across in a comfortable learning and sharing environment. Humour was often used by staff in a self-deprecating manner, for example acknowledging that they were overweight or had a large waist measurement themselves. Participants generally seemed comfortable with staff acknowledging their own shortcomings in this respect, rather than role modelling the "ideal shape". The feeling was that if the person had the knowledge to impart, then it didn't matter what they looked like themselves. A different perspective on role modelling came through in comments about the Green Prescription activity coordinator on the programme, who had been overweight and overcome his own weight problem. He was 
viewed as someone who knew what others were going through and was able to motivate them through his personal experience and faith in their ability.

The use of self-deprecating humour by the staff seemed to set the tone for using humour with clients, to give them an honest message in jest about some aspect of their behaviour. Toni gave the example of a THONR staff member asking if they were "helping themselves to get better". Another example was Sam being advised to use something other than jellybeans for hypoglycaemic episodes because they would be eating the jellybeans whether they had a "hypo" or not. Although generally a positive feature, this familiarity could also lead to people feeling pressured, especially in relation to lifestyle change; client responses varied though and the same client could even respond differently at different stages of their change process. It was also further evidence that people could not make lifestyle change until they were personally committed and ready.

Another challenge for staff was the need to maintain a professional relationship with people with whom they had developed a close bond, while being mindful that there was still a significant power imbalance between them, especially when people were very dependent on the service. Efforts to maintain this professional relationship could leave clients feeling unsupported or that they had done something wrong, while they were being encouraged to be more independent.

\section{Assessing programme impact}

Provider \#2 had received enthusiastic feedback on the day of the supermarket tour, but was also interested in assessing the long-term impact of the session. They wondered how much was being applied further down the track;

If there are any particular things that they've just latched onto and forgotten the rest or if there's that broad uptake.

Provider \#2 suggested doing a follow up session or doing the tour in two chunks, because it was quite a lot to take in, in one day. 
There was difficulty maintaining full attendance at education sessions; numbers would quickly drop from seven or nine at the first session, to two or three at some later sessions. Provider \#3 also talked of the difficulty of getting people to access all the free lifestyle education appointments they were entitled to with their organisation. According to Provider \# 1, low attendance at the Wellness with Diabetes education sessions was particularly a problem in the winter. During the study the MDNE would canvass participants to determine likely attendance at that week's education session. Drops in attendance tended to be related to the complexity of clients' health states. Other reasons for nonattendance or postponement for both clients and staff included family crises and the need to attend tangi. If numbers were going to be down the decision had to be made whether it was preferable to run the session or to postpone. This had an impact on some participants who talked about the course starting out well, but then drifting off following the postponement of several sessions.

Continuing with low numbers could also be problematic though. One week in particular there were eight educators and observers and only two participants. Although the participants said they were not concerned by this, it was not an ideal situation for the participants or for the organisation as it was not an economical use of resources. Lee identified the ideal group size as being 10 participants and that educators should stagger their arrival if participant numbers were well down. Larger numbers had been attending the new more generic monthly Whanau Hui, which had been running since the study.

\section{Element 4: Decision support}

\begin{tabular}{|l|l|}
\hline Criteria & Embed evidence-based guidelines into daily clinical practice \\
& Share evidence-based guidelines with patients \\
& Use proven provider education methods \\
Integrate specialist expertise and primary care
\end{tabular}

The programme used decision support to promote care that was consistent with scientific evidence and client preferences. It involved the integration of evidence-based guidelines such as the NZ Guidelines Group (2003b) Management of type 2 diabetes guideline and Diabetes New Zealand 
recommendations for monitoring, management and lifestyle change, into the day-to-day practice; to prescribe what needs to be done for clients, at what intervals and by whom. Other information and resources that were used came from drug companies, the internet, textbooks and journals. The MDNE was also using a range of teaching resources collected at conferences and training sessions, to give people simple descriptions of the effects of raised blood glucose on organs of the body.

\section{Element 5: Clinical information systems}

\begin{tabular}{|l|l}
\hline Criteria & $\begin{array}{l}\text { Provide timely reminders for providers and patients } \\
\text { Identify relevant sub-populations for proactive care } \\
\text { Facilitate individual patient planning } \\
\text { Monitor performance of the practice team and care system }\end{array}$
\end{tabular}

The MDNE kept detailed electronic clinic notes on all of her clients, including interventions undertaken, referrals actioned, physiological measures and clinical assessments. Many areas of her interventions were cross tabulated and the data was then collated to produce the reports that went to the DHB quarterly, from which population health statistics could be collected. These reports also provided demographic, workload, and client contact data, to further enhance the organisation's performance. This system was also used to flag when clients were due for review.

\section{Element 6: Self-management support}

\begin{tabular}{|l|l|}
\hline Criteria & $\begin{array}{l}\text { Emphasise the patient's central role in managing their health } \\
\text { Includes assessment, goal-setting, action planning, problem-solving } \\
\text { and follow-up } \\
\text { Organise internal and community resources to provide self- } \\
\text { management support to patients }\end{array}$ \\
\hline
\end{tabular}

There were many ways that the programme aimed to empower clients through self-management support, such as engaging them as active partners and helping them to develop new skills and make changes in their lifestyles. Staff generally agreed that clients had to be ready to change in order to be successful, but they had different ways of working with people to move them towards change. For the MDNE it was educating them about the condition and 
complications, but always with a focus on being well with diabetes. Provider \#1 thought it was best to make lifestyle suggestions gently and work them into everyday conversation so as not to turn people off. The activity co-ordinator talked about giving people the information so that when they were ready, they knew what to do and where to go. They all agreed on the importance of developing trusting relationships to enable this work to continue in a conducive environment, thus maintaining contact while clients worked through preparatory stages.

Staff went to considerable lengths to keep clients engaged with the programme, reminding them about upcoming events, transporting, supporting, reinforcing and removing impediments to change such as taking them for walks or providing shoes and a pedicure so that they could walk comfortably. Their efforts were usually, but not always appreciated at the time - clients might go through periods of "putting up walls" if they felt pressured or being hoha when they lost confidence, but relationships were fluid, the links were maintained and when the person was ready, they could try again. Clients had to take a long term view; permanent change was the objective so it was better to lose less weight more slowly through sensible lifestyle change than to lose a larger amount on a "crash diet".

The MDNE talked about a person who had made great lifestyle changes having lost 16 kilograms in six months. This person was initially referred to her for management of high blood glucose, but wasn't interested in lifestyle education and only contacted her when they needed monitoring supplies. The person's attitude changed when they were told they could lose their foot or whole leg. They started seeing the MDNE for education and making lifestyle changes and at a later appointment admitted that they had initially been "whakama" (embarrassed) about coming to see her due to viewing the doctor as the expert and thinking that because they were receiving medications they would stay well without making additional lifestyle change. 
The MDNE often had to work with this view of the doctor as the expert; it went along with the locus of control being with someone other than the client. She would often say "Do you control your diabetes or does your diabetes control you?" She also emphasised that blood glucose monitoring was a tool to put the client in control rather than something they had to do for the doctor.

It's about teaching them to understand what their blood sugars should be, their target, knowing what their cholesterol level should be and the targets, why it's important that they change those to protect their heart health and their kidney health, and blood pressure. Heather Oehlrich, second interview

The MDNE encouraged people to ask questions of their doctors and sought to give them the skills and support to empower them to be independent and selfmanaging. She talked about a couple who had been with them for eight years;

Both him and his wife came on board in 1999 very dependent and reliant, but they've developed the skills and expertise, so they are now self-managed in an awesome way and made some fabulous lifestyle changes and are keeping themselves well. But lifestyle changes don't happen with just one or two education sessions, they require ongoing support. Heather Oehlrich, first interview

Another THONR staff member talked of clients that they had given little hope of achieving weight loss and lifestyle change and how surprised they were to see that these people had really turned their lives around when something suddenly "clicked" for them.

\section{Providing a client centred service}

The service strived to be client centred by trying to empower clients, encouraging them to set their own goals and giving them choices in venue, timing and programme content. Participants had been consulted before setting the date and time for the two courses of the group sessions followed for the study; consideration had also been given to running a course in the evening for those who were working in the daytime (particularly men). The MDNE had attempted unsuccessfully to re-establish the Diabetes Support Group as a consumer-driven event. The Whanau Hui in their monthly format, (which now 
replaced both the diabetes group sessions and support group), discussed what the diabetes whanau wanted to focus on, such as education updates from guest speakers. These factors indicated flexibility on the part of the staff in wanting to overcome the barriers to attendance that some clients experienced.

Transportation, which is a recognised barrier to Maori accessing health care $(\mathrm{MOH}, 2006 \mathrm{~b})$ was tackled by programme staff sometimes transporting clients to appointments, education sessions and even shopping if required. Three participants had utilised this service and three others were aware of the possibility, but hadn't used it. The transport was generally considered to be a very good service. The MDNE noted that declining use of this transportation service could be viewed as an indicator of growing client independence, for example of 22 participants who attended the most recent whanau hui, only six had required transport.

\section{Providing culturally appropriate settings}

A further indication of this growing independence was the change from the MDNE having to initiate appointments, to many clients now self-initiating or just dropping in to her clinic rooms, in which case she tried to provide same-day appointment access. She had previously been seeing clients at a GP practice and thought they might have perceived the need to pay there, even though that wasn't the case. Now she was using her clinic rooms at the THONR premises, which clients seemed very comfortable with. There were conflicting opinions though about the use of the lounge at the THONR facility as a venue for the education sessions. One service provider found it to be a comfortable venue for discussion and kai after the supermarket tour, but previous and current participants complained about some interruptions from staff comings and goings.

Regarding settings, the service specifications required consideration of cultural appropriateness, accessibility and most effective/efficient use of resources (Appendix A). The three different venues used for the education sessions (the premises of the local Primary Health Organisation, the Maori Development 
Organisation and the THONR facility), were all attractively presented in terms of décor and Maori artefacts, artwork and weaving being displayed. They were all considered accessible by clients. Significant requirements that were identified in the interviews were; availability of space for group activities and the exercise session, tea and coffee making facilities, a combination of a table and chairs for kai and the education session and comfortable chairs to seat kaumatua (elders) at the informal times. There was some difficulty balancing the need to have space for group and exercise activities, yet not having too large a space when group numbers dropped. These were factors that could be considered at the time.

\section{Summary}

The findings revealed that clients were generally satisfied and comfortable with the THONR service. There were a number of examples given of aspects of the service that they could not have received from a mainstream provider, some of those were related to it being a by Maori for Maori service and others included it being free, accessible and client focused. Results indicated some improvements in physiological outcome measures in the short-term while participants received intense input, which were not maintained once they were receiving less support. Likewise most participants could identify new knowledge and behaviour change they had been able to make, but not always maintain. Finally, this section provides some understanding of the issues inherent in making and sustaining lifestyle change when beset by the co-morbidities of chronic illness.

The programme had a clear focus on collaborative goal setting and problemsolving techniques to help clients to develop the motivation, skills and confidence to manage their own condition. Many aspects of the programme design met the criteria of the CCM framework as given in Table 1 (p. 15). Criteria that were less fully achieved provide some worthwhile recommendations for programme improvement in the next chapter. The next chapter also interprets the findings and considers what they tell us about the 
functioning and effectiveness of this programme, management of diabetes and chronic illness in general and the unique contribution of Maori health providers and this Maori nurse-led service in the NZ health system context. 


\section{Chapter 6 - Discussion}

This chapter considers the extent to which the programme set up by Te Hauora O Ngati Rarua (THONR), addressed the needs of local clients with diabetes and other chronic conditions. It also seeks to understand what is significant about this programme and the way that it functions from an organisational perspective. Effectiveness is viewed from a number of aspects including: cultural appropriateness; integration with the community; accessibility; consumer participation and satisfaction; and health outcomes. The chapter highlights the important role nurse-led programmes can play in providing expert education and management in the primary health care of people with chronic illnesses. The experiences of the seven participants identify some of the salient features of being on this programme while trying to make lifestyle change and how this fits with what is known about the process of change in similar groups.

The chapter is presented in two parts. The first part considers how the programme sits in the wider context internationally, nationally and locally. The Chronic Care Model (CCM) (Wagner, 1998) is then used as a framework to evaluate the programme's effectiveness; both for the organisation and for the clients and some possible future developments are proposed. Finally the original study propositions are revisited. The second part explores my research journey and insights gained related to Maori and Pakeha working in partnership.

\section{Part 1: Evaluation of the programme}

The Wellness with Diabetes programme was true to its title as there was a clear focus on optimising wellness by teaching and supporting clients to self-manage their condition. Part of the success of the programme lay in the use of Maori processes and values to create a comfortable and supportive learning environment for participants. This was a small programme, working with a diverse population, which was spread over a large district. The client base was socio-economically diverse and disproportionately dependent on a number of social and health services 
It became apparent as the study progressed that one of the tensions for the programme and service was balancing a funded diabetes service, with the additional requirements of working with people with multiple co-morbidities. The complexities this brought to programme requirements are captured by the CCM model (Table 1, p. 15).

The findings related to the presence of co-morbidities were not unexpected, as research has found that almost half of all people with chronic illness have multiple conditions (The Health Foundation, 2008). It is generally accepted that such conditions are often not well managed, because services that have an acute orientation do not focus on keeping people with long-term conditions as healthy as possible (Improving Chronic Illness Care, 2008; McEvoy \& Barnes, 2007; Wagner, 1998). This programme addresses this issue with its specific focus on wellness. As such, the programme achieves the objectives of the CCM model.

The findings in Chapter 5 capture all six elements of the CCM model: the community, health system, clinical information system, decision support, delivery system design and self-management support. The six elements are used in Part 1 of this chapter to frame the discussion on the effectiveness of the programme. Many of the recommendations for improvement given later in Part 1 are supported by research into the design and evaluation of the CCM model. Limitations of the model in this setting are considered at the same time.

CCM proved to be an excellent model to guide the evaluation of the service, although it was designed for organisations with a larger organisational structure, it was readily applied to this setting. It integrated well with Systems Theory and the Transtheoretical Model of Change, which guided evaluation of other aspects of the outcomes and the clients' experiences. 


\section{Context and organisational influences}

This programme was not established in a vacuum, it was situated in an international, national and local context that recognised the origins of ethnic disparities in health and realised that a universal approach to health care was not addressing the issues (Anand et al., 2001; Cass, 2004; Krishnan, Diette, \& Rand, 2001; MacMillan, MacMillan, Offord, \& Dingle, 1996; Winkleby, Kraemer, Ahn, \& Varady, 1998). Nationally, targeted health services such as Maori health providers were deemed necessary to provide services that were accessible, acceptable and available to many Maori clients. Such organisations aim to provide culturally appropriate services at no or reduced cost to overcome financial barriers $(\mathrm{MOH}, 2001 \mathrm{~b})$. The Primary Health Care Strategy targets health improvement through such preventive services as health education and screening, which are to result from greater community involvement, teamwork between health professionals and innovative roles such as primary health care nurses and nurse led community clinics (MOH; Tully \& Mortlock, 2005).

Locally, the Nelson Marlborough District Health Board (NMDHB) also focuses on specific needs by offering targeted contracts such as the Maori Diabetes Nurse Educator contract for the Marlborough region. This contract led to the development of the programme that was studied. The structure of the programme was shaped by the MDNE specifications and a number of other contracts serviced by THONR. These provided both a source of clients and a means of providing a comprehensive service. For example the MDNE and Whanau Ora were funded as two distinct contracts, each with different reporting requirements, yet there was a certain amount of overlap between the two services which enabled the staff to work cohesively to provide consistent support, assessment, management and education to the clients who were covered by both.

The service specifications did not define the parameters or size of the MDNE contract; rather it was the undertaking to provide diabetes management and education to all Maori clients in the region who were referred to the service (MDNE Service Specifications, Appendix A). This research reiterated earlier 
concerns considered by the Local Diabetes Team regarding the continued growth in the MDNE workload and the lack of a clear path to discharge from the service. THONR is able to provide the service currently, because it is subsidised by the Whanau Ora contract. Abel et al. (2005) also noted this crosssubsidisation of contracts in their review of a larger Maori health provider. One way of addressing this contracting issue was requesting an integrated contract from the District Health Board (DHB). The proposed chronic conditions contract might prove to be such a contract. However, it was not the purpose of this study to determine whether contractual obligations were being met or whether the contract was realistic given the level of need in the community.

The MDNE position and this programme are examples of the key and innovative role identified for primary health care nurses in the Primary Health Care Strategy $(\mathrm{MOH}, 2001 \mathrm{~b})$. Such nurses are identified as combining generalist and specialist knowledge and skills to enable them to work autonomously and collaboratively to promote, improve and restore health. They work in partnership with people - individuals, whanau, communities and populations - to achieve the shared goal of health for all in their particular areas of professional practice (Expert Advisory Group on Primary Health Care Nursing, 2003; MOH). The programme did have obvious successes in terms of clients improving their self-management of chronic illnesses. But the findings are also consistent with the conclusions of the above advisory group that the explicit contribution that such nurses make towards reducing hospital admissions and preventing injury and disease are poorly understood. That group concludes that more accurate methods of tracking the nursing contribution to health gains are required.

One distinctive feature of this programme was the importance of teamwork, both in the group education sessions and in working with clients individually. Although there are many benefits to teamwork, Baileff (2000) and the Expert Advisory Group on Primary Health Care Nursing (2003) note some difficulties of maintaining teamwork in a primary health care setting. This often means working in isolation without a structured framework for communication between 
disciplines, which can result in duplication of services and subsequently impact continuity of care. The MDNE certainly did work in isolation but was well suited to doing this as the most knowledgeable member of the team regarding diabetes management. Clients were often being seen by a number of team members and there was some evidence of duplication of services, but this was minimal. The more recent practice of keeping appointment diaries on-line seemed to provide better co-ordination of services. Apart from this, regular team meetings provided an opportunity for communication between the disciplines.

The Expert Advisory Group on Primary Health Care Nursing (2003) concludes that once such barriers to teamwork have been overcome and an effective framework has been established, teams can benefit from a shared philosophy and objectives. Such teams are more likely to be creative and innovative in finding solutions to problems, and using the skills of the team members appropriately. There was evidence of this in the education sessions and the Whanau Hui under the new structure that involved all members of the team. Another example was the way the MDNE had been able to impart some of her knowledge and skills to less qualified team members, so that they could deal with acute client issues in her absence.

The MDNE was the only qualified nurse on staff for the latter part of the study, which had implications for the service as she had a higher level of knowledge and understanding related to diabetes than other staff members. The service would have benefited from having more than one qualified nurse on the staff at this time. It was also important to value the Whanau Ora Kaimahi though, because community health workers have been identified as playing a crucial role in supporting the self-management of chronic illness (Fisher, Brownson, O'Toole, Anwuri, \& Shetty, 2007b). Staff levels have been addressed since the study by the return of the previously employed enrolled nurse to the Whanau Ora Nurse role. While it would be desirable to have even more qualified nurses involved in delivering the programme, this may not be possible given the shortage of Maori nurses, which government workforce development strategies aim to address (Health Workforce Advisory Committee, 2006). 


\section{Effectiveness at managing chronic conditions}

The research identified that an extensive range of community contacts and resources were maintained by the staff of the programme. The organisation's high community profile contributed to the significant number of self and whanaureferrals and community screening clients. These client sources implied the staff were gaining access to some people who were marginalised from other health services. Providing this service required commitment and flexibility from staff, being prepared to work in different settings and being open to reaching out to potential clients. The various ways that Maori people accessed the service indicates that the programme was valued by Maori in the region and that there was a local need for, and comfort with, the services being offered. What was less clear was the extent to which the programme was reaching people with known access issues and those people with unmet health needs. This research showed that even without financial barriers, maintaining utilisation of services was sometimes problematic. There were many reasons that people did not continue to attend, some of these stemmed from the programme, some were personal and others were unknown.

\section{Providing an integrated service}

THONR met many of the criteria for an effective health system. The service had accreditation, was open to feedback and change and engaged in collaborative intersectorial work with other organisations (Hung et al., 2007; Improving Chronic Illness Care, 2008). Although the opinions of staff from other agencies were not canvassed, referral rates from other health providers provide evidence that the programme was integrated with, and acceptable to, the local health services. This acceptability was also signalled by the MDNE's arrangement to offer her free diabetes clinics in general practices and pass on her findings to them. Another example was the collaborative arrangement with general practices that enabled her to send their clients for blood tests when they met the criteria. 
This research highlights the problems of being a small organisation trying to provide a specialist service to a target population, within the primary health care environment. These problems included the MDNE having to advocate for clients to receive services they were entitled to, or finding that she had to provide the service herself in some instances, for the sake of her ongoing working relationships. However as long as the service carries out assessments which Primary Health Organisations (PHOs) and general practitioners (GPs) are funded to provide, there is no incentive for general practice to change. Perhaps this is an area where written protocols are required between the service and the local practices or the PHO to clarify roles. Alternatively such assessments could become a recognised and funded part of the MDNE's workload.

The findings identified many ways the service was meeting the criteria for the elements of clinical information and decision support within the CCM framework. Use of computerised clinic notes meant the MDNE could readily access client information and meet $\mathrm{DHB}$ and $\mathrm{MOH}$ reporting requirements. She also regularly accessed clinical guidelines and resources on-line, which enhanced the service she was able to provide.

\section{Defining features of the programme}

The programme was able to focus clearly and consistently on optimising wellness with diabetes and developing skills for self-management, within a delivery system design that was proactive rather than reactive. In achieving this focus the programme provided information that clients understood and that fitted with their cultural background and health literacy (Improving Chronic Illness Care, 2008; The Health Foundation, 2008). This was important because the degree of comfort individuals feel with seeking health services is known to impact their use of services, and in turn health outcomes (Baxter, 2002; Cram et al., 2003).

This research demonstrates it is possible to offer a programme which is true to Maori values and protocols, in such a way as not to alienate people who are 
less comfortable with their Maori identity or do not identify as Maori at all, given the diversity in the Maori population (Durie, 1998). This achievement was possible through the balancing of the use of te reo with English, supported by a combination of role modelling, explanations and translations. Feedback from stakeholders suggested that whanaungatanga was the most important aspect of the group sessions for most, even for those that did not feel such a need for the hui protocols, although these are essentially inseparable within Maori value systems. This outcome is not surprising as whanaungatanga is a pivotal aspect of health and wellbeing in Maori value systems (McNatty, 2001).

The informal cultural aspects of the programme, such as the sharing of kai after the group education sessions, demonstrates how familial systems can be used to bring about change by modelling healthy choices and creating a comfortable environment for discussion. It illustrates the importance of informal activities on building trust (Fisher, Brownson, O'Toole, \& Anwuri, 2007a), although this is an often unfunded way of reaching people. Other researchers have demonstrated the importance of creating a sense of community in bringing about change in chronic health conditions (McEvoy \& Barnes, 2007; The Health Foundation, 2008), which was confirmed by this study.

The results support much that is known about Maori attitudes to health (Durie, 1998; Waldon, 2003; Willams et al., 2003), but also raise some contrary perspectives. Providing a "diabetes whanau" for participants by mixing people at different ages and stages of diabetes in the education sessions so they could learn from and influence each other was generally beneficial, although it didn't appear to work so well for the younger participants. The tendency of some people to use improving health as motivation and be turned off by talk of complications, confirmed the benefits of the wellness approach. Although a potential limb amputation or untimely death also galvanised some participants to change. The study confirmed the importance of personal commitment when making change, but also identified a range of external motivators that could be called upon, particularly ways the change would benefit whanau. There were 
also examples of the influence of whanau hindering clients' progress and of change efforts putting stress on personal relationships.

Stakeholder preferences for pamphlet content and use differed, but generally confirmed recommendations regarding the development of culturally appropriate resources (MOH, 1996; Waldon, 2003; Willams et al., 2003). Using a positive message and highlighting cultural values such as whanau involvement, staying well for mokopuna (grandchildren) and care of the natural environment, were some examples given. Pamphlets that included practical examples such as healthy, low cost, Maori recipes were popular and the use of graphic examples, such as showing the fat and sugar content of common foods and bright attractive photos, rather than large volumes of text, were also supported.

There were many examples of goodwill and commitment, or going beyond what was required in the contract from the staff, especially in the way they delivered the programme and the lengths they went to keep clients engaged. Boulton (2005) in her thesis on mental health services identified this extra work and referred to it as the "invisible" Maori aspects of the service, but the nature of this phenomenon in diabetes and other chronic illness services has not been explored previously. Boulton groups these invisible aspects under three headings: work to deliver what was perceived to be a culturally appropriate service; work done out of a sense of duty to the client; and work done to improve service resources or staff capabilities. The current research identified examples of such extra work under each of those headings.

Extra work in providing a culturally appropriate service included supplying food, cultural activities and learning, and attending tangi or taking clients to tangi. Examples of uncontracted obligations to clients included; transporting and supporting them to appointments, social services, community activities and shopping, taking them for walks, getting them shoes, helping them to pack, and staying in contact after clients had left the district. As the case manager for her clients, the MDNE would often work across a network of people to broker other 
services to coordinate their care. Developing new educational resources, such as her PowerPoint sessions were examples of work done to improve the service. The commitment to be available outside normal business hours was not usually a requirement or an expectation of staff employed by mainstream services, yet THONR staff were happy to do it for their people and the organisation. It was not clear to what extent these activities were recognised in the organisation's contract.

\section{Relationships in the programme}

There appeared to be a natural tension between the objective of whanaungatanga, the need to maintain professional relationships and the need to provide a cost-effective service. Some clients commented on staff always rushing in the case management role and hoped they would get to know them better. From the staff members' perspective they felt they spent sufficient time with clients and that the importance of this was recognised within this organisation. It may be that due to the familiarity in the relationships and the service being provided by Maori - for Maori, that the clients expected more from this organisation than they would from mainstream services. On the other hand it could be argued that as whanaungatanga is one of this service's objectives, it was quite reasonable for clients to expect that they would get to know THONR staff better than those of mainstream services. It is unclear to what extent it was allowed for in the MDNE contract.

Despite these requests for closer relationships from some clients, it appeared that THONR staff did form close bonds with many clients and did more for them than would be considered necessary by mainstream service providers. This closeness and level of personal involvement could challenge THONR staff's ability to maintain a professional relationship with clients at times, especially if the clients concerned were very dependent on the service and had historically come to expect more informality. Managing such relationships seemed more complex for this Maori health provider due to cultural expectations such as whanaungatanga which other providers would not have to accommodate. 
Another factor that required careful management was following up people who had not initiated contact with the service themselves for some time. This was identified by Fisher et al. (2007b) and Highstein et al. (2007) as an important aspect of supporting sustained self-management, but it also meant it wasn't as easy for clients to "opt out" if they no longer wanted to be part of the programme. Such follow up clearly had benefits in terms of keeping clients engaged, but also had the potential to apply undue pressure or coercion.

The programme demonstrated that the use of self-deprecating humour on the part of staff could be an important aspect of keeping people safe, because it had a levelling effect in terms of the power differentials between people. Once this relaxed atmosphere of acknowledging shortcomings had been created by staff, clients were more likely to feel comfortable doing likewise. Clients still seemed to recognise the serious message when it was delivered in a lighthearted, friendly manner by staff, but they appeared less likely to take offence if it challenged their current behaviour. Within this common use of humour, staff each had their own way of working with people, what was evident though, was that it had taken time for each of them to develop and nurture trusting relationships to facilitate this level of familiarity.

Conversely, clients had generally not developed such comfortable relationships with their doctors and consequently might not admit when they didn't understand aspects of their medical management. Communication problems between Maori clients and their often Pakeha health professionals have been well documented elsewhere (Cram et al., 2003; Durie, 1998; McCreanor \& Nairn, 2002; Willams et al., 2003). Communication problems include Maori being less likely than Pakeha to question treatment plans (Jansen \& Sorrenson, 2002) and a divergence in perspective between health practitioners and their clients, which was likely to lead to discord when combined with their unequal power relationships (Penney et al., 2006). Dealing with this interface and encouraging clients to become more involved in their own care was an important part of the job for the MDNE and the team, and required the MDNE to 
support, facilitate and translate, to ensure that clients felt heard by the practitioner and understood all they had been told.

\section{Making change through self-management}

Encouraging clients to take an active role in their own management in this way is consistent with the findings of Wellingham, Tracey, Rea, and Gribben (2003) that clients with chronic diseases have better outcomes when they feel understood, respected and empowered by the general practice team to share in clinical decisions. This approach signifies a shift away from the medical dominance of the biomedical model in doctor-patient relationships to the "new professionalism' of a partnership between health professional and client (Tully \& Mortlock, 2005). This change in the doctor-client relationship has also been impacted by technology, for example Mol (1998) identified that glucometers or "minilabs" had given the patient the power to manage their own condition. The MDNE utilised this dynamic when she encouraged clients to monitor their blood glucose to put themselves in control, rather than doing it because the doctor required it.

The impact of cultural factors on client relationships with health professionals, such as experiencing feelings of whakama (shame and embarrassment) if they were not maintaining a prescribed regime or had not been successful in achieving lifestyle change, was noted earlier. Health professionals can increase these feelings of whakama in clients when they give them lifestyle advice that they are already fully aware of. Even the act of questioning can heighten this feeling, as illustrated by the example of work related lung damage from the participant interviews. This illustrated the multiple ways that clients were told both explicitly and implicitly that change was in their own hands, by health professionals and society in general. The effect of this could be to undermine clients' sense of self-efficacy, if they proved to be unable to make the desired changes. 
This threw up conflicting objectives for staff who wanted to protect their therapeutic relationships with clients, yet risked alienating those clients by advising against unhealthy lifestyle behaviours. But it is important to give the lifestyle messages anyway, because health professionals are known to be influential in dissuading clients from unhealthy practices (Mullen et al., 1997; Zimmerman et al., 2000). A strength of the THONR service was the ability to keep people engaged while they received education and worked through the change process. This involved creating a sense of them being accepted as they were, but also encouraging them to strive for improved health.

\section{Taking control - making changes}

There was a tension here between encouraging clients to take control of their own health, without which they would not be able to make changes, yet avoiding viewing lifestyle "choices" simply as a matter of personal responsibility. As outlined in Chapter 2, current models of determinants of health recognise that many complex societal factors contribute to lifestyle behaviour (HowdenChapman, 2005). These societal factors include peer group pressure and a lack of social influence, which can lead to apathy or alienation born of the belief that it is impossible to change your lot (Germov, 1999; Lawrence, 1999). Such contextual factors were relevant to at least some of the participants in this study and often had to be dealt with before people could focus on making change.

Another problem with the reasoned action approach to lifestyle change is that it assumes that everyone is at the action stage on hearing that they need to make a change. However research into the cycle of change has suggested that 80 percent of the target group will be in pre-contemplation, contemplation and preparation stages (see Table 2, p. 16). These people would require a tailored stage-specific and preferably personalised approach if they were to be helped to move on towards action (Lawrence, 1999). The findings of this study that many participants either did not accept their diagnosis of diabetes and that lifestyle change was important, or did not believe that they were able to make changes, placed them in these earlier stages of the cycle. It meant considerable 
work would need to be done to move them onto the next stage. This is where the benefits of the programme working individually with people as well as offering group education come to fruition.

For people at the pre-contemplative and contemplative stages (as per TTM cycle, see Table 2, p. 16) it is appropriate to give them information to raise their awareness as programme staff had been doing. Another strategy was to ask thought provoking questions rather than offering advice (Zimmerman et al. 2000). Research indicates that if people at these stages are moved to the next stage within a month, they double their chances of achieving a successful outcome within six months (Lawrence, 1999), so it is worth persisting with this education. But the pre-contemplative stage includes people who do not accept their condition or the need to act on it, so there is a danger that they will disengage from the programme if too much emphasis is placed on their condition and possible complications; hence Provider \#1's practice of gently feeding messages into everyday conversation. THONR's entire programme could not be delivered in this way though, so although it was important to create an enjoyable and non-threatening learning environment, it also had to be assumed that people had come to learn and receive information even if the message challenged them.

The findings concur with the view that the Transtheoretical Model (TTM) is a spiral rather than a cycle with people often coming back on at a higher level after relapse and being ready to try again sooner (Lawrence, 1999). Two of the study participants made significant change in the short term. Following relapse one of them seemed to re-enter the spiral at contemplation, indicating they would be able to try again quite soon, while the other experienced a significant sense of failure and embarrassment so re-entered at pre-contemplation and remained 'hoha' for months. It was important to make change for the right reasons and as a result of personal commitment though, otherwise lack of preparation was a possible reason for relapse (Lawrence) which may have been a contributing factor in this instance. 
There was also a suggestion from the clients' stories, that with chronic illness it is not so much a cycle or a spiral, but a pendulum as people often seemed to fluctuate between stages of action and relapse, at times taking one step forward, then two steps back, or ending up worse off than they had started. It seemed that many of the clients might not achieve lasting and consistent diabetes management and lifestyle change. Rather they would continue to slip towards increasingly unstable diabetes. Clearly more research is required to understand the reasons for this. These findings are in line with those of DunbarJacob (2001) who found that only $15-25 \%$ of patients improve their health practices after diagnosis with a chronic condition. Disease management is evidently very difficult to integrate into well established lifestyle patterns.

A difficulty in applying the cycle of change to diabetes management was that people were often at different stages of the cycle with different aspects of their management and that they had to make changes in a number of behaviours simultaneously. This added complexity to their change process, as was also noted by Highstein et al. (2007). However, a benefit was the ability to use the sense of self-efficacy from success in one area to stimulate change in another. Also, although clients had Maori ways of expressing their feelings and impediments to change such as being hoha or whakama, these impediments are consistent with problems experienced by people of other cultures and fit well within the stages of the change process as described by Prochaska and DiClemente (Lawrence, 1999; Zimmerman et al, 2000).

Determining the nature of the pattern of attempted diabetes management was further complicated because improving lifestyle did not require them to "give up" unhealthy behaviours altogether, so even with 'successful' change clients tended not to reach the termination stage, rather they continued to need occasional support to avoid relapse (Lawrence, 1999). Therefore determining whether people were engaged in a legitimate change cycle or swinging back and forth between action and relapse without making true progress was difficult to determine. Given all of the above factors it seems the Transtheoretical Model of Change might not be the best model to use for change in chronic illness or 
that preliminary progress has to be made before it is suitable. De Ridder, Geenan, Kuijer and von Middendorp (2008) identify physiological, emotional, behavioural and cognitive aspects to making a successful psychological adjustment to chronic illness. Without this, the authors claim clients will not be able to make lifestyle change. They suggest four strategies to stimulate such an adjustment: remain as active as is reasonably possible; acknowledge and express emotions; engage in self-management; and focus on potential positive outcomes of their illness. These stages may prove useful to the organisation in preparing clients for lifestyle change in the future.

In this study the prevalence of co-morbidities had a considerable impact on clients' ability to participate in activities and a depressing impact on their outlook, with five of the seven appearing to be depressed even though only three of them received anti-depressant medication. McEvoy and Barnes (2007) draw attention to the prevalence of depression among older adults with longterm physical conditions and propose the routine use of a depression screening tool to enable early intervention. McKellar, Humphreys and Piette, (2004) establish that depression can negatively impact patients' diabetes symptoms by reducing their ability to self-manage their blood glucose. They conclude that more aggressive management of depression among patients with diabetes should improve their physical health as well as their mental health.

Two of the clients identified stress as being a major causative factor in the onset of their diabetes and others identified a familial link to diabetes. The tendency of clients to identify extraneous factors such as stress and genetic links as being responsible for the onset of their cardiovascular disease is noted by Penney et al. (2006). They caution that this belief can lead to a hopelessness and disempowerment that is counterproductive to motivating people to make lifestyle change. This current research suggests the same is true for diabetes. 


\section{Where to from here?}

The programme in the form studied was meeting all the criteria under the six elements of the CCM model given in Table 1 on page 15 (Improving Chronic Illness Care, 2008), yet some elements could be developed further. Examples are given in the findings of formalised agreements that could be reached to coordinate care across organisations. Clinical guidelines could be more clearly embedded by incorporating use of point-of-care reminders, feedback, standing orders and other methods that increase their visibility (Hung et al., 2007). The established information system could also be used to identify relevant subpopulations for proactive care; to track particular risk factors; or for other preventive purposes, rather than simply its current focus on disease management (Hung et al.).

Other programmes facilitating client self-management have developed tools to enhance client success which may be helpful to the service. These include: the Resources and Supports for Self Management (RSSM) framework which references a range of useful tools (Fisher et al., 2007b); the Self-Management Goal Cycle (SMG) (Langford, Sawyer, Gioimo, Brownson, \& O'Toole, 2007); and the 5 A's Behaviour Change Model (Glasgow, Davis, Funnell, \& Beck, 2003). Another approach is integrating models applying stage appropriate interventions to the TTM model (Lawrence, 1999; Zimmerman et al., 2000).

\section{Revisiting initial propositions}

Several propositions were identified at the commencement of the study, these included the expectation that some participants would demonstrate an improvement in physiological outcome measures and most would demonstrate improved knowledge about their condition and the change process and have moved towards successful lifestyle change. These propositions regarding physiological outcome measures held true for some of the participants for a period of time during the programme when they were motivated to make lifestyle change, but sustaining the improvement proved difficult and overall the average for most measures was the same or slightly worse at the end of the 
study. All participants identified improvements in knowledge and action related to diabetes management and lifestyle behaviour, but they were not always able to maintain the changes. Research has indicated that change in knowledge alone is not strongly related to successful behaviour change (The Health Foundation, 2008).

Although the physiological outcome figures for the whole group, over the year of the study were disappointing, they are not surprising given the complexity of some clients' health issues. The pattern of participants making successful change while actively engaged with the programme, yet relapsing once this had stopped, demonstrated that clients need ongoing support (Fisher et al., 2007a). Improving Chronic Illness Care (2008) recommend maintaining ongoing internal and community support through case management and provision of support groups (Improving Chronic IIIness Care). How to balance this with an overall objective of client self-management and independence is the challenge, as research has indicated that people with chronic illness are most successful when they reach the level of independently managing their own condition (Fisher et al., 2007b; The Health Foundation, 2008).

\section{Part 2: Perspectives on partnership - insights from the process}

A distinguishing feature of this study is that it involved my role as a Pakeha researcher seeking to gain an understanding of the functioning and effectiveness of a programme that was essentially developed and delivered by Maori for Maori. This was an innately challenging situation that required those involved with THONR to trust that this process would yield worthwhile findings despite the obvious challenges in working with a researcher who brought a different cultural perspective and who lacked a deep understanding of the importance of tikanga. The risks, benefits and learnings concerning the research from THONR's point of view have not been canvassed. This section defines and encapsulates some of this learning from my perspective as a Pakeha nurse researcher in this partnership. The section also reflects on other research issues and insights that were gained through conducting this study. 
A fundamental requirement when conducting this research was it be "culturally safe" for all concerned. This involved addressing Kearns and Dyck's (2005) requirements for conducting culturally safe research such as; respecting the cultural knowledge, values and practices of others; having awareness of one's own way of seeing and doing and, analysing the effect of our actions on the knowledge that is produced. The following section explores the process of conducting and reporting this research with these key processes in mind.

\section{Setting the groundwork - the importance of open communication}

All aspects of my involvement with the programme were considered and negotiated in a series of meetings between the MDNE and myself, including the decision that it was most suitable for me to be an 'insider' to the sessions in a participant-observer role. This consultation process revealed that what was initially interpreted as a shared understanding wasn't necessarily so, but misunderstandings could be readily resolved if relationships were open and comfortable. An example was the miscommunication which led me to produce study tools and documents that were ultimately agreed to be unnecessary. The initial misunderstanding was compounded by the difficulty of scheduling regular meetings, which would have identified sooner that unnecessary work was being done. The deeper understanding and trust that developed through the process of resolving such issues were important steps in the development of the open relationship that came to exist between us.

Another aspect of this cross-cultural communication was that it added an additional dimension of uncertainty when communication was not clear. For example I initially experienced insecurity regarding whether the MDNE and the manager wished to continue with the research if calls were not answered in a timely fashion. Following an open conversation with the MDNE I realised that a lack of response to phone calls was about workload and other commitments rather than lack of interest and both the MDNE and manager were as committed to the study as I was. From that point on this ceased to be an issue 
for me. This situation also highlighted that both main parties to the partnership had very busy lives, so were not always able to maintain contact or attend scheduled meetings. This was another area where it was important for both partners to be flexible.

\section{Cultural interpretations of time}

Meleis (1996) refers to the need to provide evidence of flexibility with time in culturally competent research, as this is a construct open to cultural interpretation. I was aware of this necessity while conducting the study, both in the planning meetings and in stakeholder interviews. However, there were some occasions when time constraints did have an impact, particularly when interviews took much longer than I had anticipated. Time constraints could also impact the consultation process. Completion dates were set with partnership consultation time factored in, but if writing deadlines were not met, this compressed the time available for consultation. The process highlighted the importance of allowing extra time for consultation to protect against this eventuality. Some delays ultimately produced a better result though, for example the client enrolment form which was going to be filled in by the MDNE was eventually completed as a group activity for some participants. This meant they could see exactly what data were being collected on their health, a good example of informed consent.

\section{Complexity of cross-cultural communication}

Certain consultative processes also required sensitivity; for example finalising the contract between the research partners; explaining the study; and gaining stakeholder consent to participate. In these situations the difference in ethnicity seemed to add another dimension to what was already an ethically difficult situation. This was due to my awareness that cultural mores might affect people's responses and that what appeared to be tacit assent could in fact be a polite refusal, when not backed up by action, as in a willingness to sign a consent form. Consequently the consenting process was often not concluded until the MDNE had approached the client privately and assessed their 
preparedness to be involved in the study. Even though this raised the ethical issue of the person being studied enrolling participants; it seemed to be the best way of ensuring true informed consent without coercion.

In my reflections on what this research required of me, my ethnicity was always a significant consideration, yet in my dealings with the actual stakeholders in the study it rarely felt like an issue. Most people were very open in their communication in general, and their preparedness to explain their interpretations of words and concepts I was unfamiliar with, without this I would not have felt able to conduct this research.

In terms of communicating with participants, I preferred to do this in person rather than by telephone, but I also found it helpful sometimes to write information down in letters. This was a practice that developed gradually while recruiting people to the study. I believe it appealed to some participants as it gave them time to study and consider information. My experience was that they were usually very receptive when I contacted them to follow-up. I used this approach selectively though, as it seemed generally preferable to communicate kanohi ki te kanohi (face-to-face).

\section{Attending to that which is pertinent}

Regarding Smith's aforementioned warning that researchers "have the power to distort, to make invisible, to overlook, to exaggerate and to draw conclusions, based not on factual data, but on assumptions, hidden value judgements, and often downright misunderstandings. They have the potential to extend knowledge or to perpetuate ignorance" (1999, p.176). Another dimension was added to this responsibility in this context because somehow I, with my Pakeha understanding had to recognise and analyse the salient features of the data for the stakeholders and for the programme. Therefore, given my limited Maori cultural knowledge it was not appropriate to explore the meanings of Maori concepts such as whakama and hoha or the wider significance of tikanga in the programme, rather I chose to consider how these features shaped the 
programme, whether that meant providing something people could not access elsewhere and whether recognised concepts/models such as the cycle of change were relevant to this group of clients and programme.

\section{Conducting culturally safe research}

Another factor I was acutely aware of was the power differential between myself as the researcher and the participants. I attempted to address this imbalance by entering into a negotiated partnership, being open and transparent in my dealings with stakeholders and making the draft thesis available to stakeholders for input and clarification prior to finalising its content. During the group education sessions I participated in the group, asked questions so that participants could see that I did not hold all the knowledge myself, and tried to find ways to share knowledge without flaunting it or appearing paternalistic. In terms of the success of this approach, I drew some comfort from one participant's interview comment that they appreciated my input into the group education sessions because I came across as wanting to learn too.

Around interviews I often felt that I was taking and not giving anything back, I would take koha, but this did not feel like sufficient reciprocation. I was aware that I had the vested interest in the research, as it should lead to a Master of Nursing qualification for me, so I had to constantly balance my desire for a successful outcome with the organisation's and participants' need to have their interests protected, while receiving useful information about the programme and the needs of the clients. Among my personal hopes was the opportunity to see the educational tool I had developed (Janssen, 2006) used on the programme, but again it was important that such use be appropriate to the needs of the clients.

Finally undertaking culturally appropriate processes means leaving participants no worse off than when you entered their home, but in addition ensuring that the research outcomes are strongly recommending positive changes (BevanBrown, 1998; Walsh-Tapiata, 2003). In terms of leaving clients no worse off I 
can report that relationships with all participants that I have met subsequently have been very warm and that I have not received any reports of participants feeling damaged or disadvantaged in any way as a result of participating in the study. Regarding recommending positive changes the study affirms much of what the organisation is already doing and furthermore makes a number of recommendations that should further enhance the service being offered. Regarding reciprocity in reporting back, as the thesis goes to print the date is set to report back to the organisation and the community.

This section has outlined many of the insights gained by the researcher in this cross-cultural partnership. One of the key conclusions is that being of a different ethnicity to most stakeholders adds an extra dimension and another area for potential misunderstanding and misinterpretation to all aspects of study development, conduct and writing up. But also that much of this can be overcome by having an open and comfortable relationship with partners, so that information can be shared without either party feeling diminished by the experience.

The next chapter looks at these and other findings and conclusions to determine what contributions this case study evaluation of a nurse-led diabetes programme for Maori makes to knowledge about service provision in that area. 


\section{Chapter 7 - Conclusion}

The study confirmed many of its original propositions, at least in the short-term, but more importantly it makes three significant contributions to knowledge in this research area. Firstly it tells us about the experience of making change while dealing with co-morbidity and allows us to consider whether the experience of Maori people is similar in this respect to that of other groups. Secondly it provides insights into the way this by Maori for Maori service meets the needs of the local community, as little prior research has looked in-depth into the functioning of small Maori health providers such as Te Hauora O Ngati Rarua (THONR). Finally it demonstrates the way a Maori Diabetes Nurse Educator (MDNE) role has been operationalised within one programme. The MDNE position is an example of a primary health care nurse role, which is a relatively new innovation for the New Zealand health system. An additional benefit of the study is the insights gained into the process of a Pakeha researcher working in partnership with a Maori organisation. This knowledge may prove helpful to other researchers considering a similar project.

The study has taken some time to conduct and write up. In the intervening period the programme has already changed in ways that reflect some of the recommendations. Hopefully some of the other suggestions will prove useful in the programme's further development. Mainly this study serves as an affirmation that the programme is offering an important service and making a difference to people's lives. It also identifies that change happens gradually so it is important to keep people engaged with the service while that slow process is played out.

\section{Original propositions revisited}

The research set out to explore the effectiveness of this nurse-led diabetes and heart disease programme for Maori clients, in terms of identifiable improvements in physiological outcome measures, knowledge, diabetes monitoring and lifestyle behaviours. Other objectives included identifying how and why it was successful, as well as the salient features of having diabetes 
and attending this programme. The final aim was to identify the programme components most useful to participants and to make recommendations of possible improvements to the programme.

In terms of the initial propositions that some participants would demonstrate improved physiological outcome measures: blood glucose, HbA1c, BP, cholesterol profile and weight; the outcomes were varied. Improved physiological outcome measures were evident for some participants during periods of focused lifestyle change, illustrating that it is an achievable objective. Generally though, participants were unable to maintain this progress long-term, especially when they were receiving less input and self-management support. These findings are consistent with those of other studies into diabetes programmes internationally and confirm the importance of ongoing professional and peer group support (Deakin et al., 2007; The Health Foundation, 2008; Vermeire et al, 2005).

As expected, all participants demonstrated better knowledge related to diabetes, cardiovascular disease and risk factor management and most demonstrated better awareness of behavioural change processes. However several participants commented that although they knew what they had to do, actually doing it wasn't so easy. These findings support stage based models of change, such as the Transtheoretical Model (TTM) and holistic and structural approaches to making change rather than the medical model, which assumes that once knowledge is obtained people can make and sustain change on the basis of knowledge and reasoned action. A staged approach recognises the ups and downs of the process of making change.

The third proposition, that participants would report the programme is culturally appropriate, supportive and beneficial to their health objectives, was found to be supported. The atmosphere, wellness approach and whanaungatanga in particular, were appreciated by all participants. What this study suggests is different about this programme compared to others available in the region, is the sense of community, which is strongly influenced by Maori values and staff 
attributes, such as the use of self-deprecating humour. Being part of a community allowed clients to feel safe, to reveal their inadequacies yet remain engaged and supported so they could work on lifestyle change when they felt ready. This programme does not need to be viewed strictly as 'for Maori' though, because it was very comfortable for all concerned, including Pakeha such as myself, and the educators from other organisations. Thus it was true to Maori values and protocols without alienating those who are less familiar with those aspects.

Although these initial propositions in terms of successful lifestyle change were confirmed for a time at least, as the study progressed the complexity of clients' health status became apparent. One key revelation was that for several participants diabetes proved to be the least of their problems as the impact of their other co-morbidities became apparent. Among these, depression (a common finding with chronic illness) appeared particularly debilitating as it lowered participants' motivation and self-efficacy regarding their ability to selfmanage their diabetes and make lifestyle change such as increasing activity. This left participants disempowered and disinterested and generally of the view that the locus of control was external to themselves, often with the doctor or other health professionals. Another finding that was potentially disempowering for participants was the tendency to blame stress and genetics for the onset of their diabetes. Therefore clients should be encouraged to focus on what they can do for themselves rather than blaming factors they have little control over.

\section{Relevance of Chronic Care Model and Transtheoretical Model}

The Transtheoretical and Chronic Care Models are well accepted and widely used, both internationally and throughout New Zealand. In the current study the models allowed the features of the programme to be described and evaluated. In addition to the findings fitting with stages of the TTM model, what was also revealed was that clients had culturally-driven perspectives on their progress with aspects of their diabetes management and lifestyle behaviour. Other complexities when dealing with multiple chronic illnesses which impeded clients' 
ability to readily commit to change, and which impacted the usefulness of the model were also evident.

The Chronic Care Model was found to provide an excellent framework to direct the evaluation of the programme and to guide recommendations. The programme generally seemed to be meeting the criteria for the six elements of the model. International programmes and research based on the CCM model provide helpful recommendations to guide further development of the programme.

\section{Taking responsibility}

Exploration of the findings yielded many interesting discussion points regarding the impact of the dominant discourse of personal responsibility for health status in this setting. This study demonstrates how this societal expectation is played out in the experience and reactions of clients being told they need to make lifestyle changes. One point in particular was the interplay between the participants' descriptions of feeling whakama and hoha and the implicit and explicit ways they were often told that change was in their own hands, thus implying they were responsible for their own condition. "Taking responsibility" was problematic because it was simultaneously a necessity, a motivating factor and an impediment to making change, depending on the client's situation and mindset at the time. Another related consideration was that personal responsibly is synonymous with Pakeha cultural values of individualism and self-advocacy, and alien to traditional Maori values of collective responsibility. Focusing on rangatiratanga or Maori self-determination would be a more appropriate approach when trying to motivate people to change (Jansen \& Smith, 2006).

Another issue the research and literature search highlighted is the need to balance the development of self-management and independence with the ongoing need for professional and peer-group support and education. The study clearly highlighted the importance to clients of regular support groups. Other 
research has indicated that peer-driven groups can be helpful, but ongoing professional support is particularly important for establishing and maintaining self-management in chronic illness (The Health Foundation, 2008). The changes in the format of group education since the study, from the diabetes course to the monthly Whanau Hui is in keeping with this focus on chronic illness. Steadily increasing attendance at these hui suggests they are acceptable to clients and meeting a need for them.

\section{Unique programme contribution}

The study confirmed some previously identified barriers to Maori accessing health care, particularly transportation and cost. The programme staff's efforts to address these barriers resulted in increased attendance and participation by clients. Staff were also able to negotiate between clients and other health providers and service organisations to increase clients' access to those services. Thus staff went to considerable lengths to keep clients engaged and remove barriers to participation and lifestyle change. But the study also demonstrated that even when such barriers are removed, there may still be a drop in attendance, with the reasons for that being a mixture of personal issues, aspects of the programme and other unidentified factors. This drop in attendance is not unique to THONR though, for example Provider \#3 commented that clients tended not to access their full entitlement of three free appointments with that provider's service.

The findings suggested that the staff were very skilled in a number of areas including moving between the Maori and Pakeha "worlds". Although staff had some common approaches such as the use of humour, they also all had their individual ways of working with people. The study provided further evidence of unfunded extra work by staff, which could be viewed as a personal, professional and cultural commitment. In this example the unfunded work included undertaking additional clinical work in the interests of reaching Maori. Earlier writers such as Boulton (2005) have noted the invisible personal and cultural work of Maori health providers. 
Staff were trying to work with some conflicting objectives, namely simultaneously maintaining whanaungatanga and professional relationships while also providing a cost-effective service. This was identified in the current study as a pressure for this Maori health provider, which mainstream services do not need to address to the same extent. The latter can focus on maintaining professional relationships and cost-effectiveness above all other considerations. Also, whanaungatanga was just one example of the extra expectations placed on Maori organisations. The research thus provides additional support for the need for contracts to be

flexible enough to recognise that Maori (mental) health providers are bound by another set of 'rules' beyond those which apply universally to all health services DHBs will need to be mindful and respectful of local kawa and tikanga if they are to understand aspects of Maori service delivery. Boulton, 2007, p. 140

This study led to an understanding of some of the intricacies of service provision in the Maori health sector, including identifying a number of contractual issues such as overlapping and cross-subsidisation of contracts. These issues were explored briefly while interpreting the findings; but they constitute an interesting area for further research, especially in a study that has a contracting focus. Other contractual issues identified included the MDNE having to advocate for her clients to ensure they received services they were entitled to or having to provide services herself that the GPs were funded for. This suggested that a small organisation offering a targeted service to a fixed population in an integrated service environment, would inevitably have to initiate many of the contacts. Apart from generic drivers to contracting, more information is needed about drivers for specific contracts. These are issues that should be addressed in future contractual negotiations. Also the lack of a size limit to the diabetes and screening registers could impact the quality of service if the registers continue to grow.

The NZ Primary Health Strategy 2001 (MOH, 2001b) set a new path for health care with a greater focus on community involvement and Maori providers in 
primary health care, as a means of addressing the ongoing ethnic inequalities in health. The development of primary health care nurse roles such as the MDNE position is fundamental to the successful implementation of the strategy. This study demonstrates the key contribution a nurse-led service can make in providing and co-ordinating a programme that is proactive rather than reactive, providing continuity of care and helping to manage people in the community, thus reducing their need to access secondary services.

Teamwork was identified as an important aspect of the service as team members educated and supported each other. They each brought their own skills and knowledge to the multi-disciplinary team, which enabled them to be creative and innovative in finding solutions to problems. This was generally a benefit of the service, but it was also noted that the MDNE made a unique contribution to the programme, due to her superior knowledge and experience in the area of diabetes, which could not be replicated by any other member of the team.

\section{Insights into the partnership process}

This study is an example of a Pakeha researcher working with Maori providers to achieve goals that are important for both parties. The process of designing, conducting and writing up this study provided many interesting insights into the process of Maori and Pakeha working in partnership. These insights included the importance of good communication channels with regular face to face meetings and having a comfortable relationship with research partners so that any misunderstandings could readily be clarified and resolved. Being of a different ethnicity appeared to add another level of complexity which had to be considered in all contacts. Other considerations were the appropriate role to take in such research in terms of being inside or outside the programme and education sessions, and the need to take a flexible view on time.

The need to conduct culturally safe research overlaid the whole process with the understanding being that no one was to be left worse off as a result of 
having participated. Maintaining cultural safety also meant being aware of and addressing power differentials between the researcher and participants. Reciprocity in terms of sharing was an important concept during data collection and report-back and as an ongoing obligation to stay involved with the community following study completion.

The main conclusions of the study confirm that this service is meeting a special need for Maori clients and providing a service that they could not receive from mainstream services. This was due to a combination of cultural values and practices and the personal qualities of the staff members. An important feature was the ability to keep clients engaged with the service, even if they weren't ready to make changes at that stage. The study highlighted the complexity of people's day to day lives when they tried to make changes despite being affected by multiple chronic conditions. It also indicated that it was possible to make significant change and demonstrate an improvement in physiological measures when people were committed and believed that change was important. It also indicated that the balance between providing professional support and withdrawing to encourage independence was a difficult one to get right.

The study reinforces the importance of continuing with Maori service provision, despite the numerous challenges for the sector. It affirms the objectives of rangatiratanga in allowing Maori to determine what services are most appropriate for their people. The study demonstrates the effectiveness and commitment of Maori nurse-led health services and underlines the importance of continuing Maori health workforce development, because Maori clients do have a unique understanding and rapport with Maori health staff. 


\section{Appendices}

\section{Appendix A - MDNE Service Specifications \\ Maori Diabetes Nurse Educator \\ DIABETES EDUCATION AND MANAGEMENT \\ SERVICE SPECIFICATION}

\section{Introduction}

Diabetes is a direct cause of symptoms, which can lead to death, but the significant burden of the disease (and the majority of costs) relates to the development of complications that typically lead to hospitalisation or death.

Diabetes is a health Gain Area for Maori and is one of the thirteen New Zealand Health Strategy action priority objectives for population Health. The Nelson Marlborough District Health Board (NMDHB) has signalled that this is a significant priority in its District Annual Plan.

Prevalence, morbidity, and mortality rates from diabetes are all higher in Maori than in people of European origin. Maori have increasing and rapid morbidity and mortality particularly from 40 years onwards this is a very different pattern to non-Maori and requires differing strategies

Future trends for the Tasman, Nelson and Marlborough region suggest that the Maori population will almost double from 9,500 in 1996 to 17,200 in 2021, and a further trend indicates that in twenty years Maori people with Diabetes will nearly double.

The NMDHB is aware of these significant projections and acknowledges the need to develop strategies aimed to lesson the degree of impact these factors will have on the Maori Diabetes status in Te Tau Ihu O Te Waka A Maui in the future.

Diabetes is a huge problem for New Zealand but the impact of diabetes is substantially preventable.

\section{Impact of Diabetes on Maori}

Diabetes is a progressive and chronic disease that potentially affects every organ in the body.

Maori people are younger at diagnosis, have greater obesity, poorer diabetes knowledge and poorer glucose control. The complications of Diabetes include 
cardiovascular disease (heart attack and stroke), eye disease (retinopathy, blindness and cataract), foot disease (chronic ulceration, infection, amputation and neuropathy), and renal disease (renal failure potentially leading to dialysis and transplantation).

Any attempt to reduce the disparity of health outcome for Maori must focus on these problems, and their impact should be monitored and actively managed.

\section{Definition}

This service specification for 'Education and Management' refers to programmes that provide the skills necessary for people with diabetes to support lifestyle change and self-management of their diabetes.

The services provided are primarily for Maori but do not exclude people of other cultures.

\section{Service Objective}

The provider shall seek to improve Maori health gain through the provision of a Specialist Maori Diabetes Nurse Educator (MDNE) service that will primarily focus on early intervention initiatives, screening (general population and during pregnancy) and education around optimum self-management of diabetes.

The MDNE must have a good understanding of Maori profiles of risk, Maori models of heath and Maori best practice guidelines.

Collaborative approaches with key organisations is recognised as a key aspect of the programme, so that whanau receive the full range of primary and secondary care to enable them to manage and improve their diabetes status

The objective of this service is to allow for broad and innovative approaches to diabetes education and management to Maori. Diabetes tends to be described holistically by Maori, therefore whanaungatanga or the understanding of 'how' Maori form relationships and make connections with people is vital to achieving health gain for Maori.

A good understanding of Health Promotion strategies and programmes is an essential component of the service to ensure preventative strategies are considered and supported as priority interventions for achieving whanau ora.

\section{Service Environment and Key Service components}

People with diabetes need to manage lifestyle changes and medical treatments to reduce their risk of developing complications. A self-management focus should be encouraged as soon as people are identified as having diabetes or identified as being at high risk of developing diabetes, e.g. Impaired Glucose Tolerance (IGT). 
The MDNE role is focussed on ensuring that Maori whanau with diabetes, receive the full range of primary and secondary care to enable them to manage and improve their diabetes status. These services include:

\section{a) Free Annual Checks}

General Practitioners are funded on a" fee for service" basis to complete Free Annual Checks and Treatment Plans for people with diabetes.

Free Annual Checks have several potential benefits:

- $\quad$ Early detection and treatment of any complications

- Review and update the treatment and care plans with the person with diabetes

- $\quad$ Treatment and/or referral to a specialist if appropriate

- Update information in General Practice diabetes register

- Monitor the effectiveness of diabetes services

The General Practice treatment plan should be integrated into a multidisciplinary team plan with treatment and management targets that are owned by the individual (whanau and caregivers as appropriate.)

\section{b) Mainstream Diabetes Education and Management services and} Specialist services (mainly hospital based).

Referrals to this service tend to be for more difficult to manage type 2 diabetes and cases where complications have arisen. Many type 1 Diabetes patients are also referred to this service including all children. On referral into the service people with diabetes should be offered an education and management programme within three months. If on-going demand for education and management services cannot be met, referrals should be prioritised to ensure patients with the greatest need are seen within the resources available.

The aim is to reduce diabetes complications and diabetes admissions to hospital whilst promoting diabetes self-care to clients using the service.

The key nursing services to be provided are:

- $\quad$ Health assessment, care planning and monitoring

- Health education and healthy lifestyle planning

- Health screening and monitoring

- Health service referrals

- Health care support and follow up

- Health care integration and co-ordination

- $\quad$ Develop and maintain a register that identifies individuals with a diagnosis of diabetes 


\section{d) Local Diabetes Teams (LDTs)}

These have been established to cover every District Health Board (DHB) area in New Zealand. The primary objective of LDT's is to identify the problems and opportunities for improvement in overall services for people with diabetes.

The local Diabetes Team must have a specific focus on improving the needs of Maori and others at high risk of diabetes. The three main strategic goals for Maori health gain are - greater Maori participation, Maori provider development including workforce development, and sector enhancement. An annual report developed by the LDT must describe how the LDT has contributed to these strategic areas.

\section{e) Maori services with Diabetes components (e.g. Whanau Ora, Mobile Disease State Management)}

These are community-based services, which through Nursing and Kaiawhina roles assist and advise Maori to manage their diabetes and assist them to access other services through service contracts including Whanau Ora and Diabetes Management.

\section{f) Maori Diabetes Nurse Educator}

This is a Maori population focussed service providing the same services as the mainstream Education and Management service. For up to two days a week, this service is to be provided at the hospital as part of the mainstream diabetes team. This will both enable improved services to be provided to Maori in the hospital context as well as having the benefit of providing collegial support and training for the MDNE. For the remaining time per week, the service is to be provided in the community.

The MDNE must ensure co-ordination of necessary primary and secondary care, GP care, diabetes annual review, nutrition advice, podiatry services, eye screening, etc for each individual client to ensure effective diabetes management according to best practice guidelines.

The MDNE must be a registered nurse who has, or is prepared to work towards an appropriate qualification in diabetes education/specialist care.

The MDNE will play a key role in the development and implementation of Maori specific best practice guidelines into the Primary Care Teams practice culture.

The MDNE role should be developed to best meet the needs of the target group. Programmes may be one on one or in groups. Services should include education and follow up programmes for:

- People referred after initial diagnosis of type 2 diabetes

- People with type 2 diabetes starting insulin injections

- People with poor diabetic control

- People with type 1 diabetes

- People identified with Impaired Glucose Tolerance 
- Nutrition advice and foot care advice (not otherwise provided in dietician and podiatry purchase units)

- $\quad$ Support for people with gestational diabetes

- Specific clinical indications on referral by primary or secondary providers

- Psychological support in growing up with diabetes particularly during adolescence

The MDNE provider should have a system for contacting people who fail to attend a programme, and notifying their primary health care provider, e.g. General Practitioner, Maori Health Provider.

The MDNE provider could consider providing support to other diabetes health professionals particularly in regard to the development of services that are culturally appropriate for Maori.

The MDNE service is to focus on people at various stages in the progression of diabetes in the following ways:

\begin{tabular}{|l|l|l|}
\hline Pre- Diabetes & Diabetes & $\begin{array}{l}\text { Diabetes and } \\
\text { complications }\end{array}$ \\
\hline $\begin{array}{l}\text { Health promotion and } \\
\text { Primary prevention }\end{array}$ & $\begin{array}{l}\text { Diagnosis and medical } \\
\text { Treatment }\end{array}$ & $\begin{array}{l}\text { Specialist care or } \\
\text { review }\end{array}$ \\
\hline Early detection of diabetes & $\begin{array}{l}\text { Early detection of } \\
\text { Complications }\end{array}$ & \\
\hline
\end{tabular}

Advice and support

"Education and Management"

An electronic database must be maintained with a register of people with diabetes enrolled in the education and management programme. The information should be recorded as specified in appendix A.

The MDNE service will support the Local Diabetes Team and work with other providers to enhance quality and continuity of care for Maori people with diabetes. The service will provide the information listed in Appendix B to the LDT to enable it to monitor the operation and integration of diabetes services in the DHB region, and develop recommendations for improvement. 


\section{Entry and exit criteria}

\subsection{Entry criteria:}

There will be no restrictions on who can refer Maori people with diabetes to the

Primary Care Team for follow up advice, education and management support

The MDNE should be notified of all referrals for Maori and should carry out the initial follow up visit to identify the clients needs based on a clinical and cultural assessment.

This service is aiming to reach those clients and whanau who require information and support to effectively manage their illness.

If clients are currently managing their diabetes effectively as assessed by the MDNE or other members of the Primary Care Team, then they will receive minimal follow up.

\subsection{Exit criteria:}

Exit criteria for Maori utilising health services requires further development to ensure cultural aspects of care are carefully considered within exit criteria policy.

Holistic care for Maori goes beyond the realms of clinical care, for example tautoko, whanaungatanga and manaakitanga are recognised as concepts of wellness in Te Ao Maori, therefore exit criteria as defined in Te Ao Pakeha may not be seen to be appropriate for some whanau.

Exit criteria for clients managed by the MDNE must be developed and agreed upon with the individual.

\section{Outcomes Sought}

- $\quad$ Early identification of clients with diabetes

- $\quad$ Effective early primary care management of diabetes

- Improved early access to specialist services

- $\quad$ Increased number of clients with completed Annual Review

- Increased access to retinal screening

- Increased access to podiatry services

- $\quad$ Reduced hospital admissions for unstable diabetes 


\section{Settings}

The service will be provided in an outreach style from the Maori provider base locality and programmes will be delivered in settings most appropriate to reach clients, inclusive of but not limited to:

- Clients home

- Maori Health Provider

- Marae based

- Work based

- $\quad$ Clinic setting

- Hospital based

- Outpatient clinics

Other community settings as appropriate to the client

The MDNE will ensure Maori pathways to and through care for diabetes are identified and actively monitored for effectiveness, eg, referral to specialist services, non attendance at outpatient clinics, opportunistic screening.

Considerations in determining the setting should include (but not be limited to) issues such as: cultural appropriateness, accessibility and most effective/efficient use of resources.

The education and management services may provide provision for distance learning.

It is particularly important to reach individuals and groups who have difficulty in gaining access to services:

- people living in a rural location

- $\quad$ people whose ethnicity, culture or language may present barriers

- $\quad$ people who might not see themselves as able to be partners in their own care

\section{Service linkages}

To achieve continuum of care for clients the MDNE will need to develop formal relationships with a range of service providers and have written protocols that set out how the organisations will work together.

The service must maintain effective linkages with the following groups:

\section{Locally}

- Maori Health Providers

- Rongoa Maori practitioners 
- Maori Smokefree and smoking cessation programmes

- Maori physical activity and sports promotion programmes

- Sport Tasman/Marlborough re: Green prescription

- General Practitioners and Practice nurses

- Diabetes nurse educators/specialists

- Diabetes Physicians

- Dieticians

- Retinal screening service

- Diabetes Society

- Podiatrists

- Hospital Health services

- Local Diabetes Team

\section{Nationally}

- $\quad$ Te Hotu Manawa Maori

- Te Roopu Mate Huka

\section{Quality requirements}

\subsection{Service Quality}

The service is required to comply with the General Terms and Conditions and the Provider Quality Specifications of this Agreement.

\subsection{Service Establishment}

It is agreed between NMDHB and South Link Health Ltd that this is a new service and an establishment phase will occur. As part of the establishment of this service, the following deliverables and milestones will be met within the first six months: 


\begin{tabular}{|c|c|c|}
\hline Establishment of service & Timeframe & Report Due \\
\hline $\begin{array}{l}\text { 1. Service scope including: } \\
\text { - Purpose } \\
\text { - Aims/Objectives } \\
\text { - Service Function } \\
\text { - Service Coverage } \\
\text { - Expected Outcomes }\end{array}$ & $\begin{array}{l}\text { Progress } \\
\text { report } \\
\text { Final report }\end{array}$ & $\begin{array}{l}20 \quad \text { March } \\
2005 \\
20 \text { June } 2005\end{array}$ \\
\hline $\begin{array}{l}\text { 2. Infrastructure/Systems development } \\
\text { - Develop internal infrastructure to } \\
\text { capture } \\
\text { data } \\
\text { - Develop internal systems, procedures } \\
\text { and guidelines to assist service delivery } \\
\text { - Develop a method that evidences/ } \\
\text { captures an individual/whanau under- } \\
\text { standing of diabetes (eg questionnaire: } \\
\text { outcome Improved understanding') } \\
\text { - Develop a method to capture and report } \\
\text { individual physical/nutritional progress to } \\
\text { be } \\
\text { reported annually }\end{array}$ & $\begin{array}{l}\text { Progress } \\
\text { report } \\
\text { Final report }\end{array}$ & $\begin{array}{l}20 \quad \text { March } \\
2005 \\
20 \text { June } 2005\end{array}$ \\
\hline
\end{tabular}

\section{Reporting Requirements}

\subsection{Purchase code}

Diabetes Management - Maori MAOR 0106 
11.2. Information Reporting Requirements

\begin{tabular}{|c|c|c|c|}
\hline $\begin{array}{l}\text { COGP00 } \\
09\end{array}$ & $\begin{array}{l}\text { Diabetes } \\
\text { Education } \\
\text { \& Management }\end{array}$ & $\begin{array}{l}\text { Quarter } \\
\text { ly }\end{array}$ & $\begin{array}{l}\text { Brief narrative report including } \\
\text { service activity update, } \\
\text { concerns/issues and any apparent } \\
\text { trends in patient } \\
\text { management/health outcome. } \\
\text { Electronic dataset (subset of } \\
\text { data collection as detailed in } \\
\text { Appendix A) including: NHI; } \\
\text { Ethnicity (Maori, Pacific, Other); } \\
\text { Age; Gender; and in addition } \\
\text { patient Address (geo-coding format). }\end{array}$ \\
\hline & $\begin{array}{l}\text { Diabetes } \\
\text { Education } \\
\text { \& Management } \\
\text { for whänau }\end{array}$ & $\begin{array}{l}\text { Quarter } \\
\text { ly }\end{array}$ & $\begin{array}{l}\text { A narrative report including service } \\
\text { activity update, number of education } \\
\text { sessions provided, number of } \\
\text { education packages developed, } \\
\text { whänau satisfaction, evidence of } \\
\text { increased understanding of diabetes, } \\
\text { examples of prevention strategies } \\
\text { implemented and in practice by } \\
\text { whänau. } \\
\text { A narrative report that identifies } \\
\text { intersectoral relationships, } \\
\text { collaborative/ innovative approaches } \\
\text { and or activity. } \\
\text { Electronic dataset including Ethnicity } \\
\text { (Maori, Pacific, Other); Age; Gender; } \\
\text { address and in addition relationship } \\
\text { to patient. }\end{array}$ \\
\hline $\begin{array}{l}\text { COGP00 } \\
09\end{array}$ & $\begin{array}{l}\text { Diabetes } \\
\text { Education } \\
\text { \& Management }\end{array}$ & $\begin{array}{l}\text { Annuall } \\
y\end{array}$ & $\begin{array}{l}\text { Narrative report (as part of service's } \\
\text { annual report). }\end{array}$ \\
\hline
\end{tabular}

* Ethnicity is recorded as is perceived by the whanau/family. People may therefore perceive themselves as belonging to more than one ethnic group. Ethnicity is to be reported according to the following priority system; if perceived ethnicity includes:

- Maori, report as Maori,

- Pacific, report as Pacific,

- $\quad$ Otherwise, report as other

\subsection{Reporting to Local Diabetes Teams}

The aggregated information that must be reported annually to Local Diabetes Teams (LDT) is listed in appendix B. Local Diabetes Teams may choose to analyse or present extra information differently, but the core information must be provided as specified in the appendix B. 


\subsection{Annual Reporting Requirements}

The service must provide an annual report to the LDT by November 30 each year as a basis for its annual report on diabetes and diabetes services in the area. The report must include:

- General issues/highlights and concerns etc

- The professional resources provided by full time equivalent staff or total funding (whichever is more convenient) for nurse educators, podiatrists, and dieticians separately

- Training needs analysis and planning undertaken to meet ongoing staff training need.

- A review of the provision and education and management services

- Report on utilisation of education and management services by Maori and Pacific people

- The information required in appendix B

- Provision of an annual outline of plans/intentions for the coming year, aimed at addressing the opportunities and concerns identified.

This report should be included in the LDT report, that needs to be completed by 14 February each year.

\section{Additional Clauses}

\subsection{Confidentiality}

This service must comply with the confidentiality provisions set out in legislation and relevant codes, including the Health Information Privacy Code. 


\section{Appendix B - Programme documents}
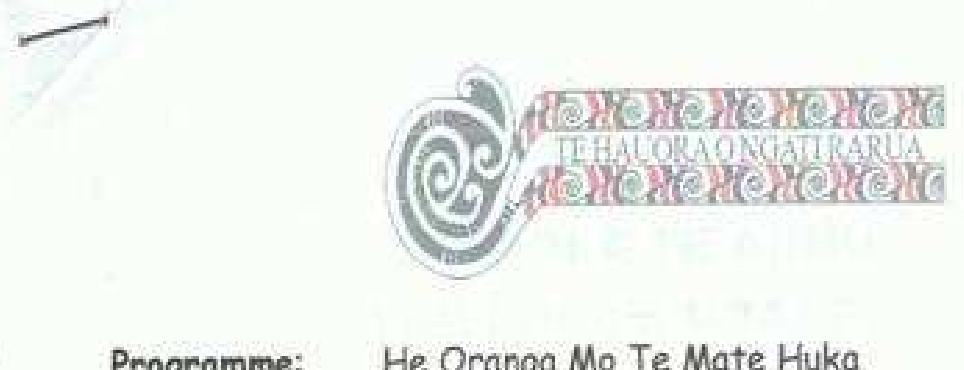

Programme: He Oranga Mo Te Mate Huka Wellness with Diabetes

Aim: To reduce the incidence and impact of Moori diabetes in Marlborough to enable whanou:

Te Hikoi O Nga Mokopuna

To walk with our grandchildren.

Objectives:

- To provide an educational program which promotes wellness and self management of Type 2 diabetes

- To use Whanaungatanga as a model to deliver health education, health promotion and diabetes self-management.

- To promote regular health checks

- To promote healthy eating and physical activity

- To increase awareness and use of diabetes services available

\section{Sessions: 2.5 hours/ 1 day/week for seven weeks: \\ Whanaungatanga Date: $17 / 05 / 2006$ Time: 2pm-4.30pm}

Venue: Poumanawa Oranga: 19 Henry St, Blenheim

Day One: What is Diabetes?

Day Two Lifestyle changes

Day Three Preventing \& Managing Complications

Day Four Healthy Kai Choices

Day Five Supermarket Tour

Day Six: $\quad$ Your partners in Diabetes Care

At completion of the program whanau can attend the Maori Diabetes Support group for ongoing group support:

Research Option: Whanau can choose to participate in the research program with Jo Janssen. If you choose not to participate in the research program you can still complete the education program.

Heather Oehlnich: Maon Diabetes Nurse Educator

PO Box 1026, Blenheim

$\mathrm{Ph} 021488634 / 5778404$

heather@ngatirarua.co.nz 


\section{TE INOI A TE ARIKI THE LORD'S PRAYER}

E to matos Matua i to rangi, Kia tapu to ingoa. Kia tae mai tou rangatiratanga. Kia meatia tau e pai ai $K i$ runga $k i$ te whenua, Kia rite oano ki to te rangi. Homai ki a matou aianei lie taro ma matou mo tenei ra. Murua o matou hara, Me matou hoki e muru nei i o te hunga $e$ hara ana $k i$ a matou Aua hoki matou e kawea kia whakawaia;

Engari whakaorangia matou i te kino:

Nou hoki te rangatiratanga, te kaha, me te kororia, Ake ake Amine
Our father which art in heaven Hallowed be thy name

Thy kingdom come Thy will be done In earth

As it is in heaven Give us this day Our daily bread Forgive us our trespasses As we forgive Those who trespass against us Lead us not into temptation

But deliver us from evil

For thine is the kingdom

The power

And the glory

For ever and ever

Amen 


\section{KARATIA}

Kia tau kia tatou katoa

Te atawhai o to tatou Ariki

A Ilıu Karaiti

Me te aroha

O Te A'TUA

Me te whiwhinga tahitanga

k̦i te Wairua Tapu

Ake ake ake

AMINE

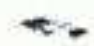



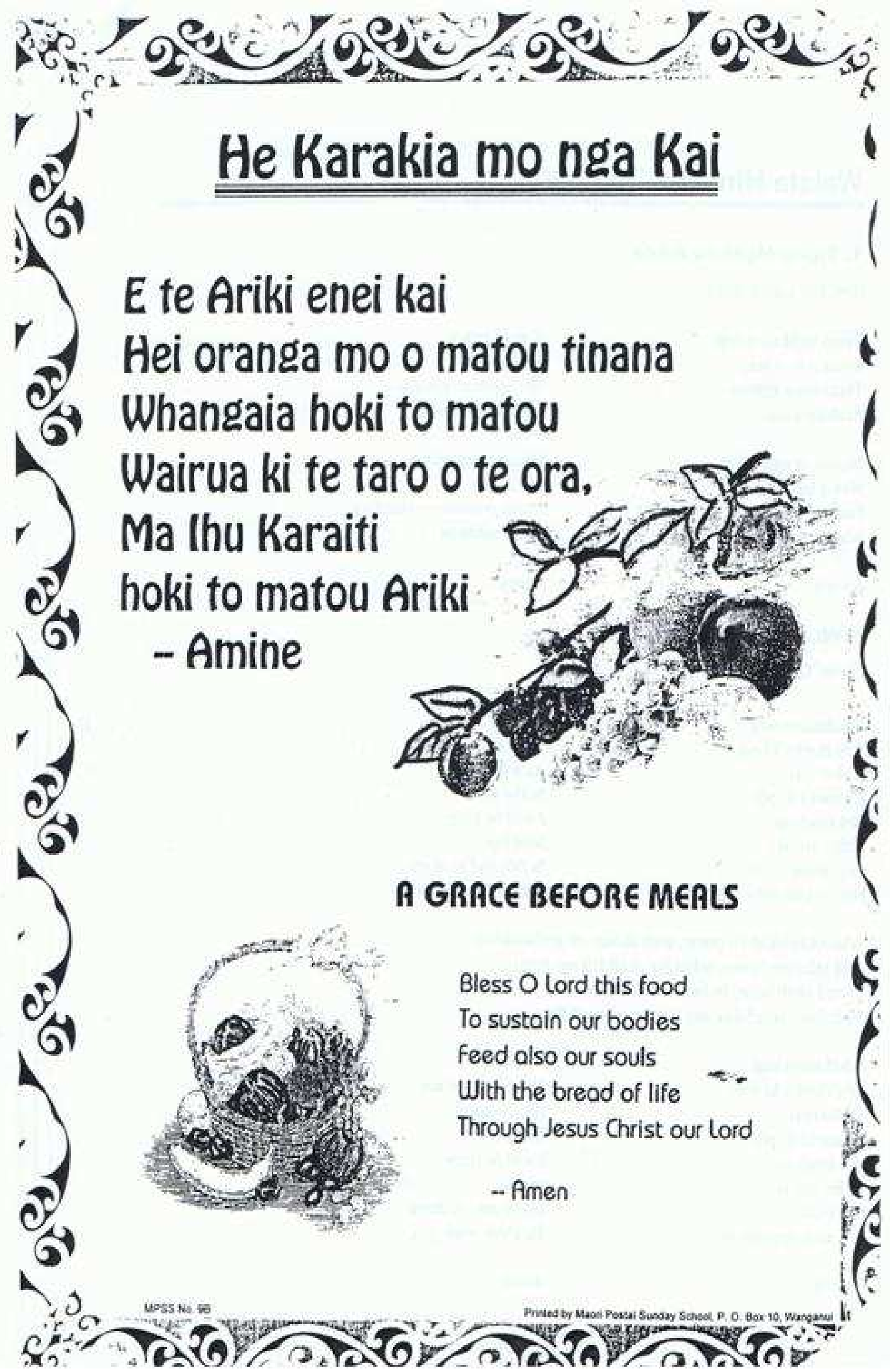


\section{Waiata Himene - Hymns}

\section{Tama Ngâkau Mărie}

(first two verses only)

Tama ngăkau mărie

Son of peace

Tama a te Atua,

Tênei tonu mãtou

Son of God

Arohaina mai.

We are here always

Be compassionate

Munua ră ngă hara:

Wetekina mai

Cleanse our sins

Enei here kino,

Cut loose

Whakaranu nei.

These pernicious shackles

that trouble us

Amine

Amen

\section{Whakaaria mai}

(Tune: O Lord my God)

Whakaaria mai

Tou rīpcka ki au;

Tiaho mai

Ra roto i te po:

Hei konã au

Titiro atu ai:

Ora, mate

Hei au koe noho ai.
Display

Your cross to me

As a beacon

In the night

I will be there

Seeking

In life and in death

To abide with you

When Christ shall come, with shouts of acclamation

And take me home, what joy shall fill my heart.

Then I shall bow, in humble adoration

And there proclaim, my God how great thou art.

Whakaaria mai

Tóu rịpeka ki a au

Tiaho mai

Ră roto i te $p \bar{~}$

Hei konã au

Titiro atu ai.

Ora mate,

Hei au koe noho ai.

Amine

$\begin{array}{ll} & \text { Display } \\ & \text { Your cross to me } \\ \text { As a beacon } & \text { In the night } \\ \therefore \quad \text { I will be there } \\ \text { secking } \\ \text { In life and in death } \\ \text { To abide with you. } \\ \text { Amen }\end{array}$


He Oranga Mo Te Mate Huka 1

\author{
Karakia Timatanga \\ Waiata \\ Whanaungatanga/ Welcome \\ Mihi \\ Group
}

Reflection on Whanaungatanga Hui

- What is diabetes?

- Metabolic Syndrome

- Who is at risk?

- Signs and symptoms

- Role of body organs

- The glucose story

- Managing our diabetes

- Signs of a hypo \& managing a hypo

- Whare Tapa Wha

Kapu $\mathrm{Ti}$

Whakapakari Tinana:

Poroporoake

Karakia Whakamutunga

PO Box 1026, Blenheim $\mathrm{Ph} 021488$ 634/5778404

heather@ngatirarua.co.nz 


\title{
What is Diabetes?
}

\author{
$W_{b}$ \\ ben food containing \\ carbobydrate (tbat is, sugar and \\ starcb) is eaten, this is what \\ bappens:

at

1. food is chewed and swallowed

2. enters the stomach food reservoir)

3. and then the intestine: (wbere food is broken down to sugar) 


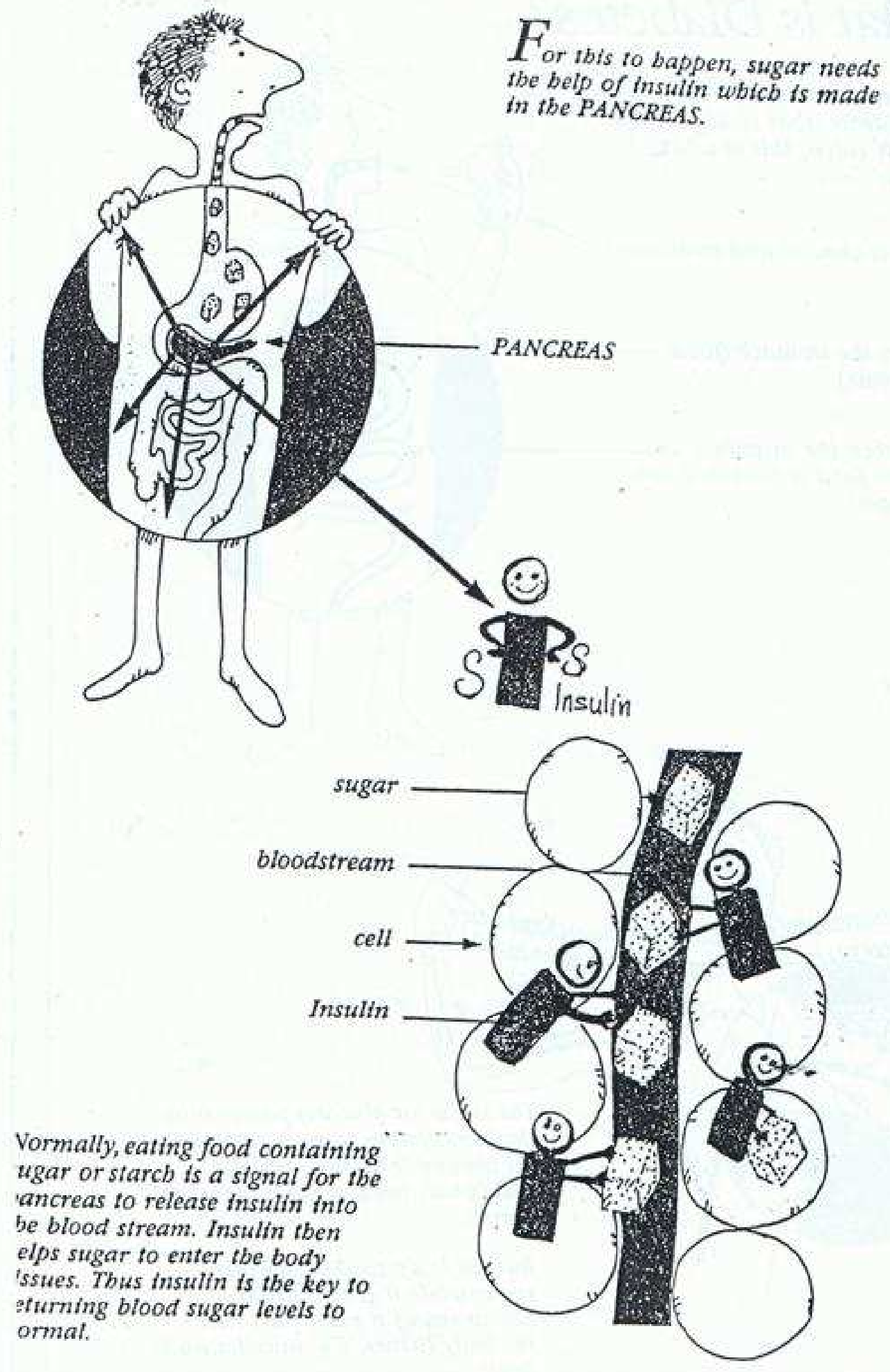




\section{TYPE 2 DIABETES}

TYPE 2 DIABETES

There's not enough insulin or it's not working properly, resulting in too much glucose in the blood.
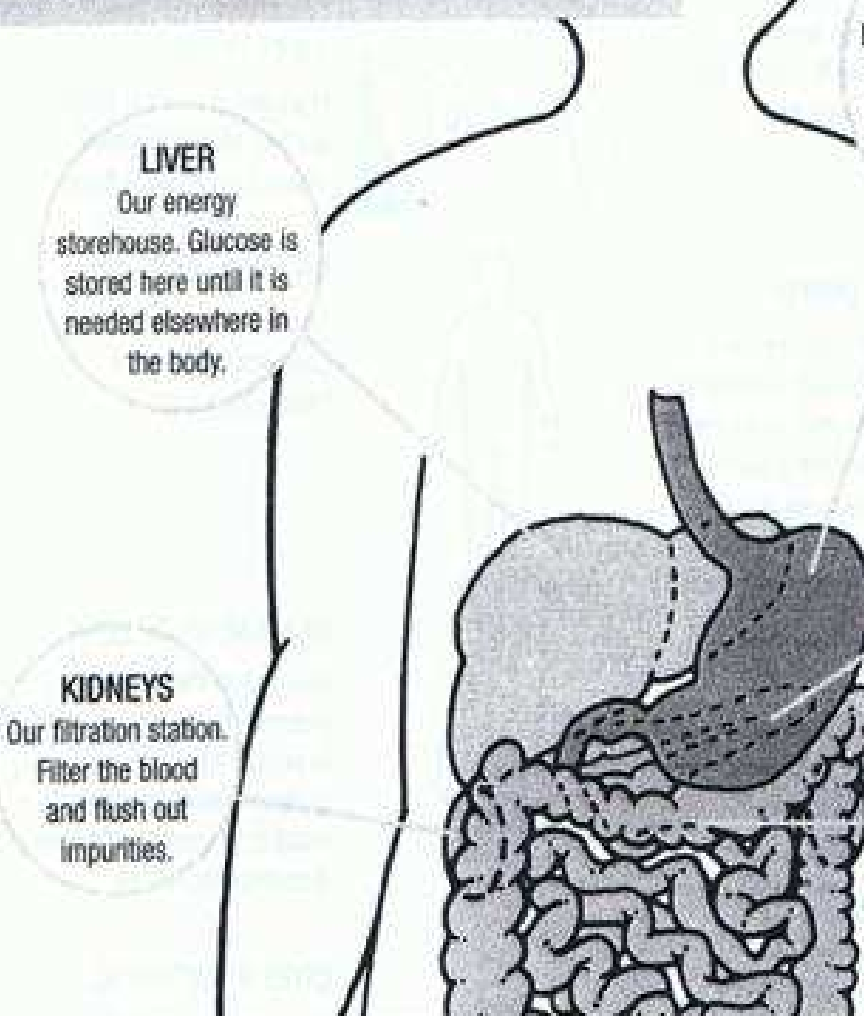

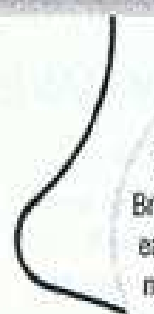

STOMACH

Our digestive engine. Breaks down the food we eat and starts to convert much of it into glucoss, which provides energy:
PANCREAS

Our dabetes iffeguard. Makes insulin and telis the liver how much glucose to store of retease.

\section{THE GLUCOSE STORY}

1. Glucose is extracted from the carbohydrate food we eat (bread, cereals, fruit, starchy veg) and used by the cells for energy.

2. The glucose can only enter the cells it insulin unlocks the glucose doors.

3. If there is insufficient insulin to open all the glucose doors, or if it is not working property, the glucose stays in the blood and your blood glucose levels will rise.

\section{CELL WITHOUT DIABETES}

\section{CELL WITH TYPE 2 DIABETES}

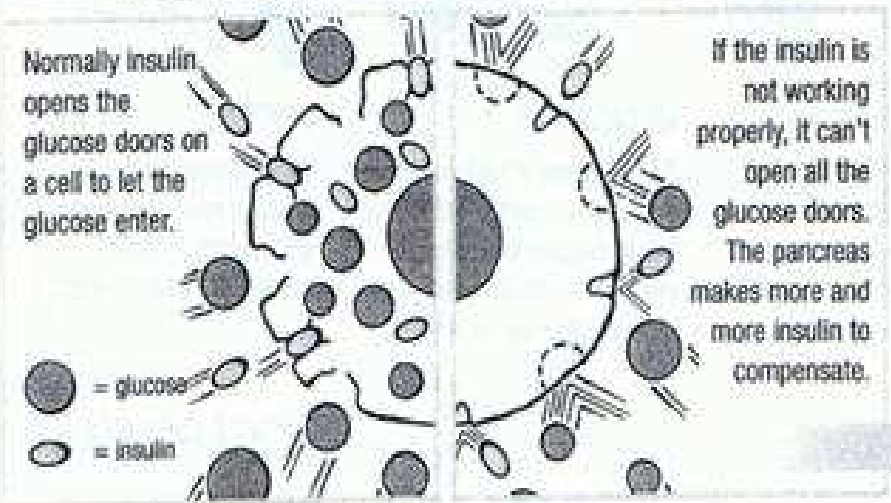

\section{PROGRESSION OF TYPE 2 DIABETES}

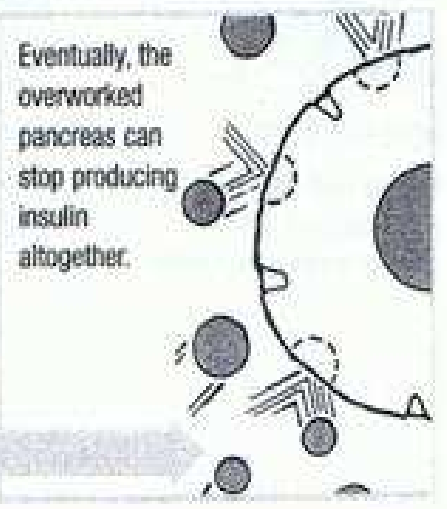




\section{WHAT DOES IT MEAN?}

\section{SYMPTOMS YOU MAY HAVE}
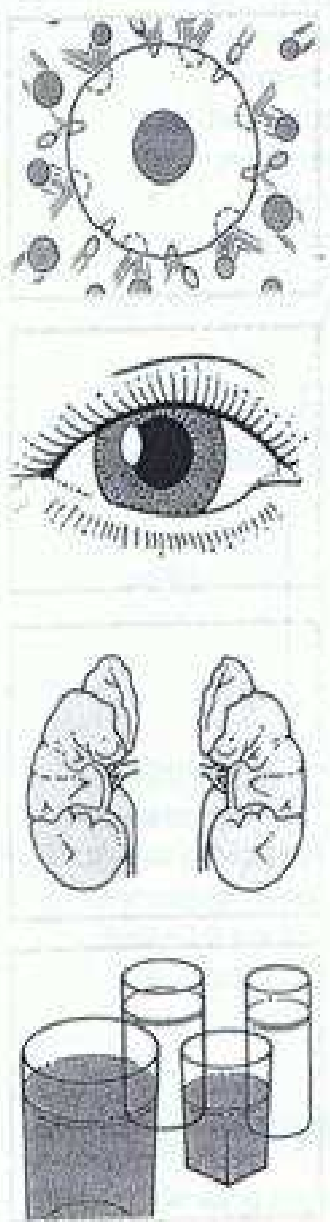

INCREASE IN THIRST

The increase in urine passed from the body causes dehydration which often leads to thirst.

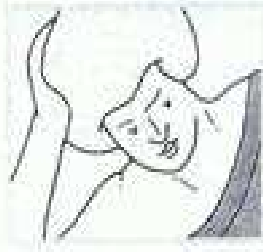

FREQUENT

You'll feel trad because your colls aren't getting the energy you need from glucose.

\section{BLURRED VISION}

The lens of the eye expands and contracts with changes in blood gluoose. Your eye cannol compensate quickly enough, causing blurred vision.

\section{FREQUENT URINATION}

The kidneys draw more water from the body to fush out the excess gluctese, so a lot more urine is passed.

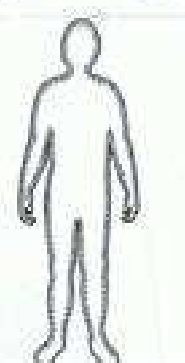

\section{NUMBNESS OF LEGS}

Damage to the nerves (neuropathy) is more common in people who have had undiagnosed diabetes for a number of years, or as your dabetes progresses.

\section{CUTS WON'T HEAL.}

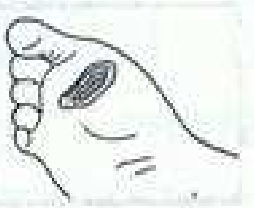

The high glucose in the blood makes it difficult for white blood cells to fight infection.

\section{HOW CAN YOU HELP?}

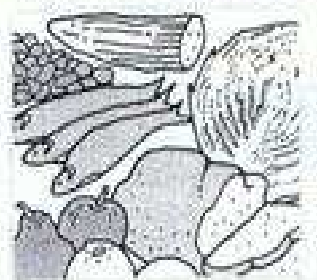

HEALTHY FOOD

Healthy food choices can help keep your blood gucose levels near nornal.
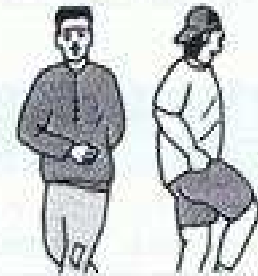

REGULAR ACTIVITY Keeping active helps keep diatetes under control.

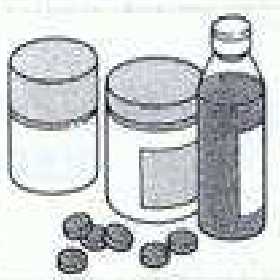

MEDICATION

Several types of tablets can help people manage their diabetes (some pecple don't require medication initially), and over time insulin may be needed.

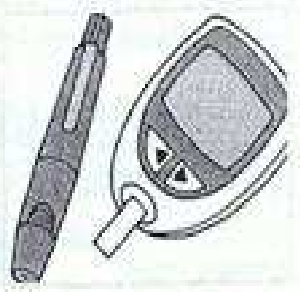

\section{TESTING}

This neasures your bilood glucose level so you can adjust your food choices ox activity levels if necessary. 


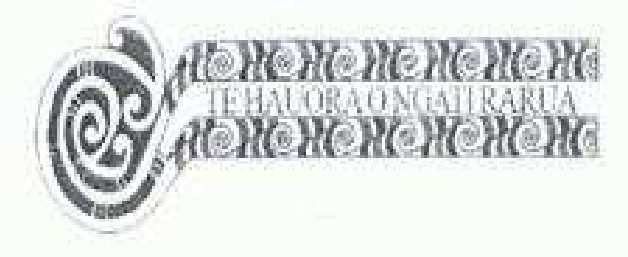

He Oranga Mo Te Mate Huka 2: Lifestyle Changes

\author{
Karakia Timatanga \\ Waiata \\ Whanaungatanga/ Welcome \\ Mihi \\ Group
}

Reflection on What is diabetes?

- Who is in Control?

- Stages of Change

- Monitoring

- Keeping a diary

\title{
Kapu Ti
}

Whakapakari Tinana

Poroporoake

Karakia Whakamutunga

$$
\begin{gathered}
\text { PO Box 1026, Blenheim } \\
\text { Ph } 5780979 \\
\text { heather@ngatirarua.co.nz }
\end{gathered}
$$




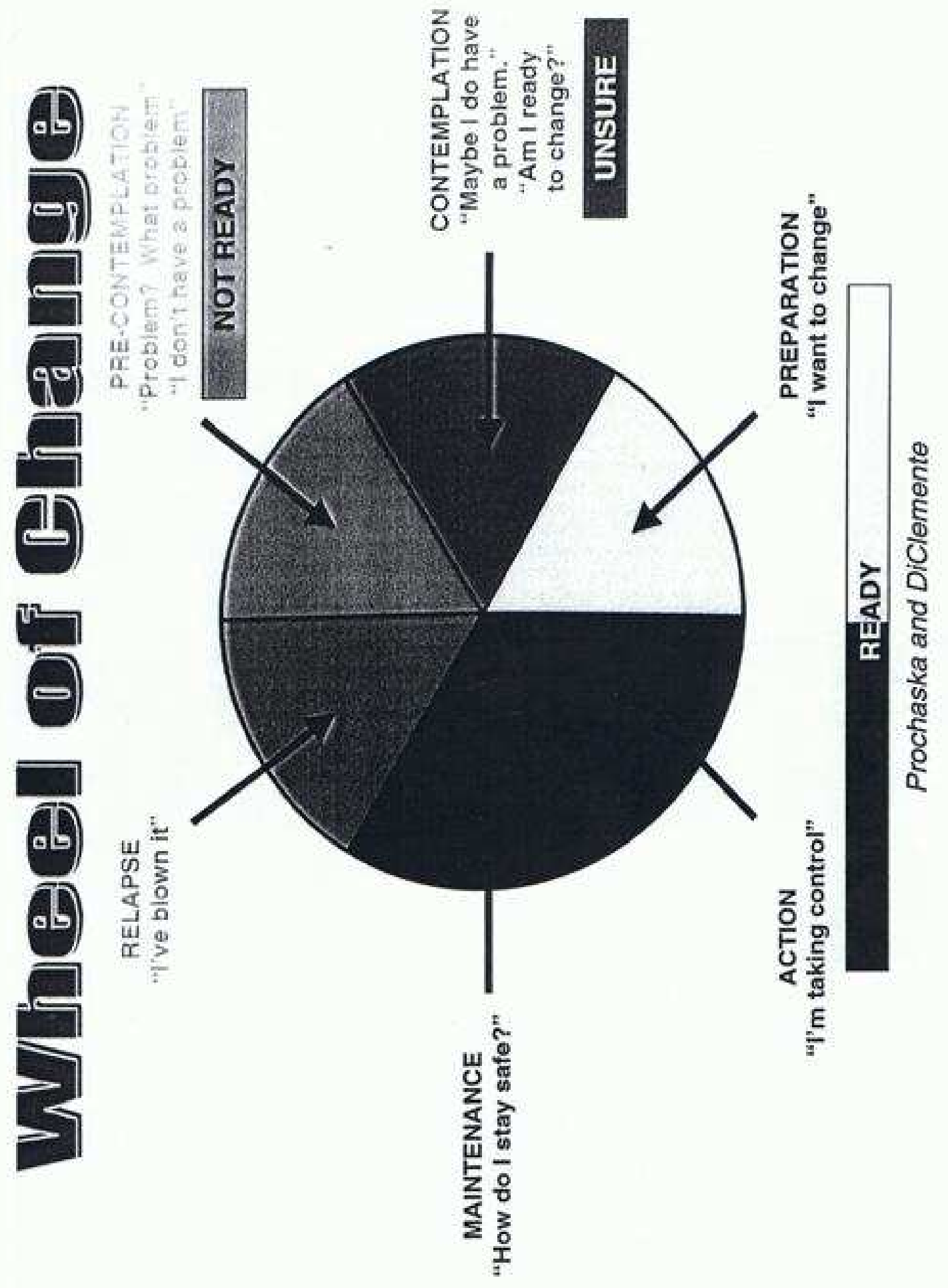

Food with Attitude - 2002 


\section{$\mathrm{HbA1c}$}

Glycosylated haemoglobin ( $\mathrm{HbA} 1 \mathrm{c})$ is a test performed in the lab on a whole blood sample.

Result reflects average blood glucose concentration over the life of the red blood cell (approx. 2 months).

Result can not be compared directly with blood glucose meter results because $\mathrm{HbA} 1 \mathrm{c}$ is a different test with a different measure.

Interpret $\mathrm{HbA1c}$ result as follows:

$\mathrm{HbA1c}$ Result Average Blood Glucose

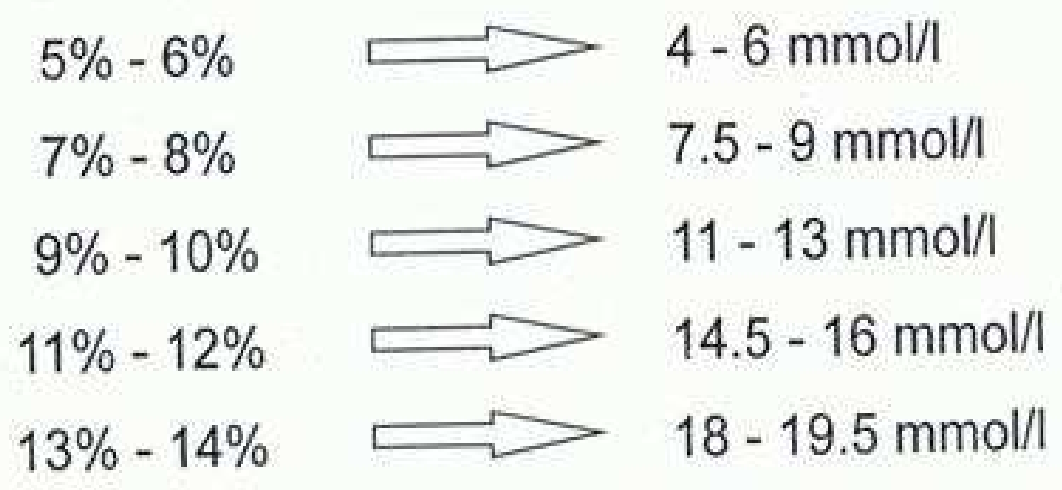
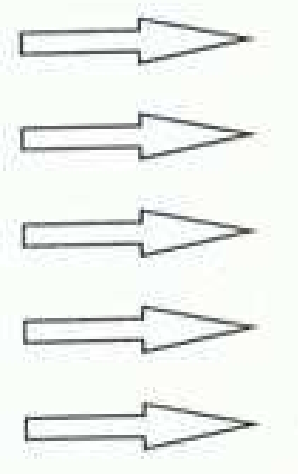

Greater than $14 \%$ Greater than $20 \mathrm{mmol} / \mathrm{l}$

Chart brought to you by Roche Diagnostics NZ L.td.

Please stay in touch by calling the ExtraCare Freephone 0800802299 
He Oranga Mo Te Mate Huka Session 3

Preventing \& Managing Complications of Diabetes

Karakia Timatanga

Waiata

Whanaungatanga/ Welcome

Mihi

Reflection on info to date

- Who is in Control?

- Stages of Change

- Monitoring

- Keeping a diary

Session 3:

- Preventing \& Managing Complications of Diabetes - Heather

- Fat and Sugar Charts Coral Hedley

- Kapu Ti

- Whakapakari Tinana

Poroporoake

Karakia Whakamutunga

PO Box 1026, Blenheim

Ph 5780979

heather@ngatirarva.co.nz 


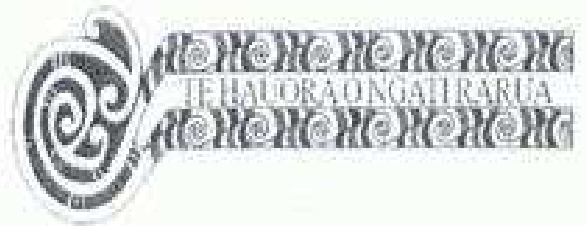

He Oranga Mo Te Mate Huka Session 4

Healthy Kai Choices

Karakia Timatanga

Waiata

Whanaungatanga/ Welcome

Mihi

Reflection on:

- Preventing \& Managing Complications of Diabetes

- Fat \& Sugar Charts

- Whakapakari Tinana

\section{Session 4:}

- Why The Fuss?

Coral Hedley

-What's on the label? Coral Hedley

- Whakapakari Tinana

Poroporoake

Karakia Whakamutunga

$$
\begin{gathered}
\text { POBox 1026, Blenheim } \\
\text { Ph } 5780979 \\
\text { heather@ngatirarua.co.nz }
\end{gathered}
$$


He Oranga Mo Te Mate Huka 5: Supermarket Tour

Karakia Timatanga

Whanaungatanga/ Welcome

Mihi

Reflection on:

- Why the Fuss

- Whats on the label?

Today's Session: Supermarket Tour

Whanau please bring your walking shoes and hikoi kete

Poroporoake

Karakia Whakamutunga

Kapu Ti

PO Box 1026, Blenheim

$\mathrm{Ph} 5780979$

heather@ngatirarua.co.nz 


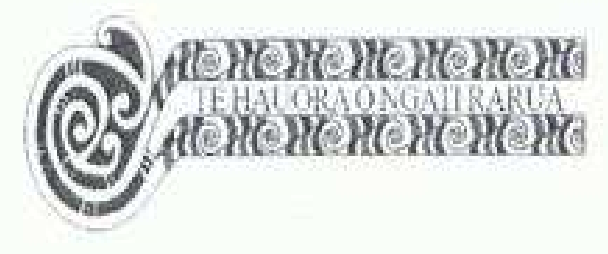

He Oranga Mo Te Mate Huka Session 6

Karakia Timatanga

Waiata

Whanaungatanga/ Welcome

Mihi

Reflection on

- Reading the labels

- Supermarket tour

Partners in Diabetes Care

Were your goals for attending this program met?

Evaluations

Where to from here?

Poroporoake

Karakia Whakamutunga

Kapu Ti

PO Box 1026, Blenheim

Ph 5780979

heather@ngatirarua.co.nz 


\section{Appendix C - Director of Maori Health letter of support}

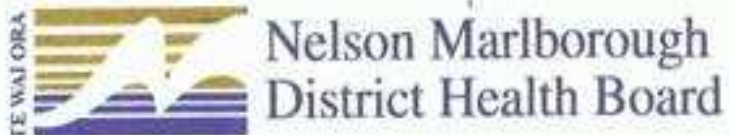

Fax: 035461747

Phone: 035461723
Maori Health Board Office

Private Bag 18 Nelson, New Zealand

9 December 2005

Jo Jannsen

294 Tynetesfeild Rd

RD6

Blenheim

Tena koc Jo Jannsen, nga mihi nui, mihi mahiana kia koe,

Re: The design, implementation and evaluation of a heart disease and diabetes education programme for Maori.

I am pleased to provide you with this letter of support for the research study as detailed above. I apologise for the delay to responding to you.

After reading the supplied information I understand that this study aims to work with a local fwi Maori health provider to design and evaluate a heart disease and diabetes programme for Maori patients. The study will collect and compare physiological measures of 10-15 patients as they progress through the study and the outcome will be to measure the effectiveness of the tools and programme.

In response to requests for support for research proposals I include the below to inform researchers of the important Marori cultural considerations significant in research. This includes ensuring:

1. Ethnicity of participants is collected.

2. Results are analysed by ethnicity.

3. Mari are included in research activity and if necessary over sampled to achieve at least demographic comparison.

4. Feedback of results occurs to Iwi and the Marori community.

5. Research has meaning for Mãori and contributes to improving health.

6. Research allows for cultural difference without disadvantage.

7. Communication with Marori should be delivered in a way that is culturally acceptable.

I am delighted to tead that your research is for Maori and meets the requirements above. Also you have made appropriate arrangements with a Maori provider to ensure your and your participants cultural safety. This study is significant, as it will provide vital information that is currently unknown and options for effective treatment.

The connection you have with Ngati Rarua via their health provider Te Hauora o Ngati Rarua provides you with opportunity and pathways to communicate with lwi. As the Director of Maori Health for the NMDHB I function as a contact and consultation point for researchers in health and the Iwi and Maori communities of our region. I do this by ensuring the Iwi Health Board are aware of your research and that information is passed through to their and other 
Maori communities - usually by sharing the research information sheet and the responding support letter written by me. If I receive feedback or questions I answer where I can and / or refer them directly to the researchers. This sharing of information also occurs as results are discovered and published. Please pass this information on to my office as it becomes available.

With regard to your proposal I offer to:

- Support your research and to share the research proposal information and results with the Iwi Health Board.

I congratulate you for your commitment to working alongside Maori health as demonstrated in this study.

Thank you. Please contact me if you have any further needs and 1 look forward to hearing the results of your study.

Noho ora mai ra,

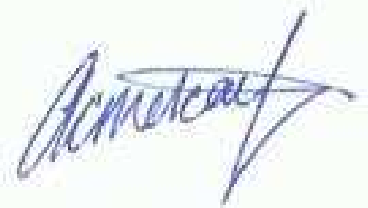

Aroha Metcalf

Director of Mãori Health

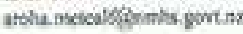




\title{
Appendix D - Contract between THONR and J. Janssen
}

\begin{abstract}
Contract for Research Proposal between Te Hauora O Ngati Rarua and Josephine Janssen (Masters in Nursing by Research student at Victoria
\end{abstract} University)

This agreement is made this $\frac{4^{\text {th }}}{\text { Te Hauora O Ngati Rarua }}$ of $20065^{9 h}$
Between

And

Josephine Janssen

\section{Research}

1.1The researcher will carry out a case study evaluation of the diabetes / heart disease education programme being offered by Te Hauora $\mathrm{O}$ Ngati Rarua.

1.2This research will form the basis of a Master in Nursing thesis and is being supervised by Dr Rose McEldowney and Dr Katherine Nelson of the Graduate School of Nursing and Midwifery at Victoria University of Wellington.

1.3The researcher will provide a detailed research proposal to Te Hauora $\mathrm{O}$ Ngati Rarua prior to commencement of the research.

1.4 The case study will follow a group of participants through the programme, Various physiological, lifestyle and knowledge related outcome measures will be assessed at programme commencement, completion and six month follow-up. Participants and programme staff will also be interviewed by the researcher at programme completion.

1.5The case study will describe, analyse and evaluate the development and workings of the diabetes / heart disease education programme.

1.6 The case study will provide feedback to Te Hauora O Ngati Rarua and contribute to knowledge on the design and delivery of diabetes and cardiac education to Maori, aspects may be applied more broadly to Maori health education in general.

\section{Indicative Time Frame}

2.1 Ethics approval granted Dec 05

2.2 Ongoing meetings between Healther Oehlrich and Jo Janssen to finalise programme and study documents by May 06

2.3 Data collection from clients will commence with the next programme currently scheduled to commence 24 May 2006. 
2.4 Research involving staff will commence in the weeks following the completion of the next programme.

2.5 Provisional findings will be available by the end of February 2007

2.6 It is intended that the whole thesis will be completed by May 2007

\section{Consultation}

3.1 The researcher and Te Hauora O Ngati Rarua will work honestly and openly raising any issues and matters of concern with the other party in a timely manner.

3.2 The researcher and Te Hauora O Ngati Rarua will work to resolve any areas of conflict.

3.3 The researcher and Te Hauora O Ngati Rarua will confer on matters not specified in the research proposal.

3.4 The researcher will meet with Te Hauora O Ngati Rarua regularly, she will attend most or all weekly education sessions and will have meetings at least monthly during the preparation and data-gathering phase. These meetings will be at a time and place convenient to both parties. If these meetings prove to be difficult to organise, other arrangements for communication will be made.

\section{Participation}

4.1 The researcher and Te Hauora O Ngati Rarua agree to work in partnership with respect to finalising the detalls of the research, such as the data to be gathered.

4.2 The researcher will have access to Te Hauora O Ngati Rarua staft, records and clients at a time and place convenient to Te Hauora O Ngati Rarua.

\section{Ownership}

5.1 All the data and findings of the case study evaluation shall be and will remain the property of Te Hauora O Ngati Rarua.

5.2 The researcher has the right to utilise the data and findings of the case. study for her Master of Nursing.

5.3 All decisions, (e.g. authorship, audience, content) regarding dissemination of all findings shall be subject to the agreement of both parties. 


\section{Confidentiality}

6.1 The researcher agrees to treat all service and client data confidentially as stated in the Upper Southern A Ethics Committee Agreement.

6.2 The data collected will be confidential with no name being attached to a record.

\section{Termination}

8.1 Where for any reason, other than outlined in 8.3 , this contract is terminated, both parties agree to consult and give reasonable notice (1 month) regarding termination.

8.2 Where for any reason this contract is terminated prior to the completion of the evaluation, agreement shall be reached as to the use of the findings to date.

8.3 The Te Hauora O Ngati Rarua shall have the right to terminate this contract without notice if the researcher acts illegally or in any way that might bring Te Hauora O Ngati Rarua into disrepute. 
This contract is between Te Hauora O Ngati Rarua and Josephine

Jansen. Both parties agree to participate in the case study under the terms and conditions mentioned above.

Signed for Te Hauora O Ngati Rarua

By:

limber Lu le

Signed:

16 On $14+11.06$

In the presence of:

witness: Heather Oehtrich

Occupation: Deletes Pure Soucetor

Address:

Signature: $2 \mathrm{c}$ Now th St.

Blentuani

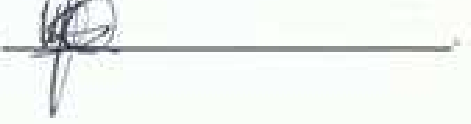

Signed by Josephine Jansen

these on 14 November 2006.

As the researcher, in the presence of:

Witness: Hen thad CEHLRCH

Occupation: Diabetes Nurse Educated

Address: $2 \mathrm{c}$. Worth St

Signature:

on 14 November 2006

Contract with Te Havora O Nat Rarua Fob 2008.

162 


\section{Appendix E - Ethics Approval}

Health
and
Disability
Ethics
Committees

21 December 2005

\author{
Jo Janssen \\ Nelson Marlborough Institute of Technology \\ 294 Tyntesfield Road \\ RD6 \\ Blenheim
}

Dear Jo Janssen,

\author{
Upper South A Regional Ethics Committee \\ Whistry of Feath \\ a' Floor. 250 Oxderd Tertace. \\ $\mathrm{PD} B \mathrm{C} \times 3877$ \\ Chrischurct \\ phove (89) 372.303 ? \\ Fax (C63) 3721015
}

The design, implementation and evaluation of a heart disease and diabetes education programme for Maori

Investigators: J Janssen, K Nelson (Supervisor)

Ethics ref: URA $05 / 11 / 149$

Thank you for your response to the Committee's suggestions. The above study has now been given ethical approval by the Upper South A Regional Ethics Committee.

\section{Approved Documents}

Participant Information Sheet and Consent Form dated December 2005

Stakeholder Information Sheet and Consent Form dated December 2005

Programme Participant Interview Guide dated December 2005

Stakehoider Interview Guide dated December 2005

Referral form dated December 2005

Pre-programme Health Assessment form Dated November 2005

\section{Certification}

The Committee is satisfied that this sfudy is not being conducted principally for the benefit of the manufacturer or distributor of the medicine or item in respect of which the trial is being carried out.

\section{Accreditation}

This Committee is accredited by the Health Research Council and is constituted and operates in accordance with the Operational Standard for Ethics Committees, March 2002.

\section{Reporting}

The study is approved until 15 May 2006. A final report is required at the conclusion of the study. The Administrator will send you a form for this purpose.

\section{Amendments}

All amendments to the study must be advised to the Committee prior to their implementation, except in the case where immediate implementation is required for reasons of safety. In such cases the Committee must be notified as soon as possible of the change.

It is also a condition of approval that the Committee is advised of any adverse events, if the study coes not commence, or the study is altered in any way, including al documentation eg advertisements, letters to prospective participants. Please quote the above ethics committee reference number in all correspondence. 


\section{General}

It should be noted that Ethics Committee approval does not imply any resource commitment or administrative facilitation by any heaithcare provider within whose facility the research is to be carried out. Where applicable, authority for this must be obtained separately from the appropriate manager within the organisation.

We wish you well with your study.

Yours sincerely

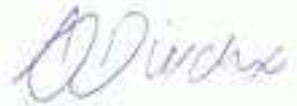

Alieke Dierckx

Upper South A Ethics Committee Administrator 


\section{Appendix F - Information Sheets}

VICTORIA UNIVERSITY OF WELLINGTON

Te Whare Wananga o te Upoko o te Ika a Maui

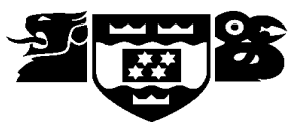

GRADUATE SCHOOL OF NURSING \& MIDWIFERY

\section{Stakeholder Information Sheet - Ngati Rarua staff \\ THE DESIGN, IMPLEMENTATION AND EVALUATION OF A DIABETES AND HEART DISEASE EDUCATION PROGRAMME FOR MAORI \\ INTRODUCTION}

You have been involved in the design and delivery of an education programme being run by Te Hauora O Ngati Rarua, which teaches people how to prevent or manage diabetes and heart disease. Jo Janssen is evaluating the programme which means: 1) Describing the programme, 2) Hearing participants' and staff views on what works well and not so well, and 3) Analysing participants' clinical and assessment data.

\section{What will this mean for you if you decide to participate?}

- $\quad$ Fulfilling your usual role in the delivery of the programme.

- Having a one-to-one confidential interview with the researcher in the next few weeks.

You have at least a week to decide whether to take part. It is entirely your choice whether or not you participate in the study.

\section{Principal Investigator for the study is: Josephine “Jo" JANSSEN}

Jo is studying towards her Master of Nursing at Victoria University of Wellington. She is also a Staff Nurse at the Coronary Care Unit at Wairau Hospital and a Nursing Tutor at Nelson Marlborough Institute of Technology. If you want more information about the study, you can reach Jo Janssen at (03) 572-4023 or on her Wairau Hospital pager (call (03) 520-9999 and ask for Jo Janssen on pager), or email her on janssen@mlb.planet.gen.nz. Jo is working in partnership with Heather Oehlrich who is coordinating the programme. You can reach Heather on: 021488634

Jo's supervisors are Dr Kathy Nelson \& Dr Rose McEldowney at the Graduate School of Nursing and Midwifery, Victoria University of Wellington. You can reach them on: 0800 108005, if you have any questions about the study.

\section{ABOUT THE STUDY}

a) We have interviewed seven programme participants and analysed their programme data like blood pressure, weight, blood tests, knowledge and lifestyle behaviours.

b) All staff involved in delivering the programme will be offered the chance to be interviewed for the study. 


\section{THE INTERVIEW}

The only requirement of being on the study is an interview with Jo Janssen.

- This will happen in the next few weeks.

- It can be at the programme rooms, at your home or some other mutually agreed venue.

- If you have to travel to get to your interview you will be reimbursed for travel costs.

- The interview will take $30-60$ mins.

- Jo will be asking you what parts of the education programme you think are working well and what is not going well. This will include considering changes to content, teaching methods and/or organisation.

- In the interview, you do not have to answer all the questions and you may stop the interview at any time.

- Jo would like to tape this interview with your permission, otherwise she is happy to take notes. The tape will be typed up by a typist who has signed a confidentiality agreement.

- Jo will show you the transcript to ensure it reflects what you really think. The transcript will not identify you or any participants or staff.

- After the study is finished you can have your tape back or Jo will dispose of it safely if you prefer.

\section{BENEFITS RISKS AND SAFETY}

- This study will enable us to improve the programme.

- There is no cost, nor financial benefit to you for taking part in this study.

- There are no anticipated health risks related to being on this study.

\section{PARTICIPATION}

- Your participation is entirely voluntary (your choice). Your employment at Te Hauora O Ngati Rarua will not be affected, irrespective of whether you decide to participate or not.

- If you do agree to take part you are free to withdraw from the study at any time, without having to give a reason.

\section{GENERAL}

- An interpreter can be provided if you require one.

- You may have a friend, family or whanau support to help you understand the risks and/or benefits of this study and any other explanation you may require.

- If you have any queries or concerns regarding your rights as a participant in this study you may wish to contact a Health and Disability Advocate, telephone 0800377766

\section{CONFIDENTIALITY}

No material that could personally identify you will be used in any reports on this study. 
There will be one master list that identifies your study number with your name. Jo Janssen will store this separate from the unidentified study data. Jo Janssen and her supervisor are the only ones who will see the study data. Once the study is complete, the unidentified study records will be stored on a locked password protected computer file. The master list of names and study numbers will be destroyed.

\section{RESULTS}

The results of this research will be published in Jo Janssen's Master of Nursing thesis, which will be held in the Victoria University of Wellington Library and a copy will be given to the Te Hauora O Ngati Rarua. Parts of the work may also be published in nursing journal/s and presented at conference/s. It is likely to take over a year from the time the study finishes, until the full thesis is written up and presented for marking. In the meantime a summary of the main results will be produced. You can gain access to this on request from Jo Janssen or Heather Oehlrich. Jo and Heather will also present the results to the stakeholders of Te Hauora $\mathrm{O}$ Ngati Rarua at this stage.

\section{STATEMENT OF APPROVAL}

This study has received ethical approval from the Upper South A Ethics Committee.

Please feel free to contact Jo Janssen if you have any questions about this study. 
GRADUATE SCHOOL OF NURSING \& MIDWIFERY

\section{Stakeholder Information Sheet - not Ngati Rarua staff THE DESIGN, IMPLEMENTATION AND EVALUATION OF A DIABETES AND HEART DISEASE EDUCATION PROGRAMME FOR MAORI}

\section{INTRODUCTION}

You have been involved in the design and delivery of an education programme being run by Te Hauora $O$ Ngati Rarua, which teaches people how to prevent or manage diabetes and heart disease. Jo Janssen is evaluating the programme which means: 1) Describing the programme, 2) Hearing participants' and staff views on what works well and not so well, and 3) Analysing participants' clinical and assessment data.

\section{What will this mean for you if you decide to participate?}

- $\quad$ Fulfilling your usual role in the delivery of the programme.

- Having a one-to-one confidential interview with the researcher in the next few weeks.

You have at least a week to decide whether to take part. It is entirely your choice whether or not you participate in the study.

\section{Principal Investigator for the study is: Josephine “Jo” JANSSEN}

Jo is studying towards her Master of Nursing at Victoria University of Wellington. She is also a Staff Nurse at the Coronary Care Unit at Wairau Hospital and a Nursing Tutor at Nelson Marlborough Institute of Technology.

If you want more information about the study, you can reach Jo Janssen at (03) 572-4023 or on her Wairau Hospital pager (call (03) 520-9999 and ask for Jo Janssen on pager), or email her on janssen@mlb.planet.gen.nz. Jo is working in partnership with Heather Oehlrich who is coordinating the programme. You can reach Heather on: 021488634

Jo's supervisors are Dr Kathy Nelson \& Dr Rose McEldowney at the Graduate School of Nursing and Midwifery, Victoria University of Wellington.

You can reach them on: 0800 108005, if you have any questions about the study.

\section{ABOUT THE STUDY}

a) We have interviewed seven programme participants and analysed their programme data like blood pressure, weight, blood tests, knowledge and lifestyle behaviours. 
b) All staff involved in delivering the programme will be offered the chance to be interviewed for the study.

\section{THE INTERVIEW}

The only requirement of being on the study is an interview with Jo Janssen.

- $\quad$ This will happen in the next few weeks.

- It can be at you workplace, at your home or some other mutually agreed venue.

- If you have to travel to get to your interview you will be reimbursed for travel costs.

- $\quad$ The interview will take $30-60$ mins.

- Jo will be asking you what parts of the education programme you think are working well and what is not going well. This will include considering changes to content, teaching methods and/or organisation.

- In the interview, you do not have to answer all the questions and you may stop the interview at any time.

- Jo would like to tape this interview with your permission, otherwise she is happy to take notes. The tape will be typed up by a typist who has signed a confidentiality agreement.

- Jo will show you the transcript to ensure it reflects what you really think. The transcript will not identify you or any participants or staff.

- $\quad$ After the study is finished you can have your tape back or Jo will dispose of it safely if you prefer.

\section{BENEFITS RISKS AND SAFETY}

- $\quad$ This study will enable us to improve the programme.

- $\quad$ There is no cost, nor financial benefit to you for taking part in this study.

- $\quad$ There are no anticipated health risks related to being on this study.

\section{PARTICIPATION}

- Your participation is entirely voluntary (your choice). Your relationship with Te Hauora O Ngati Rarua will not be affected, irrespective of whether you decide to participate or not.

- Your employment will not be affected, irrespective of whether you decide to participate or not.

- If you do agree to take part you are free to withdraw from the study at any time, without having to give a reason.

\section{GENERAL}

- $\quad$ An interpreter can be provided if you require one.

- You may have a friend, family or whanau support to help you understand the risks and/or benefits of this study and any other explanation you may require.

- If you have any queries or concerns regarding your rights as a participant in this study you may wish to contact a Health and Disability Advocate, telephone 0800377766 


\section{CONFIDENTIALITY}

No material that could personally identify you will be used in any reports on this study.

There will be one master list that identifies your study number with your name. Jo Janssen will store this separate from the unidentified study data. Jo Janssen and her supervisor are the only ones who will see the study data. Once the study is complete, the unidentified study records will be stored on a locked password protected computer file. The master list of names and study numbers will be destroyed.

\section{RESULTS}

The results of this research will be published in Jo Janssen's Master of Nursing thesis, which will be held in the Victoria University of Wellington Library and a copy will be given to the Te Hauora O Ngati Rarua. Parts of the work may also be published in nursing journal/s and presented at conference/s. It is likely to take over a year from the time the study finishes, until the full thesis is written up and presented for marking. In the meantime a summary of the main results will be produced. You can gain access to this on request from Jo Janssen or Heather Oehlrich. Jo and Heather will also present the results to the stakeholders of Te Hauora O Ngati Rarua at this stage.

\section{STATEMENT OF APPROVAL}

This study has received ethical approval from the Upper South A Ethics Committee.

Please feel free to contact Jo Janssen if you have any questions about this study. 
VICTORIA UNIVERSITY OF WELLINGTON

Te Whare Wananga o te Upoko o te Ika a Maui

GRADUATE SCHOOL OF NURSING \& MIDWIFERY

\section{Participant Information Form}

\section{THE DESIGN, IMPLEMENTATION AND EVALUATION OF A DIABETES AND HEART DISEASE EDUCATION PROGRAMME FOR MAORI}

\section{INTRODUCTION}

You have been referred to an education programme being run by Te Hauora $O$ Ngati Rarua, which teaches people how to prevent or manage diabetes and heart disease. Today we will do a physical and health assessment and talk to you about diabetes and heart disease to decide what you already know and what we need to cover on the education sessions. The education programme will run for seven weeks on a Wednesday afternoon starting on 24 May from $2 \mathrm{pm}$ to $4.30 \mathrm{pm}$. At the end of the programme we will recheck your weight and blood pressure and have a talk about how your knowledge and lifestyle might have changed as a result of being on the programme. You can also have oneto-one meetings with Heather or one of the other staff from Te Hauora O Ngati Rarua if you have health concerns related to diabetes or heart disease. We will refer to this as "case management".

The programme, described above, is the usual treatment you will receive. In addition, a researcher called Jo Janssen is evaluating the programme. This means she will be:

1) Describing the programme, 2) Hearing participants' and staff views on what works well and not so well, and 3) Gathering and analysing clinical and assessment data from programme participants.

\section{What will this mean for you if you decide to participate in the study?}

- You may have an interpreter, friend, family or whanau support person to help you understand the risks and/or benefits of this study and any other explanation you may require.

- Consenting to having your programme assessment data used by the study. That is the information we will be collecting today: health history and physical assessment, weight, height, blood pressure, current health knowledge and lifestyle behaviour. Also, we would like to use information your GP or referrer sent us like your health history and blood tests. All information used in the study will be grouped so your data will not be able to be identified. 
- Consenting to the data collected at the end of the programme being used by the study. This means that in 7 weeks your weight, blood pressure, heart rate, knowledge and lifestyle behaviour will be assessed again by the programme. This unidentified information will be available to the study to use.

- Having a one-to-one talk with Jo a few weeks after the programme finishes.

- $\quad$ Staying in touch with us so that we can check your weight, blood pressure and blood tests again six months from now.

You don't have to decide whether to take part in the study until the programme starts on 24 May 06. It is entirely your choice whether to take part in the study. You will still be able to do the programme even if you don't join the study.

\section{Principal Investigator for the study is: Josephine "Jo" JANSSEN}

Jo is studying towards her Master of Nursing at Victoria University of Wellington. She is also a Staff Nurse at the Coronary Care Unit at Wairau Hospital and a Nursing Tutor at Nelson Marlborough Institute of Technology. If you want more information about the study, you can reach Jo Janssen at (03) 572-4023 or on her Wairau Hospital pager (call (03) 520-9999 and ask for Jo Janssen on pager), or email her on janssen@mlb.planet.gen.nz Jo is working in partnership with Heather Oehlrich who is coordinating your programme. You can reach Heather on: 021488634

Jo's supervisors are Dr Kathy Nelson \& Dr Rose McEldowney at the Graduate School of Nursing and Midwifery, Victoria University of Wellington.

You can reach them on: 0800 108005, if you have any questions about the study.

\section{ABOUT THE STUDY}

- Everyone who does the programme will also be offered the chance to be on the study.

- We are looking for about 10 programme participants to be part of the study.

- Much of the information for the study, like blood pressure and weight will be collected in the usual way during the programme. Jo will give you a study number and use that, not your name to record all your study data.

- The second part of the study, which doesn't concern you, will be interviewing the programme staff to get their suggestions for programme improvement.

\section{THE MEETING WITH JO}

The main extra requirement from you due to being on the study is having a talk with Jo Janssen.

- This will happen within a few weeks of the programme finishing. 
- You can have an interpreter or whanau/support person with you for the talk.

- It can be at the programme rooms, at your home, or some other mutually agreed venue.

- If you have to travel to get to your meeting with Jo on a day when there is no programme on already, you will be reimbursed for travel costs.

- The meeting will take about half an hour to an hour.

- Jo will ask you what parts of the education programme worked well for you, what parts were not so helpful and for any suggestions you have for the next programme. She will also be asking about ways your knowledge and lifestyle behaviour has changed as a result of being on the programme.

- In the meeting, you do not have to answer all the questions and you may stop talking at any time.

- Jo would like to tape this interview with your permission; otherwise she is happy to take notes. Jo will type up the transcript of your interview. Then she can show you the transcript to ensure it reflects what you really think. The transcript will not identify you because it will only have your study number on it.

- After the study is finished you can have your tape back or Jo will dispose of it safely if you prefer.

\section{BENEFITS, RISKS AND SAFETY}

- This study will enable us to improve the programme.

- There is no cost, nor financial benefit to you for taking part in this study.

- There are no anticipated health risks related to being on this study.

\section{PARTICIPATION}

- Your participation is entirely voluntary (your choice). You do not have to take part in this study, and if you choose not to take part you will receive the usual care.

- If you do agree to take part you are free to withdraw from the study at any time, without having to give a reason and this will in no way affect your continuing health care.

\section{GENERAL}

- At the end of the study your progress on the programme will be reported to your GP, with your permission. You may still continue to see Heather or the team from Te Hauora O Ngati Rarua individually if this benefits you.

- If you have any queries or concerns regarding your rights as a participant in this study you may wish to contact a Health and Disability Advocate, telephone 0800377766

\section{CONFIDENTIALITY}

No material that could personally identify you will be used in any reports on this study. 
Te Hauora O Ngati Rarua and your GP will keep your records in the normal way. Your GP will request your blood tests and pass the results on to the programme staff. Any information required for the study will be accessed from your programme records, but will only be identified by a study number; there will be nothing on your study records that would allow you to be identified. There will be one master list that identifies your study number with your name. Jo Janssen will store this separate from the unidentified study data. Jo Janssen and her supervisor are the only ones who will see the study data. Once the study is complete, the unidentified study records will be stored on a locked, password protected, computer file. The master list of names and study numbers will be destroyed.

\section{RESULTS}

The results of this research will be published in Jo Janssen's Master of Nursing thesis, which will be held in the Victoria University of Wellington Library. Parts of the work may also be published in nursing journal/s and presented at conference/s. It is likely to take over a year from the time the study finishes, until the full thesis is written up and presented for marking. In the meantime a summary of the main results will be produced. You can gain access to this on request, from Jo Janssen or Heather Oehlrich. Jo and Heather could also present the results to the local community, if there is interest in them doing so.

\section{STATEMENT OF APPROVAL}

"This study has received ethical approval from the Upper South A Ethics Committee."

Please feel free to contact Jo Janssen if you have any questions about this study. 


\section{Appendix G - Consent Forms}

VICTORIA UNIVERSITY OF WELLINGTON

Te Whare Wananga o te Upoko o te Ika a Maui

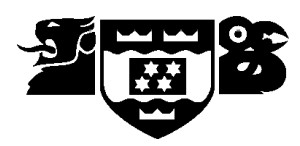

GRADUATE SCHOOL OF NURSING \& MIDWIFERY

Stakeholder Consent Form - Ngati Rarua staff

THE DESIGN, IMPLEMENTATION AND EVALUATION OF A DIABETES AND HEART DISEASE EDUCATION PROGRAMME FOR MAORI

English - I wish to have an interpreter.

YES / NO

Maori - E hiahia ana ahau ki tetahi kaiwhakamaori/kaiwhaka pakeha korero.

AE/ KAO

- I have read and I understand the information sheet dated 19 May 2007 for volunteers taking part in the study to evaluate the diabetes and heart disease education programme.

- I have had the opportunity to use whanau support or a friend to help me ask questions. I am satisfied with the answers I have been given and understand the study.

- I understand that taking part in this study is voluntary (my choice) and that I may withdraw from the study at any time and this will in no way affect my employment with Te Hauora O Ngati Rarua.

- I have had time to consider whether to take part.

- I consent to my interview being audio-taped.

YES/NO

- I would like a copy of the research findings.

YES/NO

I (full name) hereby consent to take part in this study.

Signature

Date

Full names of Researcher - Josephine "Jo" Janssen

Contact Jo on 5724023 (home) or Wairau Hospital on pager 5209999

Project explained by Jo Janssen

Signature Date 


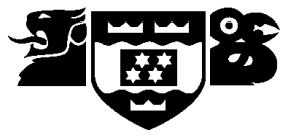

GRADUATE SCHOOL OF NURSING \& MIDWIFERY

Stakeholder Consent Form - non Ngati Rarua staff

THE DESIGN, IMPLEMENTATION AND EVALUATION OF A DIABETES AND HEART DISEASE EDUCATION PROGRAMME FOR MAORI

English - I wish to have an interpreter.

YES / NO

Maori - E hiahia ana ahau ki tetahi kaiwhakamaori/kaiwhaka pakeha korero.

AE/ KAO

- I have read and I understand the information sheet dated 19 May 2007 for volunteers taking part in the study to evaluate the diabetes and heart disease education programme.

- I have had the opportunity to use whanau support or a friend to help me ask questions. I am satisfied with the answers I have been given and understand the study.

- I understand that taking part in this study is voluntary (my choice) and that I may withdraw from the study at any time and this will in no way affect my involvement with Te Hauora O Ngati Rarua or my employment.

- I understand that my participation in this study is confidential and that no material, which could identify me, will be used in any reports on this study.

- I have had time to consider whether to take part.

- I know who to contact if I have any questions about the study.

- I consent to my interview being audio-taped.

YES/NO

- I would like a copy of the research findings.

YES/NO

I (full name) hereby consent to take part in this study.

Signature

Date

Researcher - Josephine "Jo" Janssen

Contact Jo on - 5724023 (Home) or Wairau Hospital on pager 5209999

Project explained by Jo Janssen Date 


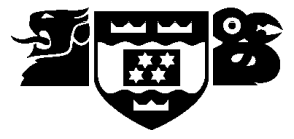

GRADUATE SCHOOL OF NURSING \& MIDWIFERY

\section{Participant Consent Form}

\section{THE DESIGN, IMPLEMENTATION AND EVALUATION OF A DIABETES AND HEART DISEASE EDUCATION PROGRAMME FOR MAORI}

\section{English - I wish to have an interpreter.}

YES / NO

Maori - E hiahia ana ahau ki tetahi kaiwhakamaori/kaiwhaka pakeha korero.

AE / KAO

- I have read and I understand the information sheet for volunteers taking part in the study to evaluate the diabetes and heart disease education programme.

- I have had the opportunity to use whanau support or a friend to help me ask questions. I am satisfied with the answers I have been given and understand the study.

- I understand that taking part in this study is voluntary (my choice) and that I may withdraw from the study at any time and this will in no way affect my continuing health care.

- I understand that my participation in this study is confidential and that no material, which could identify me, will be used in any reports on this study.

- I have had time to consider whether to take part.

- I know who to contact if I have any questions about the study.

- I consent to my talk with Jo Janssen being audio-taped.

YES/NO

- I would like a copy of the research findings.

YES/NO

- I agree to my GP passing on my blood test results and medical history to the study and to him/her being informed of the clinical results of my participation in this study.

YES/NO 

(full name) hereby consent to take part in this study.

Signature Date

Full names of Researcher - Josephine "Jo" Janssen

Contact for Jo: 5724023 (home) or Wairau Hospital on pager -520 9999

Project explained by Jo Janssen and Heather Oehlrich (Programme Coordinator)

Name

Signature Date 


\section{Appendix H - Interview Guidelines}

\section{STAKEHOLDER INTERVIEW GUIDE - Ngati Rarua staff}
KEY:
Q. - Question
P. - Prompt

First I would like to thank you for being prepared to come to this interview. Have you read and understood the Information Sheet and Consent Form?

Q. Tell me about your role on this programme as you see it.

$P$. When did your role start?

P. Has it changed over time?

P. How well prepared do you feel for your role?

$P$. What has been the preparation for this and other roles that you have had within this organisation (Ngati Rarua)?

P. Is there any further preparation that you would like?

Q. Regarding the disease process of diabetes and heart disease, and the management of these. Do you feel that the right information was covered and in an adequate depth for people to understand their condition and to be able to monitor it themselves?

P. What changes would you like to see made?

$P$. What are your thoughts on the practicality and relevance of the information for people's everyday lives?

Q. What are your thoughts about the effectiveness of the lifestyle/risk factor management component of the programme?

P. In general, what were your impressions regarding people's knowledge before and after the programme?

P. Did you get a sense of people having made positive changes to their lifestyles?

Yes - Tell me about them. No - Did you get the sense that people might have shifted into contemplating change? Tell me about that. 
Q. Now think about the organisation of the programme. Did the date, timing and venue suit you?

P. Yes - could it have been better? No - Tell me about that.

P. Tell me about the participants, did any of them raise issues around timing, transportation or venue?

P. Do you have any thoughts about the length of the course?

P. Can you think of any other improvements that could be made to the way the programme is organised?

Q. There were a number of different teaching methods used on this programme; things like group activities, brainstorming to see what people already know, talks with PowerPoint prompts, group exercise activities and practical demonstrations like label reading and the supermarket tour. Which of these do you feel worked best for people?

P. Which of these do you think they learnt the most from?

P. Which of these do you feel most comfortable using yourself?

$\mathrm{P}$. Are there other teaching methods you would like to try in the future?

Q. There were a number of programme resources used, including various pamphlets and posters and the large boards showing the fat and sugar content of some popular foods. What are your thoughts on the usefulness of these resources?

P. Share with me any participants' comments on these.

$P$. Are you aware of any other resources we could access for the future?

Q. Were you involved in any teaching or facilitation on this programme?

$P$. Did you receive any feedback from participants or colleagues about your performance?

P. How do you feel about your own performance, including knowledge and teaching skills?

Q. Did you have any involvement in the case management side of the programme? That is one-to-one meetings with participants, making sure they 
were getting optimum treatment from their primary provider and advocating for them with their provider if not.

No - Do you have any thoughts on this side of the programme that you would like to share anyway?

Yes - What were your experiences of fulfilling this role?

Q. Do you have any experience of working as a health educator or health care provider for a "mainstream" organisation? Please compare your experiences working for the different organisations.

What do you see as the benefits of this "by Maori - for Maori" service for Maori clients?

Tell me about any drawbacks or aspects that you feel could be improved.

Do you have any comments you would like to make regarding the use of te reo? 


\section{STAKEHOLDER INTERVIEW GUIDE - non-Ngati Rarua staff}

KEY: $\quad$ Q. - Question $\quad$ P. - Prompt

First I would like to thank you for being prepared to come to this interview. Have you read and understood the Information Sheet and Consent Form?

Q. Tell me about your role on this programme as you see it.

P. When did your role start?

P. Has it changed over time?

P. How well prepared do you feel for your role?

P. What has been the preparation for this and other roles that you have had within this organisation (Ngati Rarua)?

$P$. Is there any further preparation that you would like?

Q. Regarding the disease process of diabetes and heart disease, and the management of these. Do you feel that the right information was covered and in an adequate depth for people to understand their condition and to be able to monitor it themselves?

P. What changes would you like to see made?

P. What are your thoughts on the practicality and relevance of the information for people's everyday lives?

Q. What are your thoughts about the effectiveness of the lifestyle/risk factor management component of the programme?

P. In general, what were your impressions regarding people's knowledge before and after the programme?

P. Did you get a sense of people having made positive changes to their lifestyles?

Yes - Tell me about them. No - Did you get the sense that people might have shifted into contemplating change? Tell me about that.

Q. Now think about the organisation of the programme. Did the date, timing and venue suit you? 
P. Yes - could it have been better? No - Tell me about that.

$P$. Tell me about the participants, did any of them raise issues around timing, transportation or venue?

$P$. Do you have any thoughts about the length of the course?

$P$. Can you think of any other improvements that could be made to the way the programme is organised?

Q. There were a number of different teaching methods used on this programme; things like group activities, brainstorming to see what people already know, talks with PowerPoint prompts, group exercise activities and practical demonstrations like label reading and the supermarket tour. Which of these do you feel worked best for people?

P. Which of these do you think they learnt the most from?

P. Which of these do you feel most comfortable using yourself?

P. Are there other teaching methods you would like to try in the future?

Q. There were a number of programme resources used, including various pamphlets and posters and the large boards showing the fat and sugar content of some popular foods. What are your thoughts on the usefulness of these resources?

P. Share with me any participants' comments on these.

P. Are you aware of any other resources we could access for the future?

Q. Were you involved in any teaching or facilitation on this programme?

$P$. Did you receive any feedback from participants or colleagues about your performance?

P. How do you feel about your own performance, including knowledge and teaching skills?

Q. Did you have any involvement in the case management side of the programme? That is one-to-one meetings with participants, making sure they were getting optimum treatment from their primary provider and advocating for them with their provider if not. 
No - Do you have any thoughts on this side of the programme that you would like to share anyway?

Yes - What were your experiences of fulfilling this role?

Q. You are currently working as a health educator for a "mainstream" organisation that is not working from a kaupapa Maori approach. Please compare this experience with what you know of Te Hauora $\mathrm{O}$ Ngati Rarua's approach.

What do you see as the benefits of this "by Maori - for Maori" service for Maori clients?

Tell me about any drawbacks or aspects that you feel could be improved.

Do you have any comments you would like to make regarding the use of te reo? 


\section{MDNE INTERVIEW QUESTIONS}

KEY: $\quad$ Q. - Question $\quad$ P. - Prompt

Q. Tell me about your role on this programme as you see it.

P. When did your role start?

P. Has it changed over time?

P. What has been the preparation for this and other roles that you have had within this organisation?

$P$. Is there any further preparation that you would like?

Please provide a few details about the programme.

How many times has the programme run?

How many people have completed the programme?

How many potential participants do you have on your books at present?

When and how often do you plan to run the programme this year?

Q. Regarding the disease processes of diabetes and heart disease, and the management of these, do you feel that the right information was covered and in an adequate depth for people to understand their condition and to be able to monitor it themselves?

P. What changes would you like to see made?

$P$. What are your thoughts on the practicality and relevance of the information for people's everyday lives?

Q. What are your thoughts about the effectiveness of the lifestyle/risk factor management component of the programme?

P. In general, what were your impressions regarding people's knowledge before and after the programme?

P. Did you get a sense of people having made positive changes to their lifestyles?

Yes - Tell me about them. No - Did you get the sense that people might have shifted into contemplating change? Tell me about that. 
Do you feel that the recommendations suggested in diabetes resources are practical for your clients or do you find yourself deviating from them for certain clients?

Q. Now think about the organisation of the programme. Did the date, timing and venue suit you?

P. Yes - could it have been better? No - Tell me about that.

P. Tell me about the participants, did any of them raise issues around timing, transportation or venue?

P. Do you have any thoughts about the length of the course?

P. Can you think of any other improvements that could be made to the way the programme is organised?

Q. There were a number of different teaching methods used on this programme; things like group activities, brainstorming to see what people already know, talks with PowerPoint prompts and practical demonstrations like label reading and the supermarket tour.

P. Which of these do you think they learnt the most from?

P. Which of these do you feel most comfortable using yourself?

P. Are there other teaching methods you would like to try in the future?

Q. There were a number of programme resources used, including various pamphlets and posters, the 'What's the fuss' flip chart and the large boards showing the fat and sugar content of some popular foods. What are your thoughts on the usefulness of these resources?

P. Share with me any participants' comments on these.

P. Are you aware of any other resources you could access for the future?

Q. Regarding the teaching or facilitation on this programme (both yourself and others):

P. Did you receive any feedback from participants or colleagues about your own performance and/or that of others? 
P. How do you feel about your own performance, including knowledge and teaching skills?

Q. Regarding the case management side of the programme, that is one-to-one meetings with participants, making sure they were getting optimum treatment from their primary provider and advocating for them with their provider if not.

Please describe what this role involves in your experience.

Do you have any suggested changes for this role?

What particular qualities do you feel you bring to this role?

Q. Do you think that this service from Te Hauora $O$ Ngati Rarua is providing something that clients cannot or do not receive from a "mainstream" provider?

Yes - Please try to explain, i.e. What do you see as the benefits of this service for Maori clients? Non-Maori clients?

Tell me about any drawbacks or aspects that you feel could be improved.

Do you have any comments you would like to make regarding te reo? e.g. your level of knowledge and confidence with use of te reo, situations where it is useful, situations where you wouldn't use it.

Have you received any comments from clients regarding te reo or hui protocol content on the programme or in case management that you would like to share? How has it been for you being employed by this organisation, compared to your experience of working for a "mainstream" service? Try to define the differences as you see them.

Do you have any future plans for the programme or other parts of the service that you have not already mentioned?

Please describe the role of other people involved in the programme or case management so that my supervisor and I can determine whether I should interview them e.g. (names deleted). 


\section{INTERVIEW GUIDELINES - INTERVIEW WITH MANAGER 21 NOV 2007}

When and how did involvement with the agency start?

Changed over time?

Preparation for role?

Any comments about the way the service is educating people to manage their diabetes and heart disease?

Any comments about the education programme - timing, venue, attendance? One day hui?

Thoughts on content, teaching methods, resources?

Any comments re case management e.g. workloads, contract/funding?

What do you see as the benefits of this "by Maori - for Maori" service for Maori clients?

Tell me about any drawbacks or aspects that you feel could be improved

Any comments regarding use of te reo?

Any particular strategies to reach those most in need? 


\section{PROGRAMME PARTICIPANT INTERVIEW GUIDE}
KEY:
Q. - Question
P. - Prompt

First I would like to thank you for giving up your time to come to this interview. Have you read and understood the Information Sheet and Consent Form?

This interview is about the diabetes and heart disease programme you have been coming to for the last 6-8 weeks.

Q. Tell me about why you came to be on this program.

P. When did you hear about it?

P. Who did you hear about it from?

P. What did you know about it beforehand?

Q. Think about your knowledge about diabetes before the course, how do you rate it?

P. How do you rate your knowledge now?

P. Can you give me some examples?

Q. Now your knowledge about heart disease, how do you rate that before the course?

P. How do you rate it now?

P. Can you give me an example?

Q. The course aimed to teach you and your whanau how to monitor your condition, things like checking your blood glucose, foot cares, managing angina and looking for signs of heart failure like shortness of breath and swollen ankles. Do you feel more confident in managing your own care now? 
P. Tell me about these things.

P. What about your whanau, do they feel more confident, do they know what to do in an emergency, for example if you develop severe chest pain?

Q. A lot of the course content was about changing diet. Compare your knowledge on healthy eating before the course with your knowledge now.

P. Have you changed your diet as a result of being on the course?

P. What changes have you made?

Q. This dietary advice included healthier ways of preparing low cost meals and how to read food labels. Did you already know how to do these things or was this new information?

P. Do you follow these suggestions now?

Q. Have you made other lifestyle changes such as increasing activity or giving up smoking?

P. Yes - How? No - Why not?

Q. Was there anything you would have liked to learn about that wasn't in the programme?

P. Was there anything else you thought could have been in there?

Q. Has your life changed in any other way as a result of doing this course?

Yes - tell me about it. 
Q. The course used a lot of different teaching methods like Powerpoint displays during teaching sessions and group activities like cooking demonstrations, shopping trips and label reading. Which of these do you remember?

P. Were any particularly helpful?

P. Was there any method or session that you didn't like or found unhelpful?

Q. Now think about the different pictures and displays that were used by the course, I have a few of them here to remind you. What are your comments about them?

P. Were they easy to understand?

P. Did you take pamphlets away and read them?

P. Yes - what did you think? No - why not?

Q. Now think about the timing of the course. Did this suit you? 2 hours on a afternoon.

P. Should the sessions have been longer? or shorter?

P. Was $6 / 8$ weeks too long or not long enough?

P. Did you have any problems in trying to get to the sessions? Yes - tell me about these.

Q. What about the facility you came to for the sessions. Was it comfortable?

P. Would anything have made it better?

Q. Now think about the teaching on the course, did it suit your needs as a learner? 
P. Please comment on your teachers's knowledge, teaching skill and enthusiasm

P. Did you feel motivated to make lifestyle changes after coming to the sessions?

Q. Do you have any general comments about receiving health care and information from an iwi health provider rather than "mainstream" health providers? 


\section{Appendix I - Study Enrolment Form}

VICTORIA UNIVERSITY OF WELLINGTON

Te Whare Wananga o te Upoko o te Ika a Maui

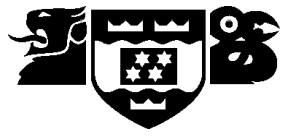

GRADUATE SCHOOL OF NURSING \& MIDWIFERY

\section{EVALUATION OF TE HAUORA O NGATI RARUA DIABETES AND HEART DISEASE EDUCATION PROGRAMME}

\section{STUDY ENROLMENT FORM}

Please complete the following details when enrolling clients in the above study. If you would like to discuss or clarify any aspect of this process please contact: Jo Janssen 5209999 on pager or Heather Oehlrich on 021488634.

STUDY NUMBER:

AGE: GENDER: MALE / FEMALE

ETHNICITY

1) HISTORY OF CARDIOVASCULAR DISEASE:

Myocardial infarction (MI) Y/N, Date/s

Coronary artery bypass grafts or angioplasty $\mathrm{Y} / \mathrm{N}$, Date/s

Angina $\mathrm{Y} / \mathrm{N}$,

Congestive heart failure (CHF) $\mathrm{Y} / \mathrm{N}$,

Ischaemic stroke $\mathrm{Y} / \mathrm{N}$, Date/s 
Transient ischaemic attack (TIA) Y/N, Date/s

Peripheral vascular disease (PVD) Y/N,

Cardiac Medications: (incl. dose)

DATE OF FASTING LIPID TEST: (in the last 3 months)

Total Cholesterol:

LDL Cholesterol:

HDL Cholesterol:

Triglycerides:

HDL/Cholesterol ratio:

2) DIABETIC HISTORY: type of Diabetes: type 1 / type 2

Duration of illness: Years or months since diagnosis.

Complications: Neuropathy $\mathrm{Y} / \mathrm{N}$, Renal Impairment $\mathrm{Y} / \mathrm{N}$,

Other $\mathrm{Y} / \mathrm{N}$ - please specify

Diabetes

Medications:

(incl.

dose)

DATE OF BLOOD TEST: (within last 3 months)

Fasting glucose:

$\mathrm{HbA1c}$ :

Albumin:

Creatinine: 
3) OTHER INFORMATION:

Other medications:

Other medical history or relevant information:

Smoker / Non Smoker / Ex Smoker (<3 yr / > 3yr)

Average daily alcohol Intake:

IMMEDIATE FAMILY MEMBER/S (parent or sibling) WITH HEART DISEASE (angina, MI, TIA, ischaemic stroke) OR DIABETES (type 1/type 2)

Relationship

Condition/s

Age of onset for each condition

Relationship

Condition/s

Age of onset for each condition

Relationship

Condition/s

Age of onset for each condition 
Blood Pressure No 1: Blood Pressure No 2:

AVERAGE BP:

Height:

Weight:

BMI:

Waist circumference:

Heart Rate:

Calculated 5 year cardiovascular risk and treatment benefit:

The client has read and understood the information sheet and consented to being a participant in this study. Yes / No 


\section{Appendix J - Transcribers Confidentiality Agreement}

VICTORIA UNIVERSITY OF WELLINGTON

Te Whare Wananga o te Upoko o te Ika a Maui

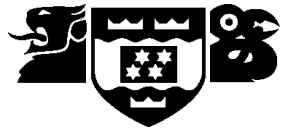

\section{GRADUATE SCHOOL OF NURSING \& MIDWIFERY}

Confidentiality Agreement for Transcriber of a Research study, titled:

The design, implementation and evaluation of a heart disease and diabetes education programme for Maori

Researcher: Jo Janssen

I have read the information sheet outlining this study. I have discussed with the researcher the nature of the research and have had any questions that I have had answered to my satisfaction. My role as the research transcriber has been outlined to me by the researcher.

At all times the research information (tapes and transcripts) will be inaccessible to other persons. The researcher has assured me that she will debrief me following transcribing to address any issues that transcribing bring up for me.

Most importantly, I understand and agree to keep the information I hear and type in the course of transcribing confidential to the researcher and myself.

Full Name:

Signature:

Date:

Researcher's Signature:

Date: 


\section{Appendix K - Rigour/Validity Strategy}

\section{INTERNAL VALIDITY}

There were multiple threats to the internal validity of the explanatory aspects of this case study, in terms of inferring that improvements in clients' physiological outcomes, diabetes management or lifestyle behaviour were due to their involvement with the programme. For example events outside the programme such as media campaigns, a personal health crisis or the influence of other health professionals, and whanau or friends could be significant. There was a potential for "instrument decay" in the sphygmomanometer and scales which were not recalibrated during the study (DePoy \& Gitlin, 2005). With the preparedness to change, diabetes management and lifestyle behaviour assessments there was a potential for a "response bias", with participants expressing more commitment to lifestyle changes than they actually felt (Gillis \& Jackson, 2002), and Peat, Mellis, Williams and Xuan (2001) warn that responses may be biased by many factors when subjective measurements are being used as they are here. This study was also at risk of the "Hawthorne effect" as subjects might be independently motivated as a function of their involvement in this research (Gillis \& Jackson, 2002).

\section{CONSTRUCT VALIDITY}

Construct validity is a form of internal validity and concerns establishing the correct operational measures for the concepts being studied. "When an instrument is valid, it measures the concept it was intended to measure" (Gillis \& Jackson, 2002, p. 428). The physiological outcome measures assessed throughout the study have established standards of validity (Peat et al., 2001), although there is vigorous debate about the legitimacy of their constructs (BMI/obesity) as risk factors and whether the established range is valid for the Maori ethnic group (Bateman, 2004; Worth, 2004). Raised fasting blood glucose and $\mathrm{HbA1c}$ give an accurate indication of the severity of diabetes and the stability of the client's blood glucose in the last three months (medicaldictionary, 2008). Serum cholesterol and hypertension are well supported as 
risk factors for diabetes and CHD, (Worth, 2004) but debate persists regarding normal ranges and ideal indicators (Garber, 1996; Rosenson, 2004; Stamler, Wentworth \& Neaton, 1986). All constituents of the fasting cholesterol, HbA1c and fasting serum glucose were assessed as part of this study. Self-reports of smoking cessation have demonstrated variable levels of reliability (Sandhu, Humphris, Whitley, Cardozo \& Sandhu, 2004; Klebanoff, 1998; McDonald, 2003; Britton, Brinthaupt, Stehle, \& James, 2004), but given the low number of participants in this study who were smoking, self-reports were thought to be adequate for the purpose.

\section{RELIABILITY}

Demonstrating reliability consists of ensuring that the operations of a study, such as the data collection procedures can be repeated, with the same results, with the goal of minimising the errors and biases in a study (Yin, 2003). There are three attributes of reliability: stability, internal consistency and equivalence (Depoy \& Gitlin, 2005). Inter-rater reliability or equivalence were not a major concern because all physiological data was collected by the MDNE using the same equipment and all interview data was collected by the researcher. The researcher worked closely with the MDNE and the participants during the process of completing the Study Enrolment Form to ensure that data was collected in an objective and systematic manner and the researcher and MDNE had regular meetings throughout the data collection phase to work through any procedural matters (Gillis \& Jackson, 2002).

\section{EXTERNAL VALIDITY - GENERALISABILITY}

This concerns establishing the domain to which a study's findings can be generalised (Yin, 2003). Baseline and outcome data for blood glucose, HbA1c, cholesterol, smoking prevalence, weight and blood pressure can be compared with the results of Russell et al. (1999) and Skeaff, Mann, McKenzie, Wilson and Russell (2001) and Robson and Harris (2007) to assess representativeness of the client group and compare the intervention with results nationally. Participant selection by the MDNE and self-selection and refusals by participants may have created a selection bias, which may affect the 
representativeness of the sample and the generalisability of the findings (Depoy \& Gitlin, 2005; Gillis \& Jackson, 2002). Also the level of co-morbidity would affect generalisability of results (Starfield, 2006). 


\section{References}

Abel, S., Gibson, D., Ehau, T., \& Tipene Leach, D. (2005). Implementing the Primary Health Care Strategy: A Maori health provider perspective. Social Policy Journal of NZ, 25, 70-87.

Ajwani, S., Blakely T., Robson, B., Tobias, M., \& Bonne, M. (2003). Decades of Disparity: Ethnic Mortality Trends in New Zealand 1980-1999. Wellington: Ministry of Health and University of Otago.

Anand, S., Yusuf, S., Jacobs, R., Davis, A., Yi, Q., Gerstein, H., et al. (2001). Risk factors, atherosclerosis, and cardiovascular disease among aboriginal people in Canada: The study of health assessment and risk evaluation in aboriginal peoples. The Lancet, 358, 1147-1153.

Anderson, R., \& McDaniel, R. (2000). Managing health care organisations: Where professionalism meets complexity science. Health Care Management Review, 25, 83-92.

Armitage, G., \& Hodgson, I. (2004). Using ethnography (or qualitative methods) to investigate drug errors: A critique of a published study. NT Research, 9, 379-387.

Baileff, A. 2000. Integrated nursing teams in primary care. Nursing Standard, 14 (48), 41-44.

Barr Taylor, C. B., Houston Miller, N., Reilly, K. R., Greenwald, G., Cunning, D, Deeter, A., et al. (2003). Evaluation of a nurse-care management system to improve outcomes in patients with complicated diabetes. Diabetes Care, 26, 1058-1063.

Bateman, K. (2004, June 1). Is there a good excuse? Retrieved November 8, 2004, from www.zoneperfect.com/Site/content/downunder_Detail.asp?id=5082

Baxter, J. (2002). Barriers to health care for Māori with known diabetes: A literature review and summary of issues. Wellington: New Zealand: National Working Group on Diabetes.

Bergen, A., \& While, A. (2000). A case for case studies: Exploring the use of case study design in community nursing research. Journal of Advanced Nursing, 31, 926-934.

Best, J., \& O'Neal, D. (2000). Treating elevated lipids - does it make a difference? Australian Family Physician, 29, 223-226.

Bevan-Brown, J. (1998). By Maori, for Maori, about Maori - is that enough? In Te Pumanawa Hauora (Ed.), Te Oru Rangahau. Maori Research and 
Development Conference 7 - 9 July 1998 Proceedings (pp. 231-245). School of Maori Studies. Palmerston North: Massey University.

Bishop, R. (2005). Freeing ourselves from neocolonial domination in research. A kaupapa Maori approach to creating knowledge. In N. K. Denzin \& Y. S. Lincoln (Eds.), The Sage Handbook of Qualitative Research (3 ${ }^{\text {rd }} \mathrm{ed}$., pp. 109-138). Thousand Oaks: Sage Publishing.

Blakely, T., Tobias, M., Atkinson, J., Yeh, L-C., \& Huang, K. (2007). Tracking disparity: Trends in ethnic and socioeconomic inequalities in mortality, 1981-2004. Wellington: Ministry of Health.

Borbasi, S., Jackson, D., \& Wilkes, L. (2005). Fieldwork in nursing research: Positionality, practicalities and predicaments. Journal of Advanced Nursing, 51, 493-501.

Boulton, A. (2005). Provision at the interface: The Maori mental health contracting experience. Unpublished doctoral thesis, Massey University, Palmerston North.

Boulton, A. (2007). Taking account of culture: The contracting experience of Maori mental health providers. Alternative, 3 (2), 125-141.

Boulton, A., Simonsen, K., Walker, T., Cumming, J., \& Cunningham, C. (2004). Indigenous participation in the 'new' New Zealand health structure. Journal of Health Services Research \& Policy. 9, S35-41.

Bramley, D., Riddell, T., Crengle, S., Curtis, E., Harwood, M., Nehua, D., et al. (2004). A call to action on Māori cardiovascular health. [Electronic version] New Zealand Medical Journal, 117, 957. Retrieved April 1, 2008 from www.nzma.org.nz/journal/117-1197/957

Britton, G. R., Brinthaupt, J., Stehle, J. M., \& James, G. D. (2004). Comparison of self-reported smoking and urinary cotinine levels in a rural pregnant population. Journal of Obstetric, Gynaecologic, \& Neonatal Nursing, 33, 306-311.

Cass, A. (2004). Health outcomes in Aboriginal populations. Canadian Medical Association Journal, 171, 597-598.

Cassie, F. (2004). Nurse practitioner preparing for the future. New Zealand Nursing Review, 4 (9), 4.

Castelli, W. P., Garrison, R. J., Wilson, P. W. F., Abbott, R. D., Kalousdian, S., \& Kannel, W. B. (1986). Incidence of coronary heart disease and lipoprotein cholesterol levels - the Framingham Study. JAMA, 256, 28352838. 
Clarke, C., \& Reed, J. (2006). Case study research. In K. Gerrish \& A. Lacey. (Eds.), The research process in nursing ( $5^{\text {th }}$ ed., pp. 302-314). Oxford, UK: Blackwell Publishing Ltd.

Collier, H. (n.d.) Te ako hikohiko (Maori and E. learning): He aronga (A Maori worldview). Maori and Administrative Studies Te Wananga-o-Raukawa. Retrieved May 24, 2006, from www.uctl,canterbury.ac.nz/documents/r02collier.doc

Cram, F., Smith, L., \& Johnstone, W. (2003). Mapping the themes of Maori talk about health. New Zealand Medical Journal, 116, 357.

Crengle, S. (2000). The development of Maori primary care services. Pacific Health Dialogue, 7, 48-53.

Cunningham, C. (1998). A framework for addressing Maori knowledge in research, science and technology. In Te Pumanawa Hauora (Ed.), Te Oru Rangahau. Maori Research and Development Conference 7 - 9 July 1998 Proceedings (pp. 394-404). School of Maori Studies. Palmerston North: Massey University.

Cunningham, C., \& Durie, M. (2005). Te rerenga hauora. In K. Dew \& P. Davis (Eds.), Health and society in Aotearoa New Zealand ( $2^{\text {nd }}$ ed., pp. 211232). Melbourne: Oxford University Press.

Cunningham, C., \& Kiro, C. (2001). Rapuhia mo te Hauora Maori. In P. Davis \& T. Ashton (Eds.), Health and public policy in New Zealand (pp. 62-81). Auckland: Oxford University Press.

Davis, P., Lay-Yee, R., Dyall, L., Briant, R., Sporle, A., Brunt, D., et al. (2006). Quality of hospital care for Māori patients in New Zealand: Retrospective cross-sectional assessment. The Lancet, 367, 1920-25.

de Ridder, D., Geenen, R., Kuijer, R., \& von Middendorp, H. (2008). Psychological adjustment to chronic disease. The Lancet, 372, 246-255.

Deakin, T., McShane, C. E., Cade, J. E., \& Williams, R. D. (2007). Group based training for self-management strategies in people with type 2 diabetes mellitus. Cochrane Database of Systematic Reviews 2005, Issue 2.

Depoy, E., \& Gitlin, L. N. (2005). Introduction to research: Understanding and applying multiple strategies ( $3^{\text {rd }}$ ed.). St Louis: Elsevier Mosby.

Dew, K., \& Kirkman, A. (2002). Sociology of health in New Zealand. Melbourne: Oxford University Press.

Dunbar-Jacob, J., \& Mortimer-Stephens, M. K. (2001). Treatment adherence in chronic disease. Journal of Clinical Epidemiology, 54, S50-60. 
Durie, M. (1998). Whaiora Maori health development $\left(2^{\text {nd }}\right.$ ed.). Melbourne: Oxford University Press.

Durie, M. (1999). Te Pae Mahutonga: A model for Maori Health Promotion. Health Promotion Forum of New Zealand Newsletter, 49, 2-4.

Ellison-Loschmann, L., \& Pearce, N. (2006). Improving access to health care among New Zealand's Maori population. American Journal of Public Health, 96, 612-617.

Expert Advisory Group on Primary Health Care Nursing. (2003). Investing in Health: Whakatohutia te Oranga Tangata framework for activating primary health care nursing in New Zealand. Wellington: Ministry of Health. Retrieved Aug 3, 2008 from http://www.moh.govt.nz/moh.nsf/ea6005dc347e7bd44c2566a40079ae6f/a 4d86036478a63a7cc256bde006ff204/\$FILE/InvestingInHealth.pdf

Ferguson, W., \& Candib, L. (2002). Culture, Language, and the Doctor-Patient Relationship. Family Medicine, 34, 353-361.

Fisher, E. B., Brownson, C. A., O'Toole, M. L., \& Anwuri, V. V. (2007a). Ongoing follow-up and support for chronic disease management in the Robert Wood Johnson Foundation Diabetes Initiative. The Diabetes Educator 33 (Suppl. 6), 201S-207S.

Fisher, E. B., Brownson, C. A., O'Toole, M. L., Anwuri, V. V., \& Shetty, (2007b). Perspectives on self-management from the diabetes initiative of the Robert Wood Johnson Foundation. The Diabetes Educator, 33 (Suppl. 6), 216S$224 S$.

Foley, J. (2008). Community Services Card Review. Retrieved May 28, 2008 from www.moh.govt.nz/moh.nsf/pagesmh/5531/\$File/CSCReviewReport.pdf

Garber, A. M. (1996). Review: Cholesterol lowering reduces mortality in highrisk, middle-aged men. ACP Journal Club, 125, 13-15.

Germov, J. (1999). Second opinion: An introduction to health sociology (Rev. ed.). Melbourne: Oxford University Press.

Gillis, A., \& Jackson, W. (2002). Research for nurses: Methods and interpretation. Philadelphia: F.A. Davis Company.

Glasgow, R., Davis, C., Funnell, M., \& Beck, A. (2003). Implementing practical interventions to support chronic illness self-management. Joint Commission Journal on Quality and Safety, 29, 563-574.

Greenhalgh, T. (2001). How to read a paper (2nd ed.). London: BMJ Publishing Group. 
Hansen, C., Carryer, J., \& Budge, C. (2007). Public health nurses' views on their position within a changing health system. Nursing Praxis in New Zealand, 23, 14-26.

Harris, M., \& Associates. (2002). Managing health services concepts and practice. Sydney: MacLennan and Petty Pty Ltd.

Harris, R., Tobias, M., Jeffreys, M., Waldegrave, K., Karlsen, S., \& Nazroo, J. (2006). Effects of self-reported racial discrimination and deprivation on Māori health inequalities in New Zealand: Cross-sectional study. The Lancet, 367, 2005-2009.

Health Promotion Forum of New Zealand. (2002). Tuha - NZ a Treaty understanding of hauora in Aotearoa - New Zealand. Health Promotion Forum of New Zealand.

Health Research Council of New Zealand (HRC). (1998). Guidelines for researchers on health research involving Maori. Retrieved November 6 , 2004, from http://www.hrc.govt.nz

Health Workforce Advisory Committee. (2006). Report of the Health Workforce Advisory Committee on Encouraging Māori to Work in the Health Professions. Retrieved August 2, 2008, from http://www.hwac.govt.nz/publications/EncouragingMaoritoWorkintheHealth Professions.pdf

Highstein, G. R., O'Toole, M. L., Shetty, G., Brownson, C. A., \& Fisher, E. B. (2007). Use of the Transtheoretical Model to enhance resources and supports for diabetes self management. Lessons from the Robert Wood Johnson Foundation Diabetes Initiative. The Diabetes Educator, 33(Suppl.6), 193S-200S.

Holloway, I., \& Todres, L. (2006). Ethnography. In K. Gerrish \& A. Lacey. (Eds.), The research process in nursing ( $5^{\text {th }}$ ed., pp. 209-223). Oxford, UK: Blackwell Publishing Ltd.

Howden-Chapman, P. (2005). Unequal Socio-economic determinants, unequal health. In K. Dew \& P. Davis (Eds.), Health and society in Aotearoa New Zealand ( $2^{\text {nd }}$ ed., pp. 51-68). Melbourne: Oxford University Press.

Hung, D. Y., Rundall, T. G., Tallia, A. F., Cohen, D. J., Halpin, H. A., \& Crabtree, B. F. (2007). Rethinking prevention in primary care: Applying the Chronic Care Model to address health risk behaviours. The Milbank Quarterly, 85, 69-91.

Hutchinson, L. (1999). Evaluating and researching the effectiveness of educational interventions. British Medical Journal, 318, (Health Module), 1267-1269. 
Improving Chronic Illness Care. (2008). The Chronic Care Model. Retrieved June 22, 2008, from http://www.improvingchroniccare.org/index.html

Israel, B. A., Cummings, K. M., Dignan, M. B., Heaney, C. A., Perales, D. P., Simons-Morton, B. G., et al. (1995). Evaluation of health education programs: Current assessment and future directions. Health Education Quarterly, 22, 364-387.

Jansen, P., \& Smith, K. (2006). Maori experiences of primary health care: Breaking down the barriers. New Zealand Family Physician, 33, 298-300.

Jansen, P., \& Sorrensen, D. (2002). Culturally competent health care. New Zealand Family Physician, 29, 306-311.

Janssen, J. (2006). Fat simple - a nursing tool for client education. Nursing Praxis in New Zealand, 22 (2), 21-32.

Jones, C. (2000). Levels of racism: A theoretical framework and a gardeners tale. American Journal of Public Health. 90, 1212-1215.

Kearns, R., \& Dyck, I. (2005). Culturally safe research. In D. Wepa (Ed.), Cultural safety in Aotearoa New Zealand (pp. 157-169). Auckland: Pearson Education New Zealand.

Kearse N., Buetow S., Mainous A., Young G., Coster G., \& Arroll B. (2004).Physician-patient relationship and medication compliance: $A$ primary care investigation. Annals of Family Medicine, 2, 455-461.

Kerr, G., Gamble, G., Doughty, R., Simmons, D., \& Baker, J. (2006). Mortality in individuals with type 2 diabetes and heart disease in a unique New Zealand population. Diabetic Medicine, 23, 1313-1318.

Klebanoff, M. A., Levine, R. J., DerSimonian, R., \& Wilkins, D. G. (1998). Serum cotinine concentration and self-reported smoking during pregnancy. American Journal of Epidemiology, 148, 259-262.

Krishnan, J., Diette, G., \& Rand, S. (2001). Disparities in outcomes from chronic disease. British Medical Journal, 323, 950.

Langford, A.T., Sawyer, D.R., Gioimo, S., Brownson, C.A., \& O'Toole, M.L. (2007). Patient-centred goal setting as a tool to improve diabetes selfmanagement. The Diabetes Educator, 33 (Suppl. 6), 139S-144S.

Lathlean, J. (2006). Qualitative analysis. In K. Gerrish \& A. Lacey. (Eds.), The research process in nursing ( $5^{\text {th }}$ ed., pp. 417-433). Oxford, UK: Blackwell Publishing Ltd.

Lawrence, T. (1999). A stage-based approach to behaviour change. In E. R. Perkins, I. Simnet \& L. Wright (Eds.), Evidence-based health promotion (pp. 64-75). Chichester: John Wiley \& Sons Ltd. 
Macdonald, J., \& Park, J. (2005). The culture of health and illness. In K. Dew \& P. Davis (Eds.), Health and society in Aotearoa New Zealand $\left(2^{\text {nd }}\right.$ ed., pp. 86-98). Melbourne: Oxford University Press.

MacLeod, G.K. (1994). II. International report. Health care financing reform in New Zealand. Health Affairs. 13, 210-214. Retrieved June 19, 2008, from http://content.healthaffairs.org/cgi/reprint/13/4/210

MacMillan, H., MacMillan, A., Offord, D., \& Dingle, J. (1996). Aboriginal health. Canadian Medical Association Journal, 155, 1569-1578.

Malcolm, L. (2004). Are we providing fair access to our health services for Maori? Retrieved February 18, 2007, from www.pha.org.nz/viewpoints.html

Manchester, A. (2006, June). Finding better ways of raising awareness of diabetes. Kai Tiaki Nursing New Zealand, 28-29.

Manchester, A. (2008). Home visiting key to successful nursing model. Reconnecting patients to primary health care. Kai Tiaki Nursing New Zealand, 14 (4), 11-13.

Maori Health Directorate. (2008). Maori Health Providers. Retrieved May 27, 2008, from www.maorihealth.govt.nz/moh.nsf/menuma/Maori+Health+Providers

Maori Health. (2008). Risk and protective factors > body weight. Retrieved August 10, 2008, from http://www.maorihealth.govt.nz/moh.nsf/indexma/body-weight

Mathison, S. (1988). Why triangulate? Education Researcher, 17(2), 13-17.

McCreanor, T., \& Nairn, R. (2002). Tauiwi general practitioners talk about Māori health: Interpretative repertoire. New Zealand Medical Journal, 115 (1167). Retrieved August 20, 2007, from http://www.nzma.org.nz/journal/115$1167 / 272 /$

McDonald, S. P., Maguire, G. P., \& Hoy, W. E. (2003). Validation of selfreported cigarette smoking in a remote Australian Aboriginal community. Australian \& New Zealand Journal of Public Health, 27, 57-60.

McEvoy, P., \& Barnes, P. (2007). Using the chronic care model to tackle depression among older adults who have long-term physical conditions. Journal of Psychiatric and Mental Health Nursing, 14, 233-238.

McKellar, J., Humphreys, K., \& Piette, J. (2004). Depression increases diabetes symptoms by complicating patients' self-care adherence. The Diabetes Educator, 30, 485-492. 
McNatty, W. (2001). Whanaungatanga. Department of Psychology, University of Waikato. Retrieved December 24, 2006, from www.starlight.net.nz/bill/whanaungatanga.htm

Medical Dictionary. (2008) Glycosylated hemoglobin Retreived September 16, 2008, from http://medical-dictionary.thefreedictionary.com/Hba1c

Meleis, A. I. (1996). Culturally competent scholarship: Substance and rigor. Advances in Nursing Science, 19(2):1-16.

Merriam, S., B. (1998). Qualitative research and case study applications in education. San Francisco, CA: Jossey-Bass Publishers.

Miles, M. B., \& Huberman, A. M. (1994). An expanded sourcebook: Qualitative data analysis (2nd ed.).Thousand Oaks: Sage Publications.

Mill, J. E., \& Ogilvie, L. D. (2003). Establishing methodological rigour in international qualitative nursing research: a case study from Ghana. Methodological Issues in Nursing Research. Journal of Advanced Nursing, $41,80-87$

Ministry of Health. (1996). He tatai $i$ te ara: Determining the path. Wellington: Author.

Ministry of Health. (2000). New Zealand Health Strategy. Wellington: Author.

Ministry of Health. (2001a). The New Zealand Disability Strategy. Wellington; Author.

Ministry of Health. (2001b). The Primary Health Care Strategy. Wellington; Author.

Ministry of Health. (2002a). He Korowai Oranga: Māori Health Strategy. Wellington: Author.

Ministry of Health. (2002b). Reducing inequalities in Health. Wellington: Author.

Ministry of Health. (2005a). Evolving models of Primary Health Care nursing practice. Wellington: Author.

Ministry of Health. (2005b). The Annual Report 2004/2005 including the Health and Independence Report. Wellington: Author.

Minister of Health. (2006a). Implementing the New Zealand Health Strategy 2006: The Minister of Health's sixth report on progress on the New Zealand Health Strategy. Wellington: Author.

Ministry of Health. (2006b). Tatau Kahukura: Maori health chart book. Public Health Intelligence Monitoring Report No.5. Wellington: Author. 
Ministry of Health. (2007). An indication of New Zealanders' health 2007. Wellington: Author.

Ministry of Health. (2008a). Care Plus. Retrieved August 7, 2008, from http://www.moh.govt.nz/moh.nsf/indexmh/phcs-projects-careplusservice

Ministry of Health. (2008b). Diabetes and Cardiovascular Disease Quality Improvement Plan. Wellington: Author.

Ministry of Health and University of Otago. (2006). Decades of disparity III: Ethnic and socioeconomic inequalities in mortality, New Zealand, 19811999. Wellington: Author.

Ministry of Social Development. (2006). The Social Report 2006: Indicators of social wellbeing in New Zealand. Wellington: Author.

Mol, A. (1998). Lived reality and the multiplicity of norms: A critical tribute to George Canguilhem. Economy and Society, 27, 274-284.

Moloney-Moni, J., \& North, N. (2003). Innovations in service delivery to improve Maori health outcomes: A mobile disease state management nursing service. Pacific Health Dialog, 10, 171-177.

Mullen, P., D., Simons-Morton, D., G., Ramirez, G., Frankowski, R., Green, L., W., \& Mains, D., A. (1997). A meta-analysis of trials evaluating patient education and counseling for three groups of preventive health behaviours. Patient Education and Counseling, 32, 157-173.

New Zealand Guidelines Group (NZGG). (2003a). The assessment and management of cardiovascular risk. Wellington: Author.

New Zealand Guidelines Group (NZGG). (2003b). Management of type 2 diabetes. Wellington: Author.

Nutbeam, D. (1998). Evaluating Health promotion - progress, problems and solutions. Health Promotion International, 13, 27-44.

Oberle, K., \& Storch, J. L. (2004). Nursing Ethics and Research. In J. Storch, L. P. Rodney \& R. Starzomski (Eds.), Toward a moral horizon - nursing ethics for leadership and practice (pp. 357-377). Toronto: Pearson Prentice Hall.

Oehlrich H. (2007). Marlborough Diabetes Nurse Educator Report 2007 to Nelson Marlborough District Health Board. Unpublished document.

Otago University. (2008). Ngati and healthy prevent diabetes project. Retrieved April 2, 2008, from www.otago.ac.nz/diabetes/research/ngati.html

Patton, M. Q. (1997). Utilisation-focused evaluation: A new century text. (3rd ed.). Thousand Oaks, California: Sage Publications. 
Peat, J., Mellis, C., Williams, K., \& Xuan, W. (2001). Health science research: A handbook of quantitative methods. NSW: Allen \& Unwin.

Penney, L., McCreanor, T., \& Barnes, H. M. (2006) New perspectives on heart disease management in Te Tai Tokerau: Māori and Health Practitioners Talk. Te Ropu Whariki. Auckland: Massey University

Perkins, E., Simnet, I., \& Wright, L. (1999). Evidence-based health promotion. Chichester: John Wiley and Sons Ltd.

Polonsky, W., Earles, J., Smith, S., Pease, D., Macmillan, M., Christensen, R., et al. (2003). Integrating medical management with diabetes selfmanagement training. Diabetes Care, 26, 3048-3053.

Prochaska, J. O., \& DiClemente, C. C. (1983). Stages and processes of selfchange of smoking: Toward an integrative model of change. Journal of Consulting and Clinical Psychology, 51(3), 390-395.

Public Health Consultancy. (2001). An assessment of health needs in the Nelson Marlborough District Health Board Region: Te tirohanga Hauora o te tau ihu o to waka a maui. Wellington School of Medicine and Health Sciences.

Ramsden, I. (1990). Cultural safety. NZ Nursing Journal, 83 (11), 18-19.

Reid, P., \& Robson, B. (2006). The state of Maori health. In M. Mulholland (Ed.) \& contributors, State of the Maori Nation twenty-first-century issues in Aotearoa (pp.17-31). Auckland: Reed Publishing Ltd.

Reid, P. (1999). Nga mahi whakahaehae a te tangata tiriti. In P. Davis \& K. Dew (Eds. in association with Te Ropu Rangahau Hauora a Eru Pomare.), Health and society in Aotearoa New Zealand (pp. 83-94). Auckland: Oxford University Press

Riddell, T., Jackson, R., Wells, S., Broad, J., \& Bannink, L. (2007). Assessing Maori/non-Maori differences in cardiovascular disease risk and risk management in routine primary care practice using web-based clinical decision support: (PREDICT CVD-2). New Zealand Medical Journal, 120 (1250). Retrieved September 6, 2008, from www.nzma.org.nz/journal/120$1250 / 2445 /$

Robbins, L., Pender, N., Conn, V., Frenn, M., Neuberger, G., Nies, M., et al. (2001). Physical activity research in nursing. Journal of Nursing Scholarship, 33, 315-321.

Robson, B., \& Harris, R. (Eds.). (2007). Hauora: Maori standards of health IV. A study of the years 2000-2005. Wellington: Te Ropu Rangahau Hauora a Eru Pomare. 
Robson, C. (2006). Evaluation research. In K. Gerrish \& A. Lacey (Eds.), The research process in nursing ( $5^{\text {th }}$ ed., pp. 289-301). Oxford, UK: Blackwell Publishing Ltd.

Rosenson, R. S. (2004). Overview of treatment of hypercholesterolaemia. Retrieved November 7, 2004, from www.utdol.com/application/topic/marketing/topicOutline.asp?file=lipiddis/5 110

Rowley, K., Daniel, M., Skinner, K., Skinner, M., White, G., \& O'Dea, K. (2000). Effectiveness of a community-directed 'healthy lifestyle' program in a remote Australian Aboriginal community. Australian and New Zealand Journal of Public Health, 24, 136-144.

Royal Commission on Social Policy, \& Te Komihana A Te Karauna Mo Nga Ahuatanga-A-Iwi. (1988). The Royal Commission on Social Policy. Wellington.

Russell, D., Parnell, W., Wilson, N., Faed, J., Ferguson, E., Herbison, P., et al. (1999). NZ Food: NZ People. Key results of the 1997 National Nutrition Survey. Wellington: NZ Ministry of Health.

Ryan, P.M. (1995). The Reed dictionary of Modern Maori ( $2^{\text {nd }}$ ed.). Wellington: Wright and Carman (NZ) Ltd.

Sandhu, S., Humphris, G., Whitley, S., Cardozo, A., \& Sandhu, A. (2004). Smoking habits in patients who have been treated for an oral cancer: validation of self-report using saliva cotinine. Oral Oncology, 40, 576-578.

Satterfield, D., Volansky, M., Caspersen, C., Engelgau, M., Bowman, B., Gregg, E. et al. (2003). Community-based lifestyle interventions to prevent type 2 diabetes. Diabetes Care, 26, 2643-2652.

Shea, S. (2006). Improving Maori access to primary care. Retrieved April 6, 2008, from www.sheaconsulting.co.nz

Simmons, D., Schaumkelt, J., Cecilt, A., Scott, D., \& Kenealy, T. (1999). High impact of nephropathy on five-year mortality rates among patients with type 2 diabetes mellitus from a multi-ethnic population in New Zealand. Diabetic Medicine, 16, 926-931.

Simmons, D., \& Voyle, J. (2003). Reaching hard-to-reach, high-risk populations: piloting a health promotion and diabetes disease prevention programme on an urban marae in New Zealand. Health Promotion International, 18, 41-50.

Simmons, D., Weblemoe, T., Voyle, J., Prichard, A., Leakehe, L., \& Gatland, B. (1998). Personal barriers to diabetes care: Lessons from a multi-ethnic community in New Zealand. Diabetic Medicine, 15, 958-964. 
Skeaff, C. M., Mann, I., McKenzie, J., Wilson, N. C., \& Russell, D. (2001). Declining levels of total serum cholesterol in adult New Zealanders. New Zealand Medical Journal, 114, 131-134.

Smith, L. T. (1999). Decolonizing methodologies research and indigenous peoples. London: Zed Books Ltd.

Smith, L. T. (2005) On tricky ground. Researching the native in the age of uncertainty. In N. K. Denzin \& Y. S. Lincoln (Eds.), The Sage Handbook of Qualitative Research (3 ${ }^{\text {rd }}$ ed., pp. 85-107). Thousand Oaks: Sage Publishing.

Stake. R. E. (1995). The art of case study research. Thousand Oaks: Sage Publications.

Stake, R. E. (2005). Qualitative case studies. In N. K. Denzin \& Y. S. Lincoln (Eds.), Handbook of qualitative research (3 ${ }^{\text {rd }}$ ed., pp. 443-466). Thousand Oaks: Sage Publications.

Stamler, J., Wentworth, D., \& Neaton, J. D. (1986). Is relationship between serum cholesterol and risk of premature death from coronary heart disease continuous and graded? JAMA, 256, 2823-2828.

Starfield, B. (2006). Threads and yarns: Weaving the tapestry of comorbidity. Annals of Family Medicine, 4, 101-103.

Statistics NZ. (2008). New Zealand Life Tables 2000- 2002. Retrieved April 2, 2008, from

http://www2.stats.govt.nz/domino/external/pasfull/pasfull.nsf/84bf91b1a7b 5d7204c256809000460a4/4c2567ef00247c6acc256e660082356b?OpenD ocument

Taubes, G. (2001). The soft science of dietary fat. Science, 291(5513), 25362545.

Te Hauora O Ngati Rarua. (2004). Strategic Plan 2005-2010. Unpublished document.

The Health Foundation. (2008). Briefing May 2008. Co-creating health. Retrieved June 21, 2008, from www.health.org.uk

Tipene-Leach, D., Pahau, H., Joseph, N., Coppell, K., McAuley, K., Booker, C., et al. (2004). Insulin resistance in a rural Maori community. New Zealand Medical Journal, 117 (1207). Retrieved April 24, 2005, from www.nzma.org.nz/journal/abstract.php?id=1208

Tod, A. (2006). Interviewing. In K. Gerrish \& A. Lacey (Eds.), The research process in nursing $\left(5^{\text {th }}\right.$ ed., pp. 337-352). Oxford, UK: Blackwell Publishing Ltd. 
Topping, A. (2006). Choosing the right approach. In K. Gerrish \& A. Lacey (Eds.), The research process in nursing ( $5^{\text {th }}$ ed., pp. 157-172). Oxford, UK: Blackwell Publishing Ltd.

Tukuitonga, C., \& Bindman, A. (2002). Ethnic and gender differences in the use of coronary artery revascularisation procedures in New Zealand. New Zealand Medical Journal, 115, 179-182.

Tully, E., \& Mortlock, B. (2005). Professionals and practices. In K. Dew \& P. Davis (Eds.), Health and society in Aotearoa New Zealand. $\left(2^{\text {nd }}\right.$ ed., pp. 130-145). Melbourne: Oxford University Press.

Turner, B. S. (1999). Citizenship and health as a scarce resource. In Germov, J. (Ed.). Second opinion: An introduction to health sociology (Rev. ed., pp. 302-314). Melbourne: Oxford University Press.

Twinn, S. (2000). The evaluation of the effectiveness of health education interventions in clinical practice: A continuing methodological challenge. Journal of Advanced Nursing, 34, 230-237.

Van Horn, L. (2001). A summary of the science supporting the new National Cholesterol Education Program dietary recommendations: What dietitians should know. Journal of the American Dietetic Association, 101, 11481154.

Vermeire, E., Wens, J., Van Royen, P., Biot, Y., Hearnshaw, H., \& Lindenmeyer, A. (2005, April). Interventions for improving adherence to treatment recommendations in people with type 2 diabetes mellitus. Cochrane Database of Systematic Reviews 2005, (2). Retrieved May 17, 2008, from Cochrane Database of Systematic Reviews.

Wagner, E. H. (1998). Chronic disease management: What will it take to improve care for chronic illness? Effective Clinical Practice, 1, 2-4.

Waikato DHB. (2005). Maori spearhead largest diabetes prevention study. (Media release) September 29, 2005. Retrieved April 2, 2008, from www.waikatodhb.govt.nz/WDHB/default.asp?Content=1055

Waldon, J. (2003). Oranga kaumatua: Perceptions of health in older Maori people. Pacific Health Dialog, 10, 79-86.

Walsh-Tapiata, W. (2003). The praxis of research - what can social services learn from the practice of research in an Iwi setting. Social Work Review. Spring 2003. 25-29.

Watson, H., \& Whyte, R. (2006). Using observation. In K. Gerrish \& A. Lacey (Eds.), The research process in nursing ( $5^{\text {th }}$ ed., pp. 383-398). Oxford, UK: Blackwell Publishing Ltd. 
Wellingham J., Tracey J., Rea H., \& Gribben B. (2003). The development and implementation of the Chronic Care Management Programme in Counties Manukau New Zealand Medical Journal, 116 (1169). Retrieved March 6, 2008, from www.nzma.org.nz/journal/116-1169/327/

Westbrooke, I., Baxter, J., \& Hogan, J. (2001). Are Maori under-served for cardiac interventions? New Zealand Medical Journal. 114, 484-487.

Whariki. (2005). Whariki 2005 Report. Te Ropu Whariki - Whariki Research Group. Massey University. Retrieved April 21, 2008, from www.whariki.ac.nz

Whittaker, R., Bramley, D., Wells, S., Stewart, A., Selak, V., Furness, S., et al. (2006). Will a web-based cardiovascular disease (CVD) risk assessment programme increase the assessment of CVD risk factors for Maori? New Zealand Medical Journal, 119 (1238). Retrieved September 5, 2008, from www.nzma.org.nz/journal/119-1238/2077/

Willams, P., Gray, M., Ka'ai, T., Moorfield, J., Mcpherson, K., Weinstein, P., et al. (2003). Maori men's perceptions and experiences of health seeking for prostate health problems in New Zealand. Pacific Health Dialog, 10, 71-78.

Willett, W., C., \& Stampfer, M., J. (2003). Rebuilding the food pyramid. Scientific American, 288, 64-71.

Wilson, D., \& Roberts, M. (2005). Maori health initiatives. In D. Wepa (Ed.), Cultural safety in Aotearoa New Zealand (pp. 157-169). Auckland: Pearson Education New Zealand.

Winkleby, M. A., Kraemer, H. C., Ahn, D. K., \& Varady, A. N. (1998). Ethnic and socioeconomic differences in cardiovascular disease risk factors. JAMA, 280, 356-362.

Wong, S., Wong, J., Makrides, L., \& Weerasinghe, S. (2002). A conceptual model for a culturally responsive community-based diabetes prevention programme. International Journal of Health Care Quality Assurance, 15 (13), 1-11.

World Health Organisation. (2000). The World Health Report 2000. Health systems: Improving performance. Geneva: Author.

World Health Organisation. (2008). Indigenous people's right to health. Retrieved August 23, 2008, from

http://www.who.int/hhr/activities/indigenous_peoples/en/index.html

Worth, P. (Interviewee). (2004). Interview with Linda Clark regarding relationship between $B M I$ and mortality (Radio Interview): Wellington: Radio New Zealand 
Yin, R. K. (1999). Enhancing the quality of case studies in health services research. Health Services Research, 34, 1209-1224.

Yin, R.K. (2003). Case study research design and methods. ( $3^{\text {rd }}$ ed.) Thousand Oaks: Sage Publications.

Zimmerman, G., Olsen, C., \& Bosworth, M. (2000). A 'stages of change' approach to helping patients change behaviour. American Family Physician, 61, 1409-1416. 